\title{
Challenges and Opportunities for Childhood Cancer Drug Development
}

\author{
Peter J. Houghton and Raushan T. Kurmasheva \\ Greehey Children's Cancer Research Institute, University of Texas Health, San Antonio, Texas
}

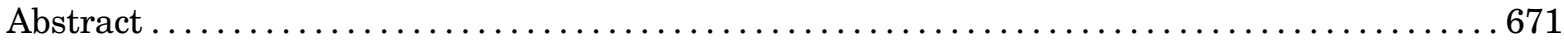

I. Status of Therapy for Childhood Cancer..................................... 672

II. Genetics of Childhood Cancer: Dividing a Small Pie ........................... 673

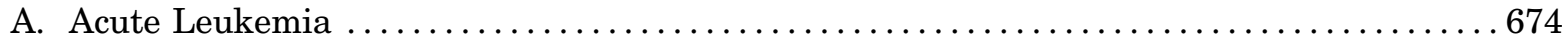

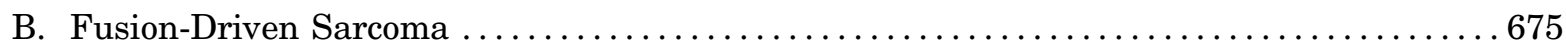

C. Brain Tumors....................................................... 675

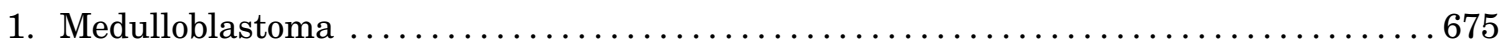

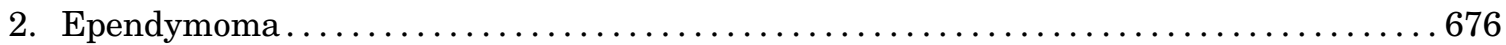

3. Diffuse Intrinsic Pontine Glioma ..................................... 676

4. Rhabdoid Tumors..................................................... 676

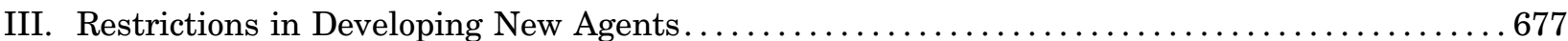

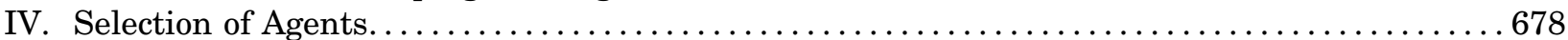

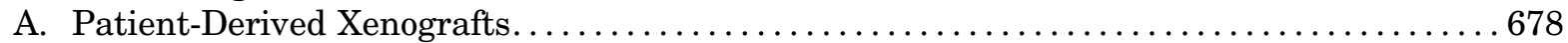

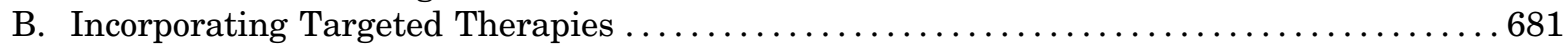

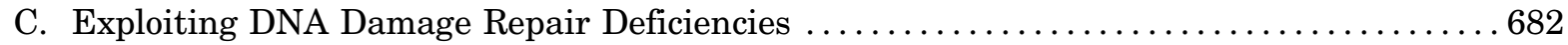

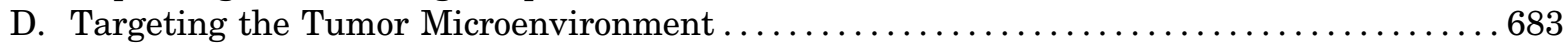

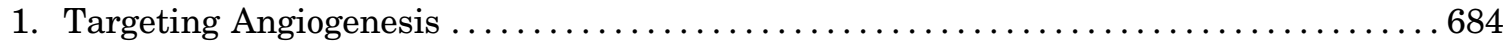

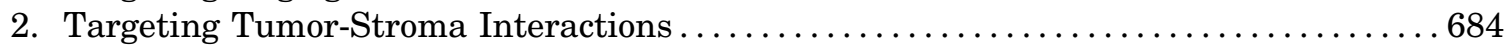

3. Targeting Tumor Microenvironment: Clinical Experience $\ldots \ldots \ldots \ldots \ldots \ldots \ldots \ldots \ldots 684$

4. Genetically Engineered Mouse Models ..............................664 68

5. General Limitations to Accurate Model Translation $\ldots \ldots \ldots \ldots \ldots \ldots \ldots \ldots \ldots \ldots \ldots 65$

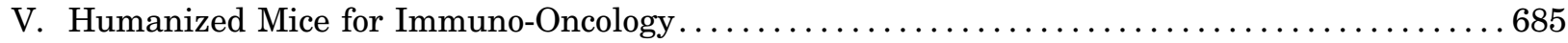

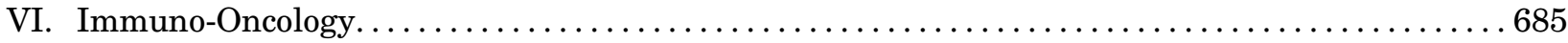

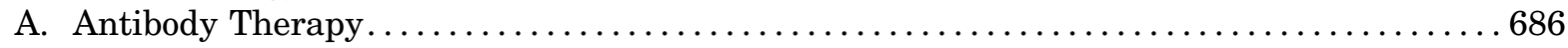

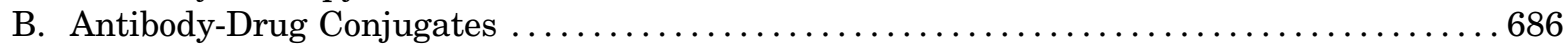

C. Chimeric Antigen Receptor Engineered T-cells ...........................666

D. Resistance to Chimeric Antigen Receptor Engineered T-cell Therapy ...............6 687

E. Chimeric Antigen Receptor Engineered T-cell Therapy for Solid Tumors . . . . . . . . . 687

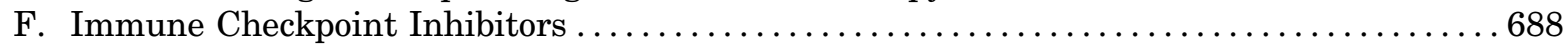

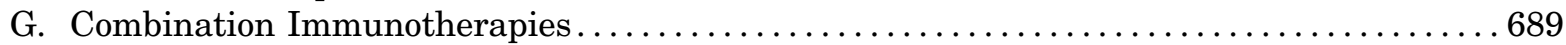

H. Mutation Frequency ..................................................... 690

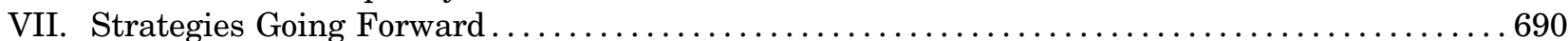

VIII. Summary............................................................ 690

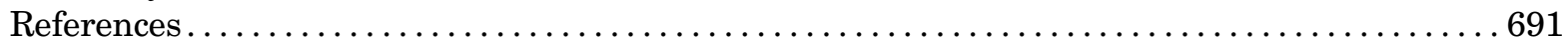

Address correspondence to: Dr. Peter J. Houghton, Greehey Children's Cancer Research Institute, University of Texas Health, San Antonio, TX 78229. E-mail: HoughtonP@uthscsa.edu

This work was supported by National Institutes of Health National Cancer Institute [Grants N01-CM4226, U01 CA199297, CA169368, and CA165995]. Cancer Prevention and Research Institute of Texas (CPRIT) [Grant RP160716]. Original work presented or referenced was supported by National Cancer Institute [Grants CA23099, CA77776, CA169368, CA165995, N01CA42216, and U01CA199297].

https://doi.org/10.1124/pr.118.016972. 
Abstract - Cancer in children is rare with approximately 15,700 new cases diagnosed in the United States annually. Through use of multimodality therapy (surgery, radiation therapy, and aggressive chemotherapy), $70 \%$ of patients will be "cured" of their disease, and 5-year event-free survival exceeds $80 \%$. However, for patients surviving their malignancy, therapyrelated long-term adverse effects are severe, with an estimated $50 \%$ having chronic life-threatening toxicities related to therapy in their fourth or fifth decade of life. While overall intensive therapy with cytotoxic agents continues to reduce cancer-related mortality, new understanding of the molecular etiology of many childhood cancers offers an opportunity to redirect efforts to develop effective, less genotoxic therapeutic options, including agents that target oncogenic drivers directly, and the potential for use of agents that target the tumor microenvironment and immune-directed therapies. However, for many highrisk cancers, significant challenges remain.

\section{Status of Therapy for Childhood Cancer}

Treatment of childhood cancer has essentially relied on surgery, radiation therapy, and systemic therapy using cytotoxic agents. From 1969 until 2012, childhood cancer mortality rates have declined by $66 \%$ and 5 -year survival has increased from $58 \%$ to $83 \%$ (Siegel et al., 2017). Thus, intensive therapy has resulted in dramatic increases in survival for patients, particularly those with hematopoietic malignancies, such as acute leukemias and lymphomas (Fig. 1; Jemal et al., 2017). Similarly, gains have been made for many other cancers, including neuroblastoma, soft tissue sarcomas, and some brain tumors. Standard of care agents that have improved survival have been largely cytotoxic agents that target DNA. For Ewing sarcoma and rhabdomyosarcoma, drugs include cyclophosphamide, doxorubicin, vincristine, etoposide, topotecan, irinotecan, actinomy$\operatorname{cin} \mathrm{D}$, and ifosfamide. Cisplatin is used in neuroblastoma and temozolomide for treatment of synovial sarcoma and glioblastoma and, at relapse, in Ewing sarcoma in combination with irinotecan. With the exception of vincristine, which causes depolymerization of microtubules and mitotic arrest, the other classes of agents (bifunctional or monofunctional alkylating agents, topoisomerase I or II poisons) induce single- and double-strand DNA breaks or DNA adducts that, if unrepaired, induce programmed cell death, or apoptosis. Similarly, ionizing radiation, used in most high-risk and intermediate-risk protocols, targets DNA to induce single and double strand breaks. Treatment is generally adjusted for stage of disease or risk-factors, with more aggressive regimens being used with advanced or metastatic disease. While cytotoxic therapies may induce complete responses in patients with solid tumor metastatic disease, treatment is rarely curative. Treatment of acute lymphoblastic leukemias has used many of the same DNA-targeted agents, with the addition of corticosteroids (prednisone and dexamethasone), cytosine arabinoside (cytarabine), 6-mercaptopurine (antimetabolites), methotrexate (antifolate), and L-asparaginase.

While gains in survival have been very impressive, long-term consequences of chemoradiation therapy can be devastating (Eissa et al., 2017; Chow et al., 2018; Henderson and Oeffinger, 2018; Turcotte et al., 2018). For brain tumors, standard radiation doses (45-70 Gy) far exceed the dose thresholds for neurocognitive deficits ( $>18 \mathrm{~Gy}$ ) and neuroendocrine deficits (growth hormone $>18$ Gy, gonadotrophins-ACTH-TRH $>40$ Gy). For soft tissue sarcoma, 36- to 65 Gy radiation doses exceed the threshold for muscular hypoplasia ( $>20 \mathrm{~Gy}$ ) or bone growth retardation, resulting in deformity or bone shortening ( $>20 \mathrm{~Gy}$ ). Unfortunately, chronic health conditions continue to increase in survivors with increasing age (Bhakta et al., 2016), and cardiovascular disease and second malignancies contribute to life-threatening morbidities (Bhakta et al., 2017). Chronic health issues such as myocardial infarction subsequent to mediastinal radiation and anthracycline-related heart failure are well recognized outcomes (Chow et al., 2018), and hence may be avoided by more contemporary treatment protocols. Thus, the future of pediatric cancer therapy presents many challenges. Cytotoxic agents with radiation therapy cure the majority of patients, but the burden of late effects is unacceptable, and efforts to reduce risks associated with cyclophosphamide and radiation have been attempted with some level of success, for example, in the treatment of rhabdomyosarcoma (Hawkins et al., 2014).

Large-scale analysis of somatic mutations in adult cancers have revealed oncogenic drivers that can be targeted with biologic agents with or without small molecule inhibitors for treatment of Her2 amplified breast cancer (Pondé et al., 2018) or small molecule inhibitors in ALK-rearranged NSCLC (Muller et al., 2016; Peters and Zimmermann, 2018) BRAF mutant melanoma (Knispel et al., 2018; Wahid et al., 2018), with approximately $37 \%$ of patients having an identified "actionable mutation" (Zehir et al., 2017). Recent

ABBREVIATIONS: ALL, acute lymphoblastic leukemia; AML, acute myeloid lymphoma; BCR, B-cell receptor; BiTE, bispecific T-cell engager; CAR-T, chimeric antigen receptor engineered T-cell; CTLA-4, T-lymphocyte-associated protein 4; DIPG, diffuse intrinsic pontine glioma; EZH2, enhancer of zest homolog 2; GEM, genetically engineered mouse; MATCH, Molecular Analysis For Therapeutic Choice; MLL, mixed lineage leukemia; MMAE, monomethyl auristatin E; MTD, maximum tolerated dose; NK, natural killer; NSCLC, non-small cell lung cancer; ORR, objective response rates; PARP, poly-(ADP-ribose) polymerase; PDL-1, programmed cell death protein 1; PDL-2, programmed cell death protein 2; PDX, patient-derived xenograft; PPTP, Pediatric preclinical testing program; PRC, polycomb repressive complex 2; RACE, Research to Accelerate Cures and Equity for Children Act; TME, tumor microenvironment; VGEF, vascular endothelial growth factor. 


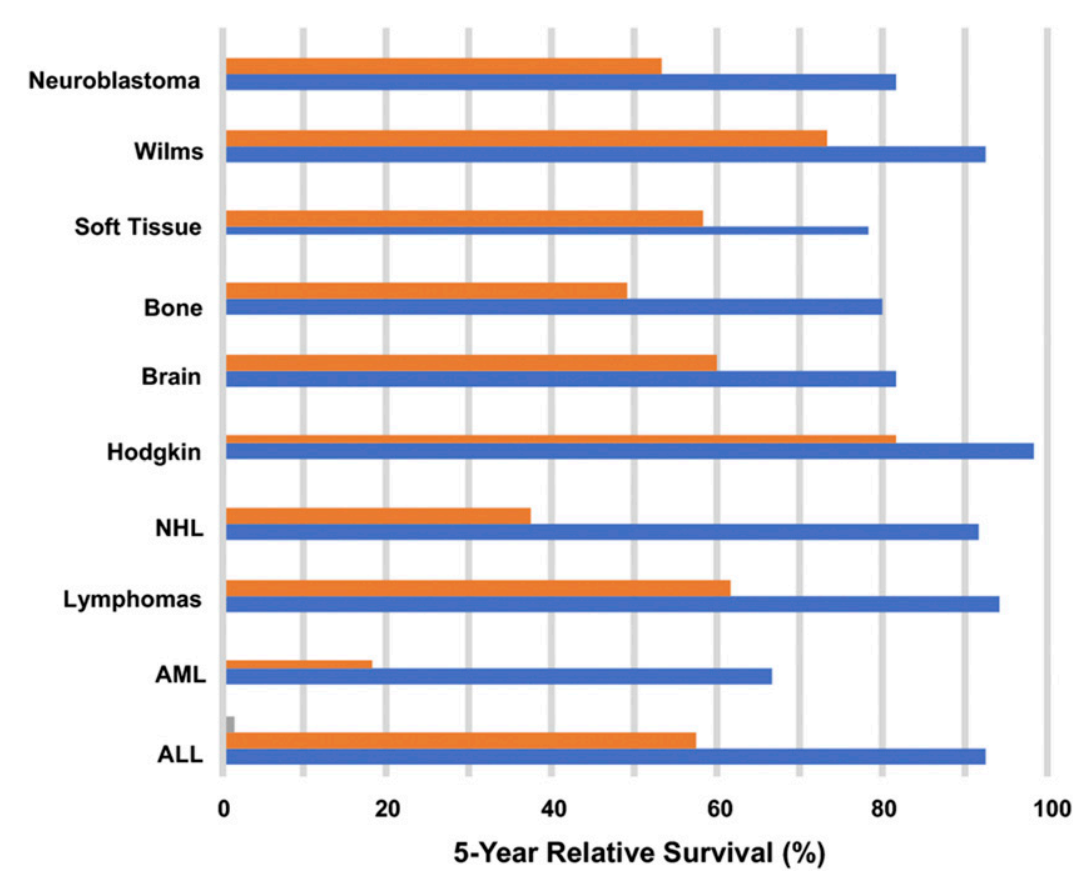

Fig. 1. Changes in 5-year relative survival rates for the most prevalent cancers in children $0-14$ years. Data show 5-year survival in from the period 1975 to 1977 (orange bars) and from 2006 to 2012 (blue bars) [adapted from Jemal et al. (2017) with permission].

studies have reported on the genetic landscape of pediatric tumors. The somatic mutation frequency of most tumors at diagnosis is low relative to adult cancers (Mody et al., 2015). Many sarcomas are driven by fusion oncogenes that result from chromosomal translocations, whereas neuroblastoma appears to be largely driven by copy number changes (Matthay et al., 2016). There is some indication that mutation frequencies are increased in neuroblastoma at relapse (Fletcher et al., 2018), perhaps offering greater potential for molecular targeted therapies or immune checkpoint inhibitors (Le et al., 2015), although the threshold for mutational load in patients with microsatellite instability who responded to anti-PD1 therapy (1782 somatic mutations) was far in excess of that reported in neuroblastoma at relapse. The relationship between mutational load and response to immune checkpoint inhibitors also assumes that increased mutation frequency translates into increased neoantigen presentation, which has not been validated in pediatric cancers. For hematologic malignancies, the first targeted therapy was imatinib, which inhibits the BCR-ABL tyrosine kinase in $t(9 ; 22)$ Philadelphia chromosome $(\mathrm{Ph}+)$ positive chronic myelogenous leukemia and results in a significant survival advantage when combined with intensive chemotherapy (Schultz et al., 2014). For chronic lymphocytic leukemia, diffuse large B-cell lymphoma, and other mature B-cell malignancies, the importance of Bruton's tyrosine kinase has been established (Davis et al., 2010; Herman et al., 2011; Ponader et al., 2012). For certain acute leukemias, there is considerable excitement for kinase inhibitors targeting B-cell receptor (BCR) signaling (Young and Staudt, 2013;
Burger, 2014). Most ALL with the $t(1 ; 19)$ chromosomal translocation are dependent on pre-BCR-dependent signaling for their proliferation (Bicocca et al., 2012), and pre-BCR-dependent ALL are highly sensitive to BCR signaling inhibitors (Geng et al., 2015; Köhrer et al., 2016). Similarly, in MLL translocated mixed lineage leukemias, the basis for transformation (Krivtsov et al., 2017) and the relevance of binding of the MLLfusion to Menin (Yokoyama et al., 2005; Yokoyama and Cleary, 2008) has led to development drugs that block the MLL-Menin interactions and look highly promising for treatment of MLL-rearranged ALL and AML in both children and adults (Borkin et al., 2015). These examples illustrate the importance of understanding the mechanism(s) by which transformation is driven that offer great opportunities for developing effective and less toxic therapeutics. Here, some of the challenges and opportunities for developing effective new therapies for childhood cancer will be reviewed.

\section{Genetics of Childhood Cancer: Dividing a Small Pie}

For many childhood cancers, prognosis can be correlated with stage of disease, tumor location, patient age, and molecular phenotype. Molecular characterization, by genome sequencing or expression profiling, can refine subclassification, leading to more accurate risk assessment, and reveal the underlying etiology of the disease. Of potential importance, in an era of precision medicine, these analyses may identify novel therapeutic targets. However, from the perspective of conducting clinical trials to assess new therapies, this creates a new 
challenge in that the numbers of patients within a subclassification may be very small, requiring national or international trials to accrue adequate numbers of patients. Unlike adult cancers, with the exception of familial cancer disposition syndromes, such as Li Fraumeni (Guha and Malkin, 2017), mutations of TP53 tumor suppressor gene are relative rare in pediatric tumors (Taylor et al., 2000; Ognjanovic et al., 2012). This may account, in part, for the relatively low mutational burden observed in many pediatric cancers (Mody et al., 2015). Recent large-scale sequencing studies have defined frequent somatic mutations in many pediatric cancer histotypes, including acute lymphoblastic leukemias, sarcoma, neuroblastoma, and brain tumors.

\section{A. Acute Leukemia}

This disease represents the most frequently occurring malignancy in children, and based upon phenotype and clinical manifestations it has been subtyped into 12 different entities, the prevalence of some subtypes varies with age. Genomic analysis has further defined subclasses of leukemias and revealed the remarkable genetic heterogeneity of this disease (Mullighan, 2014). The Ph-like acute lymphoblastic leukemia (ALL) subgroup, which has clinical manifestation similar to leukemias harboring the "Philadelphia" chromosome (Nowell and Hungerford, 1960) (a consequence of a reciprocal chromosomal translocation between chromosomes 9 and 22), was identified through expression profiling. These leukemias are negative for the $B C R$ - $A B L 1$ rearrangement found in chronic myelogenous leukemia, but exhibit gene expression profiles similar to $B C R-A B L 1$ positive ALL. They have alteration of B-lymphoid transcription factor genes and are associated with poor outcome. Kinase activating alterations through chromosomal translocations were found in $91 \%$ of cases (Roberts et al., 2014). The genetic rearrangements that juxtapose a kinase 3 ' to an actively transcribed gene in Ph-like ALL are shown in Table 1 (Mullighan, 2014; Roberts et al., 2014). Importantly, translocations in these leukemias often involve a kinase as the fusion partner, hence conferring putative therapeutic targets. T-lineage acute lymphoblastic leukemia is associated with genetic alterations that activate NOTCH1 signaling together with inactivation of INK4/ARF locus. Genome-wide sequencing has revealed marked heterogeneity, with 106 putative driver genes being identified with 10 recurrently altered pathways associated with stage or subtype of T-ALL (Liu et al., 2017). Neuroblastoma, a malignancy of the developing sympathetic nervous system, is associated with a low median exonic mutation frequency, with few recurrently mutated genes in samples taken at diagnosis (Pugh et al., 2013; Chmielecki et al., 2017); however, two recent studies identified a significantly increased mutational frequency in relapse samples (Eleveld et al., 2015; Schramm et al., 2015), including increased frequency of $A L K, A T R X$, and NRAS mutations (Fletcher et al., 2018). Whereas obtaining tumor at relapse is possible in the context of leukemia and neuroblastoma (from bone marrow aspirates), rebiopsy of recurrent solid tumors is rarely undertaken in children with solid or brain tumors for ethical reasons. Consequently, our understanding of genetic or epigenetic mechanisms of drug resistance is poorly understood for most of these cancers. The Pediatric MATCH trial (NCT03155620) will attempt to direct therapy based upon "actionable mutations" (Allen et al., 2017). If this trial is successful and the response rate for genomically directed therapy is superior to typical relapse protocols, this may facilitate rebiopsy as standard of care, as the results may be valuable in directing subsequent therapy. Obtaining routine biopsy at relapse will also facilitate our understanding of genetic changes associated with therapy resistance. Currently, the pediatric MATCH trial is limited to testing of single agents. While this may be informative, developing combinations of targeted therapies based on the genetic characteristics of individual tumors is likely to be more successful in preventing emergence of resistance. For example, combination of a BRAF inhibitor (dabrafenib) with a MEK inhibitor (trametinib), significantly increased event-free survival in adults with advanced melanoma (Flaherty et al., 2012; Spagnolo et al., 2015).

TABLE 1

Kinase rearrangement and therapeutic targets in Ph-like ALL. The TKIs shown are known or predicted to be active against rearrangements involving the listed kinase in experimental models but, with the exception of imatinib/dasatinib in EBF1-PDGFRB ALL, have not been shown to be effective in ALL [data from Roberts et al. (2014) and adapted from Mullighan (2014)].

\begin{tabular}{llccl}
\hline \multicolumn{1}{c}{ Kinase } & \multicolumn{1}{c}{ TKI } & No. of Partners & No. of Cases & \\
\hline$A B L 1$ & Dasatinib & 6 & 14 & ETV6, NUP214, RCSD1, RANBP2, SNX2, ZMIZ1 \\
ABL2 & Dasatinib & 3 & 7 & PAG1, RCSD1, ZC3HAV1 \\
$C S F 1 R$ & Dasatinib & 1 & 4 & SSBP2 \\
$P D G F R B$ & Dasatinib & 4 & 11 & EBF1, SSBP2, TNIP1, ZEB2 \\
$C R L F 2$ & JAK2 Inhibitor & 2 & 30 & IGH, P2RY8 \\
JAK2 & JAK2 Inhibitor & 10 & 19 & ATF7IP, BCR, EBF1, ETV6, PAX5, PPFIBP1, SSBP2, STRN3, TERF2, TPR \\
EPOR & JAK2 Inhibitor & 2 & 9 & IGH, IGK \\
DGKH & Unknown & 1 & 1 & ZFAND3 \\
IL2RB & JAK1/3 inhibitor & 1 & 1 & MYH9 \\
NTRK3 & Crizotinib, LOXO-101 & 1 & 1 & ETV6 \\
$P T K 2 B$ & FAK inhibitor & 2 & 1 & KDM6A \\
$T S L P$ & JAK2 Inhibitor & 1 & 1 & $I Q G A P 2$ \\
$T Y K 2$ & TYK2 inhibitor & 1 & 1 & $M Y B$ \\
\hline
\end{tabular}




\section{B. Fusion-Driven Sarcoma}

In general, fusion-driven tumors, where a transcription factor is fused to another gene, have low rates of mutations. Prevalent and novel (Xiao et al., 2018) translocations and fusion partners for sarcomas are presented in Table 2. Both pediatric and adult sarcomas have a low overall somatic mutation burden (1.06/Mb) (Cancer Genome Atlas Research Network, 2017). The exonic mutation frequency in Ewing family of tumors, characterized by fusion of EWSR1 with an ETS family member (most frequently FLI1), is low ( 0.15 mutations/ $\mathrm{Mb}$ ). Frequent deleterious mutations include homozygous deletion of CDKN2A (p16), STAG2 (Brohl et al., 2014; Crompton et al., 2014), a subunit of the cohesion complex, and of note is that these mutations are mutually exclusive (Tirode et al., 2014). Rhabdomyosarcoma, a cancer of skeletal muscle lineage, based on expression of myogenic markers (Abraham et al., 2014), is classified as fusion positive (alveolar) or fusion negative (embryonal) variants that have different prognosis and age of diagnosis. Alveolar rhabdomyosarcoma is associated with fusions between $P A X 3$ or $P A X 7$ and FOXO1 (P3F, P7F), and both fusion-positive variants are associated with low mutational load. Embryonal tumors have an increased mutation frequency and are associated with mutations in $R A S, N F 1$, and activation of FGFR4/PI3K pathways (Shern et al., 2014; Fig. 2).

\section{Brain Tumors}

For pediatric glioma, low-grade tumors are associated with activation of BRAF through a truncated tandem duplication that results in the KIAA1549-BRAF fusion (Parsons et al., 2008) or through an activating point mutation of BRAF (predominantly V600E). More recent data suggest that the KIAA1549-BRAF fusion is largely restricted to juvenile pilocytic astrocytoma (90\%), whereas $\mathrm{BRAF}^{\mathrm{V} 600 \mathrm{E}}$ occurs more frequently in grade II-IV gliomas [ $\sim 23 \%$; although lower frequencies have been reported (Schindler et al., 2011)], gangliogliomas, diffuse gliomas (Schindler et al., 2011; Dahiya et al., 2013), and in $60 \%$ of xanthoastrocytomas (DiasSantagata et al., 2011; Schindler et al., 2011). Thus, activating mutation of $B R A F$ appears to be the most common genetic alteration in non-juvenile pilocytic astrocytoma. Homozygous deletion of the CDKN2A locus is frequent $(\sim 70 \%)$ in tumors harboring the $B R A F^{V 600 E}$ mutation (Schiffman et al., 2010), whereas mutations in PIK3CA are reported to be rare in these tumors (El-Habr et al., 2010). NTRK2 and -3 fusions occur in pediatric gliomas (Vaishnavi et al., 2015), and LOXO-101, a selective NTRK inhibitor, has shown activity in preclinical models of TRK-fusions and clinically in sarcoma (Doebele et al., 2015).

1. Medulloblastoma. A tumor arising in the cerebellum is now subdivided into four distinct molecular subgroups based upon gene expression signatures, the spectrum of mutations, copy number alterations, and clinical features (Northcott et al., 2012). This classification allowed a molecular underpinning of clinical outcome for low risk ( $>90 \%$ survival), average risk $(75 \%-90 \%$ survival), high risk (50\%-75\% survival), and very high risk ( $<50 \%$ survival) (Ramaswamy et al., 2016). Group 1 has a WNT signature and Group 2 a Sonic Hedgehog

TABLE 2

Common and novel recurrent translocations in soft tissue tumors

\begin{tabular}{|c|c|c|}
\hline Tumor & Chromosome Translocation & Fusion Transcript \\
\hline \multirow[t]{5}{*}{ Ewing sarcoma/primitive neuroectodermal tumor } & $\mathrm{t}(11 ; 22)(\mathrm{q} 24 ; \mathrm{q} 12)$ & FLI-EWS \\
\hline & $\mathrm{t}(21 ; 22)(\mathrm{q} 22 ; \mathrm{q} 12)$ & $E R G-E W S$ \\
\hline & $\mathrm{t}(7 ; 22)(\mathrm{p} 22 ; \mathrm{q} 12)$ & $E T V 1-E W S$ \\
\hline & $\mathrm{t}(17 ; 22)(\mathrm{q} 12 ; \mathrm{q} 12)$ & $E 1 A F-E W S$ \\
\hline & $\mathrm{t}(2 ; 22)(\mathrm{q} 33 ; \mathrm{q} 12)$ & $F E V-E W S$ \\
\hline \multirow[t]{2}{*}{ Desmoplastic round cell tumor } & $\mathrm{t}(11 ; 22)(\mathrm{p} 13 ; \mathrm{q} 12)$ & WT1-EWS \\
\hline & $\mathrm{t}(11 ; 22)(\mathrm{q} 24 ; \mathrm{q} 12)$ & $F L I-E W S$ \\
\hline \multirow[t]{2}{*}{ Synovial sarcoma } & $\mathrm{t}(\mathrm{X} ; 18)(\mathrm{p} 11.23 ; \mathrm{q} 11)$ & $S S X 1-S Y T$ \\
\hline & $\mathrm{t}(\mathrm{X} ; 18)(\mathrm{p} 11.21 ; \mathrm{q} 11)$ & $S S X 2-S Y T$ \\
\hline \multirow{7}{*}{$\begin{array}{l}\text { Alveolar rhabdomyosarcoma embryonal rhabdomyosarcoma spindle cell } \\
\text { rhabdomyosarcoma }\end{array}$} & $\mathrm{t}(2 ; 13)(\mathrm{q} 35 ; \mathrm{q} 14)$ & PAX3-FOXO1 \\
\hline & $\mathrm{t}(1 ; 13)(\mathrm{p} 36 ; \mathrm{q} 14)$ & PAX7-FOXO1 \\
\hline & $\mathrm{t}(2 ; 2)(\mathrm{q} 35 ; \mathrm{p} 23)$ & $P A X 3-N C O A 1^{a}$ \\
\hline & $\mathrm{t}(2 ; 8)(\mathrm{q} 35 ; \mathrm{q} 13)$ & $P A X 3-N C O A 2^{a}$ \\
\hline & & VGLL2-NCOA $2^{a}$ \\
\hline & & $T E A D-N C O A 2^{a}$ \\
\hline & $\mathrm{t}(2 ; 8)(\mathrm{q} 35 ; \mathrm{q} 13)$ & $S R F-N C O A 2^{a}$ \\
\hline Clear cell sarcoma & $\mathrm{t}(12 ; 22)(\mathrm{q} 13 ; \mathrm{q} 12)$ & ATF1-EWS \\
\hline \multirow[t]{2}{*}{ Myxoid liposarcoma } & $\mathrm{t}(12 ; 16)(\mathrm{q} 13 ; \mathrm{p} 11)$ & CHOP-FUS \\
\hline & t(12;22)(q13;q12) & CHOP-EWS \\
\hline Extraskeletal myxoid chondrosarcoma & $\mathrm{t}(9 ; 22)(\mathrm{q} 22 ; \mathrm{q} 12)$ & CHN-EWS \\
\hline Dermatofibrosarcoma/giant cell fibrosarcoma & $\mathrm{t}(17 ; 22)(\mathrm{q} 22 ; \mathrm{q} 13)$ & $C O L 1 A 1-P D G F B$ \\
\hline Congenital fibrosarcoma and mesoblastic nephroma & $\mathrm{t}(12 ; 15)(\mathrm{p} 13 ; \mathrm{q} 25)$ & ETV6-NTRK3 \\
\hline \multirow[t]{2}{*}{ Lipoblastoma } & $\mathrm{t}(3 ; 8)(\mathrm{q} 12 ; \mathrm{q} 11.2)$ & PLAG1-HAS2 \\
\hline & $\mathrm{t}(7 ; 8)(\mathrm{q} 31 ; \mathrm{q} 13)$ & ? \\
\hline Undifferentiated small round cell sarcoma & $\mathrm{T}(4 ; 19)(\mathrm{q} 35 ; \mathrm{q} 13.1) \mathrm{T}(6 ; 8)(\mathrm{p} 12 ; \mathrm{q} 11.2)$ & $C I C-D U X 4^{a}$ \\
\hline Undifferentiated (infants) & $\mathrm{T}(10 ; 19)(\mathrm{q} 26.3 ; \mathrm{q} 13) \mathrm{T}(17 ; 22)(\mathrm{q} 12 ; \mathrm{q} 12)$ & $E I A F-E W S^{a}$ \\
\hline
\end{tabular}

${ }^{a}$ Novel fusions [from Xiao et al. (2018)]. 


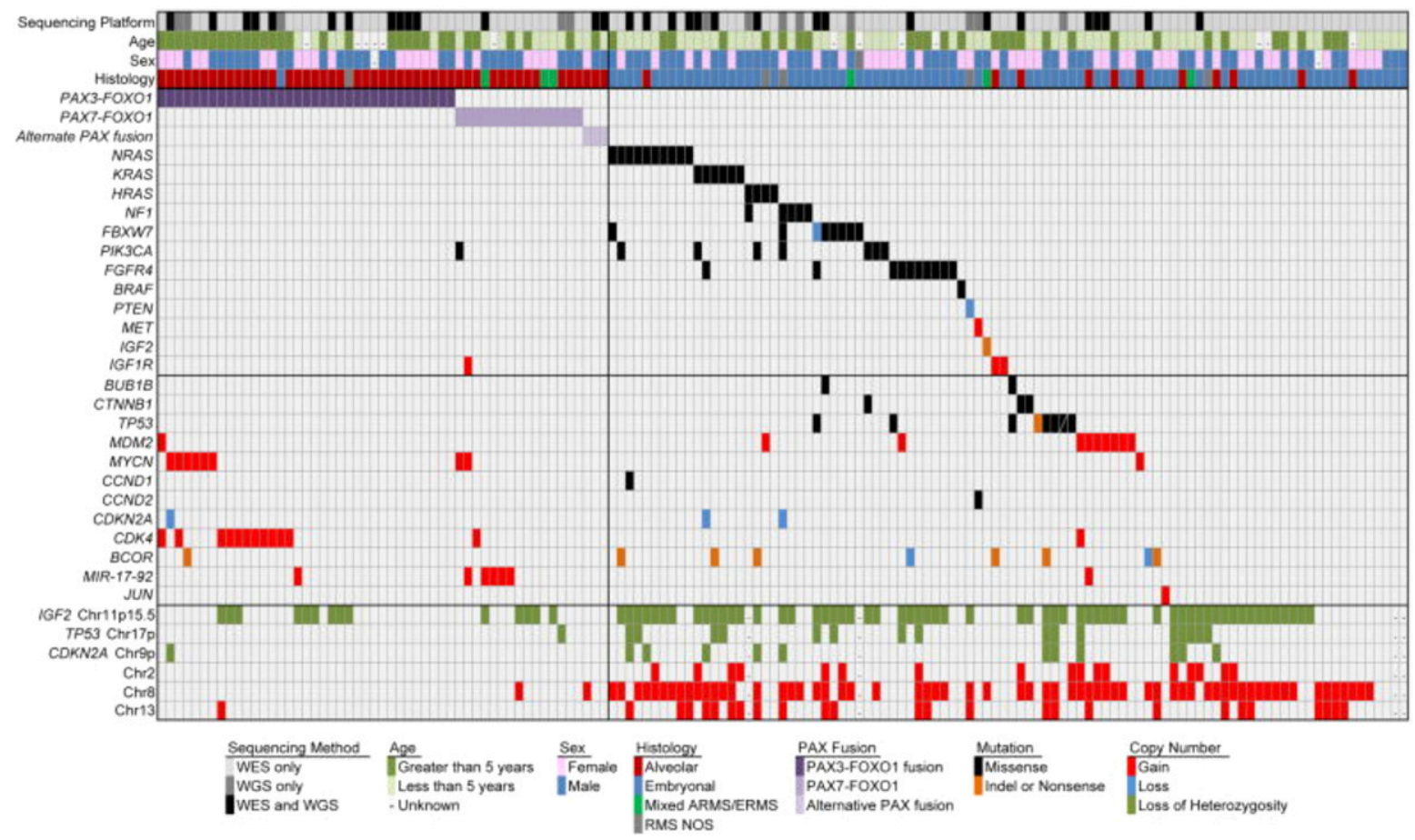

Fig. 2. Genomic landscape of pediatric RMS highlighting candidate alterations. Demographic characteristics, histologic subtypes, and selected genes with copy number alterations or somatic mutations across 147 rhabdomyosarcoma cases. Unique sample identifier and sequencing platform. Sex, males in blue, females in pink. Age, years at diagnosis divided into less than 5 years and greater than 5 years. Histologic diagnosis, red, alveolar; blue, embryonal including spindle and botryoid subtypes; gray, RMS not otherwise specified. Mixed alveolar and embryonal histology in green. Copy number gains and losses for selected genes. Blue, losses; red, gains; green, loss of heterozygozity. Selected genes with somatic mutations. Purple, fusion protein; black, missense; orange, nonsense/splice site/indel mutations [from Shern et al. (2014) with permission].

expression signature, the latter offering a potential therapeutic target using smoothened inhibitors.

2. Ependymoma. This is the third most common brain cancer in children, occurring in different anatomic sites (posterior fossa, hindbrain, spine) and now considered a distinct molecular entity based on location and putative cell of origin. Radial glial cells from different anatomic locations in the brain have distinct expression profiles, and ependymomas resemble the radial glial cell from the same location (Thompson et al., 2015). Hindbrain ependymomas have an extremely low mutation rate but demonstrate a $\mathrm{CpG}$ methylator phenotype. Transcriptional silencing converges on the polycomb repressive complex 2 (PRC2) and represses expression of differentiation genes through trimethylation of H3K27, offering potential therapeutic rational for use of epigenetic modifier drugs (Mack et al., 2014).

3. Diffuse Intrinsic Pontine Glioma. There has been considerable progress in understanding the genetic and epigenetic bases for pediatric cancers (Huether et al., 2014). The highest frequency of mutations in epigenetic regulator genes is in glioblastoma and diffuse intrinsic pontine glioma (DIPG), with approximately $30 \%$ and $80 \%$, respectively, demonstrating $\mathrm{K} 27 \mathrm{M}$ mutations in the H3F3A gene that encodes the histone variant H3.3 (Venneti et al., 2014). Other cancer "drivers" being more recently recognized are genetic changes that result in alteration in chromatin architecture and hence gene expression. Synovial sarcoma, which arises in adolescents and young adults, is driven by the SS18-SSX fusion oncogene, leading to loss of BAF47 subunit assembly and retargets $\mathrm{BAF}$ complexes to polycomb domains to oppose PRC2-mediated gene repression and to activate bivalent genes (McBride et al., 2018).

4. Rhabdoid Tumors. Other tumors associated with the SWI/SNF (BAF) chromatin remodeling complex include malignant rhabdoid tumors (AT/RT) of the central nervous system or kidney that are frequently associated with germ line alterations. This tumor occurs frequently in infants, has a poor prognosis, and is associated with homozygous deletion of SMARCB1 (known also as INI1), a core subunit of the BAF complex (Kalimuthu and Chetty, 2016). Truncating mutations in both alleles of $S M A R C B 1$, homozygous deletions or microdeletions have been reported in extraskeletal myxoid chondrosarcoma, and complete loss of SMARCB1 expression occurs in approximately half of epithelioid malignant peripheral nerve sheath tumors and pediatric soft tissue myoepithelial carcinomas (Hollmann and Hornick, 2011). Approximately $45 \%$ of patients with familial schwannomatosis have $S M A R C B 1$ mutations (Masliah-Planchon et al., 2015). It has been proposed that tumors deficient in SMARB1, hence defective in BAF complex function, have a synthetic lethal dependency on EZH2 (enhancer of zest homolog 2) (Wilson et al., 2010) and an EZH2 inhibitor-induced complete regression of a SMARCB1-deleted rhabdoid tumor model in mice (Knutson et al., 2013), although less 
impressive activity was reported in other SMARCB1deficient models (Kurmasheva et al., 2017). EZH2 is the enzymatic subunit of a multiprotein histone methyltransferase complex (polycomb recessive complex 2; PRC2) and is associated with several cancer types. Heterozygous mutations within the catalytic SET domain occur in approximately $20 \%$ of germinal center B-cell-like diffuse B-cell lymphoma and follicular lymphoma, resulting in large increases in H3K27 trimethylation, abnormal repression of PRC2 targets, and lymphoma development, providing the rationale for treatment of these lymphomas with inhibitors of EZH2 (Morin et al., 2010; Knutson et al., 2014). Alterations in BAF chromatin remodeling complexes are now implicated in many pediatric and adults cancers (Fig. 3; St Pierre and Kadoch, 2017) and potentially offer new avenues for effective therapy of these tumors (McBride and Kadoch, 2018).

\section{Restrictions in Developing New Agents}

Constraints in developing new therapies for treatment of childhood cancer can be classified as both logistical and ethical. Cancer in children is rare, but when one considers each cancer type as an entity, the numbers of patients with a particular diagnosis become extremely small (Adamson et al., 2014). Thus, ALL represents $40 \%$ of all pediatric cancer in the United States but can be classified into multiple molecular subtypes having different outcomes and potentially responding to different "targeted" therapies. Thus, even for the most common cancer type, the number of patients within a molecular subtype is small, presenting challenges to conducting clinical trials in these populations. The other consideration is that overall the "cure" rate for pediatric cancer is around $70 \%$, and most recent American Cancer Society data suggest the 5-year eventfree survival is $83 \%$. As a consequence, relatively few patients are eligible for experimental trials (phase I or phase II), and almost invariably these patients will have received standard of care therapeutic regimens. For example, the most recent Children's Oncology Group trial in patients with high-risk rhabdomyosarcoma (NCT00354744) incorporated all known active drugs plus radiation therapy over a 51-week period (Weigel et al., 2016). Twenty-five percent of patients progressed during the period of therapy, and $80 \%$ had events within 24 months of starting treatment. Thus, patients moving to subsequent therapies probably have tumors that express mechanism(s) of resistance to highly complex multidrug therapies and may not be optimal subjects in which to identify active new agents. Some support for this comes from studies conducted in the $1980 \mathrm{~s}$, where melphalan was evaluated in a relapse setting and had relatively little activity, whereas in an up-front window trial in patients with advanced rhabdomyosarcoma, the drug was highly active (Horowitz et al., 1988). However, ethical considerations, including high progression rates during "window" therapy, the potential for window therapy to compromise subsequent care, and inclusion of patients who may have a higher probability for long-term survival, have essentially prevented further testing of therapeutics in treatment naive patients. Another ethical constraint is the issue of testing a drug initially in children, where safety

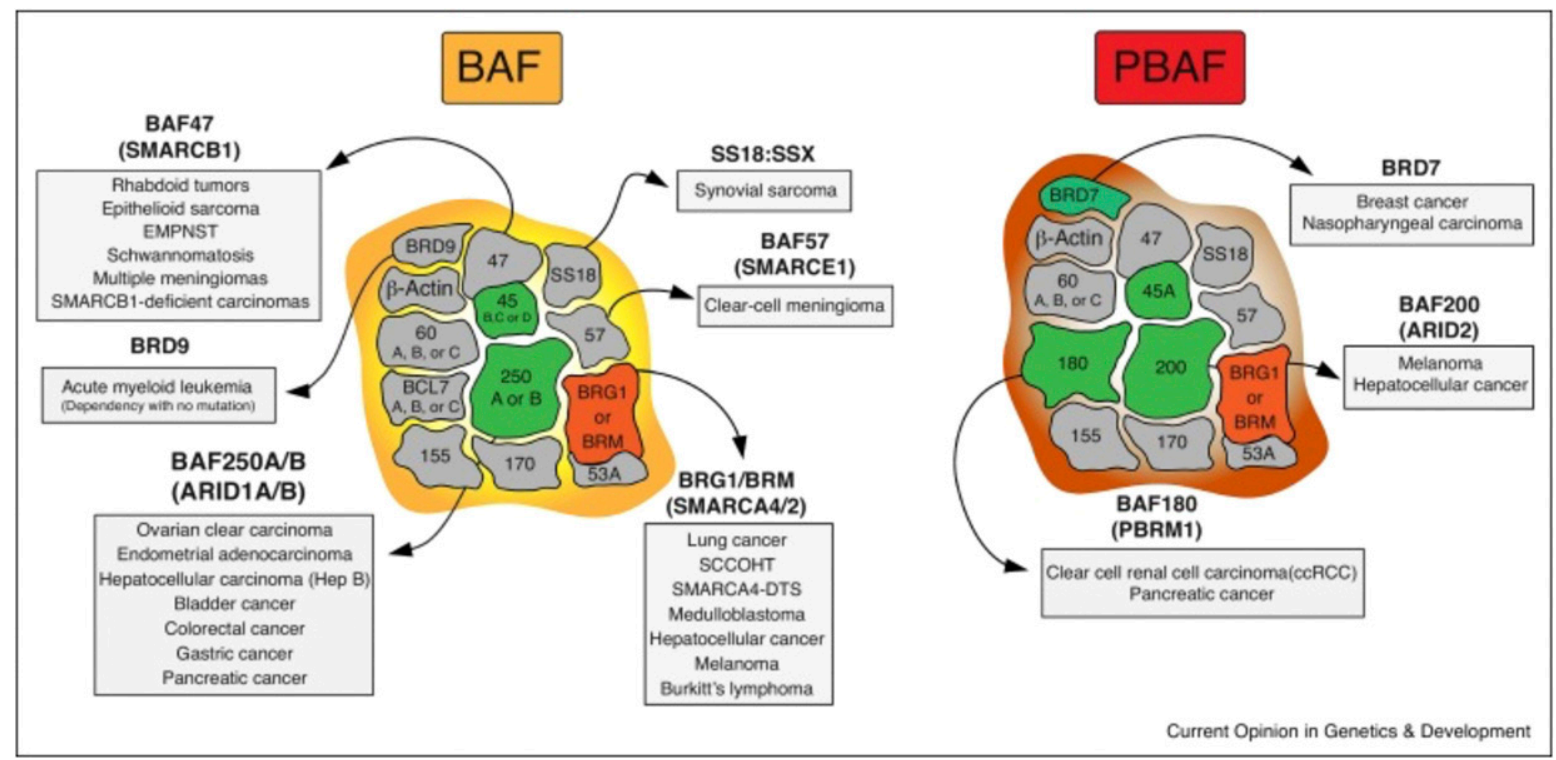

Fig. 3. mSWI/SNF chromatin remodeling complexes in human cancer. Mammalian SWI/SNFcomplexes are separated into two separate forms: BRG1/ BRM associated factor (BAF or SWI/SNF-A) and polybromo-associated BAF (PBAF or SWI/SNF-B). BAF and PBAF complexes share numerous subunits, including both ATPases BRG1 and BRM (depicted in red). BAF and PBAF differ from one another by incorporation of key peripheral subunits (depicted in green). Mutations in the genes encoding mSWI/SNF complex subunits are present in over 20\% of human cancers, with specific subunits mutated in specific malignancies [from St Pierre and Kadoch (2017) with permission]. 
guidelines require initial doses to be below those likely to give therapeutic benefit. Thus, with few exceptions, new agents are first tested in adult cancer patients, and once a recommended phase 2 dose is established, pediatric trials may start at one or two dose levels below the recommended phase 2 dose. This minimizes the number of patients required to establish a maximum tolerated dose in children and minimizes the probability of dosing that will not be effective achieving target inhibition. However, for many agents, pediatric trials are initiated after adult trials have been completed, often years after the new drug has been approved for use in adults (Khan et al., 2019). Roadblocks to progress in drug discovery for pediatric cancer include a lack of "market initiative" on the part of pharmaceutical companies, where the pediatric market is below that considered profitable and, although unsubstantiated, a fear of adverse events in children that could derail development for adult indications (Adamson et al., 2014). The Institute of Medicine made recommendations for developing drugs for children with cancer (Adamson et al., 2005) that included creating a virtual drug development enterprise that would facilitate partnerships of stakeholders in the drug development process, including pharmaceutical companies, non-government organizations, and federal agencies. Worthy of note is the rapid development and Food and Drug Administration approval of the TRK inhibitor larotrecrinib for treatment of TRK fusionpositive tumors that involved trials that simultaneously enrolled both adult and pediatric patients (Drilon et al., 2018; Laetsch et al., 2018). Another approach that may speed drug development is the recent recommendation that late-stage trials for diseases common to both adult and pediatric populations routinely include patients 12 years of age or older. This is based on the similarity in drug metabolism and excretion between adults and postpubertal adolescents (Gore et al., 2017). Other proposals include design of "master protocols" that incorporate precision medicine processes with the ability to assess safety and efficacy in early stage clinical trials, with the objective of accelerating approval of agents for children with cancer (Khan et al., 2019). In the United States, the regulatory environment, through the Research to Accelerate Cures and Equity for Children Act (RACE for Children Act) as part of the FDA Reauthorization Act, requires FDA to develop a list of molecular targets and molecular targets of new drugs and biologics in development, which are determined to be substantially relevant to the growth and progression of pediatric cancer and may trigger the requirement for pediatric investigations, again with the intent of engaging pharma in pediatric testing at an early stage in drug development (https://www. fda.gov/about-fda/oncology-center-excellence/pediatriconcology). Under the RACE for Children Act, FDA may now require pediatric assessments when molecular targets under FDA review are substantially relevant to childhood cancer. While pediatric cancer drug development has been largely undertaken in cooperative groups such as the Children's Oncology Group Phase I Consortium and smaller groups such as the Pediatric Oncology Experimental Therapeutics Investigators Consortium (POETIC) and New Approaches to Neuroblastoma Therapy (NANT), there is now a trend to establishing European-United States and other cooperative groups to conduct trials in specific indications or rare subgroups with poor prognosis (Dome et al., 2015; Mauz-Körholz et al., 2015; Moreno et al., 2017). Such globalization, while presenting challenges through standardization of assessment methods, risk assessment, and conduct of clinical trials, appears to be essential to meet the challenge of molecular stratification and evaluation of molecularly targeted agents.

\section{Selection of Agents}

It is estimated that over 1100 medicines and vaccines are currently in development by US biopharmaceutical companies for treatment of cancer (http:// phrma-docs.phrma.org/files/dmfile/2018_MID_Cancer); however, with only rare exceptions (Erkizan et al., 2009), are entities being specifically developed for treatment of pediatric cancer. Taken together with the limitations of clinical testing in children, it is apparent that very few drugs or biologicals will be tested adequately in the pediatric cancer population (Adamson et al., 2014). One approach has been to develop appropriate preclinical models that could be used to identify drugs that had either broad-spectrum activity or tumor-type specificity against pediatric cancer. These models include cell culture, syngeneic or genetically engineered mouse (GEM) models, or cellline or patient derived xenografts (PDX) where human cancers are grown in immune-deficient mice. PDX models have been used extensively in drug development for both adult and pediatric cancer, whereas the use of GEM models has been more restricted, particularly in drug development for pediatric cancer.

\section{A. Patient-Derived Xenografts}

Patient-derived xenograft models, where patient tumor is directly implanted into immune-deficient laboratory rodents, have increasingly become the preferred research tool to understand tumor biology, drug sensitivity, and aid in translation for optimal use of therapies in patients (Williams, 2018). PDX models retain histologic characteristics of the original tumor, and maintain a high degree of fidelity compared with the original tumor with respect to genome, transcriptome, and phospho-proteome integrity (Whiteford et al., 2007; Neale et al., 2008; Li et al., 2013). While PDX research in adult cancer has exploded over the past decade, PDX models established from pediatric cancers 
(Houghton et al., 1982b; Meyer et al., 1990) have been used for the past 40 years to identify novel agents (Houghton et al., 1991, 1992, 1993), and drug combinations that have been prospectively tested in the clinic. Attempts to develop and molecularly characterize large numbers of pediatric cancer PDX models are underway in both Europe and the United States under the direction of the Innovative Therapies for Children with Cancer project - Pediatric Preclinical Proof of Concept Platform (ITCC-P4), the Pediatric Preclinical Testing Program/Consortium (PPTP/C) that has established and characterized over 300 pediatric cancer PDX models, and the Childhood Solid Tumor Network (Stewart et al., 2016). Other groups have developed panels of hepatoblastoma PDX models that may advise clinical management (Nicolle et al., 2016). Thus, large numbers of well-characterized pediatric PDX models are available for the community. However, the number of models available for study of extremely rare pediatric cancers remains problematic. There are very few models of alveolar soft part sarcoma or clear cell sarcoma, for example, and panels of such models would be highly valuable for developing novel therapeutic approaches. An initiative to build a web-based inventory of all adequately characterized pediatric PDX models is ongoing. These newer large-scale PDX programs are largely based on early studies at St. Jude Children's Research Hospital, which pioneered the development of PDX models of sarcoma, neuroblastoma, and brain tumors. These models identified known clinically active agents and prospectively identified novel drugs and combinations that have significant clinical utility (Houghton et al., 1982a,b, 1992, 1993, 2002; Houghton and Houghton, 1989) and are now components of standard of care protocols in the United States, Europe, and Japan. Early studies by Lock and colleagues (Lock et al., 2002; Liem et al., 2004) established the value of acute lymphoblastic leukemia PDX models for studying both biologic characteristics and for evaluation of therapeutic agents (Jones et al., 2016) or resistance mechanisms (Samuels et al., 2014; Yadav et al., 2016). Promising results from these PDX models led to the National Cancer Institute-sponsored Pediatric Preclinical Testing Program (PPTP), which evaluated over 80 drugs or drug combinations in a range of pediatric cancer models (Houghton et al., 2007). Summary results from the PPTP were published recently (Geier et al., 2015; Jones et al., 2016; Kurmasheva and Houghton, 2016) and demonstrate some principles that may relate to how new agents are developed in pediatric cancer. The PDX models comprised kidney tumors (Wilms tumor and malignant rhabdoid tumors), sarcoma (Ewing, rhabdomyosarcoma, osteosarcoma), neuroblastoma, brain tumors (medulloblastoma, ependymoma, glioblastoma), and ALL, totaling about 50 models used for most of the drug testing. This panel was limited as resource constraints mandated only 3-8 models per tumor type, thus underrepresenting the genomic heterogeneity/complexity of each disease, although individual panels could be expanded if a drug was highly active against specific tumor models in the initial screen. However, several principles for drug discovery are apparent from the data set. First, response criteria relevant to clinical evaluation criteria are essential for accurate translation to clinical trials. The PPTP used approaches based upon the NCI RECIST revised criteria (Eisenhauer et al., 2009), with tumor regression and event-free survival being criteria for advancing a drug or combination. With these criteria, few molecularly targeted agents showed high levels of activity. For example, against the neuroblastoma PDX panel ( $n=6)$, of 22 signaling inhibitors, targeting IGF-1R/PI3K/mTOR, NOTCH or the MAPK pathway, there were six objective regressions in 113 drug/tumor experiments $(5.3 \%)$, similar to that in sarcoma panels where the overall objective response rate was 5.7\% (20 regressions/346 drug/tumor tests (Fig. 4 ; Geier et al., 2015). These large-scale screens suggest that developing inhibitors of signaling pathways as broad-spectrum agents, as has been the paradigm for cytotoxic agents, will not be a productive approach to clinical development. Importantly, mere demonstration of pathway activation (e.g., phosphorylation of ERK1/2 or AKT) within a tumor model did not predict drug sensitivity. In contrast, activation of a pathway through mutation, such as $\mathrm{BRAF}^{\mathrm{V} 600 \mathrm{E}}$ confers sensitivity to the MEK inhibitor selumetinib in an astrocytoma PDX (Kolb et al., 2010) and this agent was subsequently shown to be active in children with low-grade glioma (Banerjee et al., 2017; Fangusaro et al., 2019). Comparisons between preclinical efficacy and phase II clinical trials results are complicated; many preclinical models represent disease at diagnosis, whereas new agents are tested in patients refractory to conventional therapy, a population that may not be optimal for identifying an active drug in a diagnosis setting (Horowitz et al., 1988). A second issue is the relevance of the drug exposure in mice compared with patients. While preclinical modeling may use data from adult pharmacokinetics, this may not be appropriate for translating to children. For example, alisertib, an aurora kinase A-selective inhibitor, showed good activity in models of neuroblastoma and ALL, however, toxicity in children resulted in an approximately eightfold decrease in exposure per 21-day cycle, and loss of activity. This loss of activity was also observed in ALL models using the clinical schedule (Mossé et al., 2019). Other issues that preclude comparison between preclinical and clinical efficacy include examples where the agent is not advanced to phase II trials. The proteasome inhibitor bortezomib, for example, was highly active in B-precursor ALL xenografts (Houghton et al., 2008), and subsequently in clinical testing (NCT00440726) (Messinger et al., 2012), whereas the agent had little 


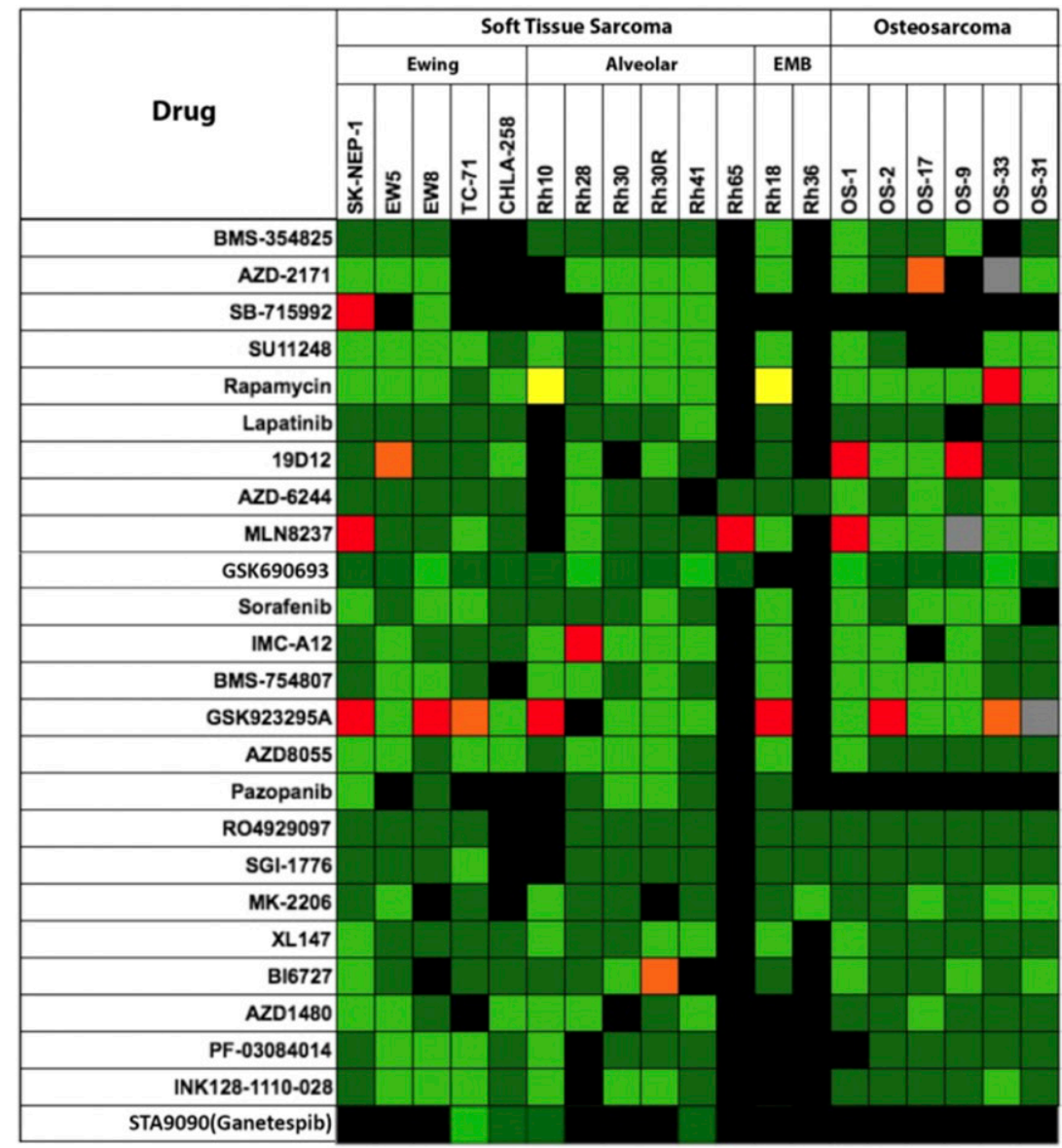

\begin{tabular}{|l|l|}
\hline \multicolumn{1}{|c|}{ Tumor Response } & \\
\hline Progressive disease 1 & \\
\hline Progressive Disease 2 & \\
\hline Stable Disease \\
\hline Partial response & \\
\hline Complete Response & \\
\hline Maintained Complete Response & \\
\hline Not tested & \\
\hline
\end{tabular}

Fig. 4. Heat map representation of the activity of signaling inhibitors screened by the PPTP against sarcoma xenografts. Drugs are shown in the left column and sarcoma models in the top rows [from Geier et al. (2015) with permission].

activity against solid tumor models and little activity in phase I trials (Blaney et al., 2004; Horton et al., 2007), and no phase II trials of single agent bortezomib have been reported for solid tumor patients. Thus the experience with pediatric PDX models appears to parallel clinical experience and suggests that with sufficient PDX models represented in a screen, exceptional responders can be identified and the underlying molecular/genetic biomarker identified (Geier et al., 2015; Smith et al., 2015a).

Another observation, made in retrospectively analyzing the large data set generated through PPTP testing, was that essentially the same data could be generated using a single mouse in the treatment group, rather than 8-10 mice as in conventional studies (Murphy et al., 2016; Fig. 5). Use of a reduced number of mice to signal "large effects" potentially allows a study design that would encompass many more models of each pediatric cancer type, facilitating the identification of exceptional responders, and relating these to the underlying molecular characteristics (Gao et al., 2015).

Although the PDX models have value, every model system has its limitations. The PDX system lacks host immunity, which limits their value in identifying immune-oncology agents. Attempts to humanize the mouse immune system is an active field of research (vide infra). As discussed above, a spectrum of PDX models can represent the "omic" diversity/heterogeneity of clinical disease. These PDX models retain characteristics [mutations, expression profiles, DNA methylation profiles (Neale et al., 2008; Stewart et al., 2017)] of patient tumors more accurately than cell lines in culture. The most obvious failure of PDX models in general [also relevant to pediatric cancer (Carol et al., 2011; Houghton et al., 2011)] is overprediction of efficacy for a novel agent. In most instances, mouse tolerance for the agent far exceeds that of patients, and the drug fails in phase II trials (Carol et al., 2011; Houghton et al., 2011). While this oversimplifies a complex set of issues that ultimately lead to failure of $95 \%$ of oncology drugs, results from the PPTP and others suggest this is a major issue in successful translation of preclinical results in pediatric PDX models and successful pediatric clinical trials (Leggas et al., 2002; Peterson and Houghton, 2004). As most, if not all, drugs are first tested in adults to define tolerability and pharmacokinetics, it is important to define preclinical activity in childhood cancer models using appropriate response criteria at human-relevant drug systemic exposures (Peterson 


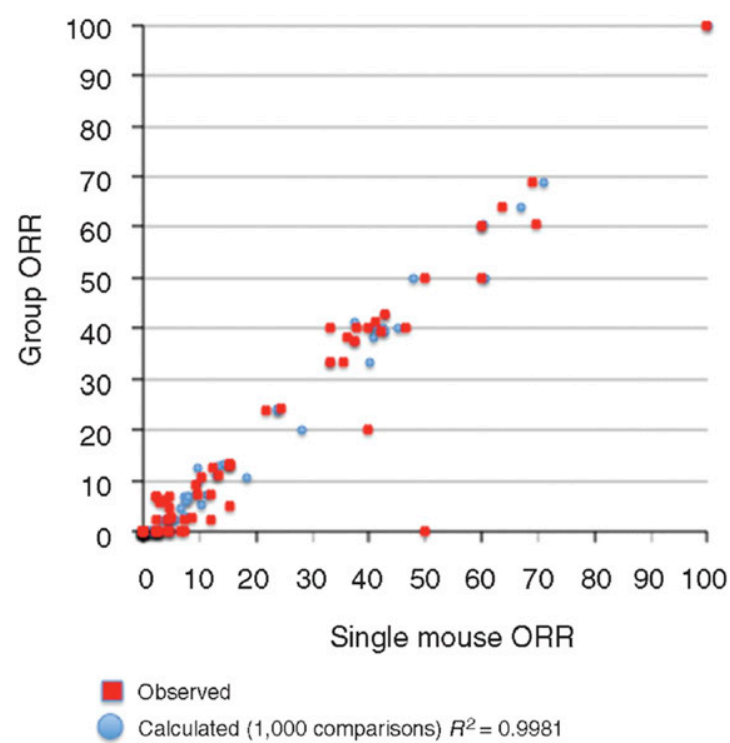

Fig. 5. Objective response rates (ORR) were calculated for all tumor models tested for a particular drug $(n=1$ to $n=55)$ for different studies, based upon the group median response. Red, responses predicted from a randomly chosen single mouse are plotted against group median response; blue, the single mouse ORR mean ORR correlation based on 1000 single mouse samples [from Murphy et al. (2016) with permission].

and Houghton, 2004), a point often neglected in both in vitro and in vivo studies (Smith and Houghton, 2013).

Recently, PDX models of adult cancers have been the focus of correlative clinical trials and have largely demonstrated that PDX responses largely recapitulate patient responses (Siolas and Hannon, 2013; Hidalgo et al., 2014; Gao et al., 2015; Izumchenko et al., 2017). The SPIDER trial at University of California, Davis, is prospectively testing the validity of PDX models in NSCLC that have an identified molecular driver (Gandara et al., 2015). In this study, biopsy is taken pretreatment and at the time of relapse to establish PDX models that are treated with the same agent used in the patient. The objective is to determine whether the PDX models accurately recapitulate the sensitivity of the patient tumor at different points in the course of disease. One of the objectives of such coclinical studies is to use the tumor xenograft derived from an individual patient (an "avatar") to guide therapy for that individual patient and to identify effective agents that may be used at time of patient relapse (Malaney et al., 2014). Conduct of similar coclinical trials has not been reported for pediatric cancer PDX models, perhaps in part because of the complexity of current therapeutic protocols. While, for pediatric patients, such studies are unlikely to yield real-time information valuable for directing therapy for that individual patient, developing PDX models resistant to multichemoradiation therapy protocols may be valuable in understanding the mechanism(s) that may confer resistance under more "clinical" conditions (Nicolle et al., 2016). However, it is unclear how such approaches would model clinical situations where an indicator lesion regresses on treatment, but another lesion progresses, unless PDX models are established from multiple biopsies. It is also important to understand that transplantation of tumor from patient to mouse is not always successful, hence the tumors that successfully engraft may represent a subset of a particular cancer, as shown for subsets of NSCLC (John et al., 2011; Stewart et al., 2015), or select for limited clones within a heterogeneous tumor (Mardis, 2015).

\section{B. Incorporating Targeted Therapies}

One of the challenges in developing novel approaches to treatment of many childhood cancers is that current protocols are, in most cases, highly effective, thus compromising the ability to test the new agent in the drug-naive patient. Novel agents are evaluated in phase I/II clinical trials, as single agents, or when incorporated into "backbone therapy," allowing for direct comparison of the efficacy of experimental agents when incorporated into a standard relapse protocol-the so-called "pick the winner" trial design. It is in this setting that PDX models may be valuable in assessing the combination of targeted agents in the context of standard of care cytotoxic agents. An assumption is that addition of a targeted agent will enhance standard of care therapy, although the support for this is often based only on in vitro experiments that use nonphysiologic exposures to drugs. Indeed, recent studies indicate that small molecule kinase inhibitors may antagonize cytotoxic agents, such as vincristine (Morton et al., 2012), or compromise the doses of other drugs frequently used for treatment of sarcoma (Bandyopadhyay et al., 2018). In part, these effects may be mediated by these ATP-competitive agents interacting with $\mathrm{ABC}$ transporters that efflux xenobiotics (such as vincristine, topotecan, actinomycin $\mathrm{D}$, etoposide, and doxorubicin) and protect normal host tissues (Erlichman et al., 2001; Houghton et al., 2004; Stewart et al., 2004; Leggas et al., 2006). On the other hand, angiostatic agents, such as sorafenib and sunitinib, may also sensitize tumor endothelial cells to standard cytotoxic agents by inhibiting ABCB1, promoting killing of vasculature and potentiating antitumor activity (Bani et al., 2017). Although of interest, one has to interpret combination studies with some caution when the modulator is combined with standard of care drugs at doses far below the maximum tolerated dose (MTD), where potentiation of toxicity would not have been identified using this experimental design. While antiangiogenic agents can "normalize" tumor vasculature, reduce interstitial pressure, and enhance uptake of cytotoxic agents (Goel et al., 2012; Jain, 2014), antiangiogenic drugs may also have negative effects on intratumoral delivery of anticancer agents (Steins et al., 2017). Recently, two antiangiogenic agents, bevacizumab, an antibody that binds 
to and neutralizes VEGF, and the macrocyclic lactone temsirolimus (a rapamycin analog) that selectively inhibits the TOR complex 1 through a non-ATP competitive mechanism to inhibit angiogenesis (Guba et al., 2002), were compared in a "backbone" in patients with rhabdomyosarcoma at relapse. In preclinical testing, rapamycin enhanced the antitumor activity of both cyclophosphamide and vincristine administered at their respective MTDs (Houghton et al., 2010) and in the clinical trial was shown to be more active in a therapy backbone of cyclophosphamide combined with vinorelbine than bevacizumab in the same backbone (Mascarenhas et al., 2010).

Of importance in interpretation of "modulator" studies is that the effect of the therapy for the combination is compared with that of the cytotoxic agent administered on an optimal schedule at its MTD. This is of critical importance, as "modulators" in most instances will enhance the toxicity to normal tissues of the anticancer drug being modulated-for example, modulators of P-glycoprotein-mediated multidrug resistance or modulators of DNA damage repair pathways (Tew et al., 1993). Flawed preclinical experimental designs have led to testing of agents such as $\mathrm{O}^{6}$-benzylguanine, buthionine sufoxamine, and many multidrug resistance modulators in multiple clinical trials that ultimately failed. With the sparse clinical resources for testing new agents, it is imperative that these pediatric clinical studies are informed by well-conducted preclinical studies.

\section{Exploiting DNA Damage Repair Deficiencies}

Inhibitors of poly-(ADP-ribose) polymerase (PARP) that exploit the deficiency in homologous recombination in BRCA-deficient cancers such as breast and ovarian carcinomas (Lord and Ashworth, 2013; Konecny and Kristeleit, 2016) have confirmed the concept of "synthetic lethality" established first in yeast model systems (Hartwell and Weinert, 1989) in a clinical setting. Spurred by the success of PARP inhibitors in adult cancer trials, there are several approaches in addition to PARP inhibitors that are being pursued for treatment of pediatric cancers. However, whereas the synthetic lethality of PARP inhibition in the context of deficient homologous recombination has a mechanistic underpinning, it is less clear what mechanisms confer synthetic lethality to cell cycle checkpoint inhibitors or ATM/ATR inhibitors in the context of pediatric cancers. Rare hematopoietic and brain cancers in pediatric patients with a severe form of Fanconi anemia are due to inherited biallelic BRCA2 mutations (Howlett et al., 2002); however, the frequency of BRCA mutations and loss of heterozygosity, with the possible exception of osteosarcoma (Kovac et al., 2015), appears low in most pediatric cancers. In osteosarcoma over $80 \%$ of clinical samples exhibited combinations of single-base substitutions, loss of heterozygosity, or large-scale genome instability signatures considered characteristic of BRCA-deficient tumors (Kovac et al., 2015), although such a relationship was not reported in another study (Chen et al., 2014). In support of the BRCA-ness it was reported that osteosarcoma cell lines were sensitive to the PARP inhibitor talazoparib (with $\mathrm{IC}_{50}$ concentrations between 33 and $450 \mathrm{nM}$ ) (Engert et al., 2017). However, in vitro, both Ewing sarcoma $\left(\mathrm{IC}_{50}\right.$ range: 3.7-68 $\mathrm{nM}$ ) and rhabdomyosarcoma ( $\mathrm{IC}_{50}$ range 5-31 $\mathrm{nM}$ ) cells were markedly more sensitive to talazaparib than osteosarcoma cell lines, even allowing for differences in assay conditions (Smith et al., 2015a); hence the meaning of "sensitivity" based on a BRCA-ness profile is unclear. Ewing sarcoma has a negligible incidence of $B R C A$ mutations, thus, alternative mechanisms must be in play to explain the sensitivity of Ewing sarcoma to PARP inhibitors (Garnett et al., 2012). The fusion oncogene, EWSR1-FLI1, caused by reciprocal translocation between chromosome 11 and 22 , in Ewing sarcoma has been reported to enhance transcription of PARP1 and PARP1 enhances the transcriptional activity of EWSR1-FILI1 (Brenner et al., 2012), suggesting that inhibition of PARP1 may partially suppress the EWSR1-FLI1 oncogene. An alternative hypothesis is that EWSR1-FLI1 may increase transcription to cause R-loops and block BRCA1mediated DNA repair (Gorthi et al., 2018). However, while Ewing sarcoma cells are among the most sensitive to PARP inhibitors in vitro, across a spectrum of pediatric solid tumors, including osteosarcomas and leukemia xenografts, the PARP inhibitor talazoparib showed little activity. The most sensitive xenograft model was a Wilms tumor with a PALB2 truncating mutation analogous to mutations associated with hereditary breast and ovarian cancer that abrogate homologous recombination repair (Smith et al., 2015a). The lack of single agent activity in Ewing sarcoma models is consistent with the clinical activity of the PARP inhibitor olaparib (Choy et al., 2014). In contrast, when combined with temozolomide, talazoparib was synergistic in 5 of 10 Ewing sarcoma xenograft models but showed very little activity in other tumor types (Smith et al., 2015b). The lack of talazoparib single agent activity against preclinical osteosarcoma models (Smith et al., 2015a) would appear also to refute the BRCA-ness phenotype proposed (Kovac et al., 2015) and susceptibility for talazoparib sensitivity of osteosarcoma cells in vitro (Engert et al., 2017). Notable in the preclinical study showing synergy in Ewing sarcoma models was that maintaining higher doses of talazoparib required dose reduction of temozolomide to $<20 \%$ of its MTD, whereas lower doses of talazoparib allowed 50\% of the MTD for temozolomide, with both regimens giving similar antitumor synergy. Early results from the NCT02116777 trial in the Children's Oncology Group suggest similar dose reductions are necessary when these agents are combined. PARP 
inhibitors also potentiate the topoisomerase I poisons in preclinical models (Stewart et al., 2014), although like temozolomide require dose reduction in human trials (Kummar et al., 2011). Preliminary data indicate a very low response rate in both trials, suggesting that the preclinical models overpredicted the clinical utility of these combinations. In general combinations of PARP inhibitors with standard of care cytotoxic agents have not shown superiority over single agent activity in adult trials (Khan et al., 2011; Plummer et al., 2013).

The success of PARP inhibitors has raised the possibilities of using other inhibitors of DNA damage repair pathways for cancer therapy (Puigvert et al., 2016; Carrassa and Damia, 2017). In a model of cancer progression, it has been proposed that in premalignant conditions, oncogenes induce replication stress through activating ATR/Chk1 signaling, which in turn activates the ATM/Chk2-p53 pathway to induce apoptosis or senescence and to prevent tumor progression or genome instability (Gorgoulis et al., 2005; Bartkova et al., 2006; Halazonetis et al., 2008). Loss of ATM-p53 checkpoint control allows cell proliferation in the presence of oncogene-mediated replication stress (Puigvert et al., 2016), but potentially presents a cancer cell-specific vulnerability to inhibition of the ATR-Chk1 pathway (Sanjiv et al., 2016). Levels of ATM were reported to be lower in solid tumor PDX models than in leukemia PDXs (Cam et al., 2010). Inhibitors of the ATR-Chk1 and ATM-Chk2 pathways are being actively pursued (Manic et al., 2015; Babiker et al., 2017; Forment and O'Connor, 2018). Pediatric cancer cell lines were among the most sensitive to the Chk1 inhibitor prexasertib, and this drug induced regression of neuroblastoma xenografts (Lowery et al., 2017). ATR inhibitors AZ20 and MSC253 also inhibited growth of Ewing sarcoma xenografts (Nieto-Soler et al., 2016), although more modest antitumor activity was reported from the PPTP study, which evaluated the ATR inhibitor M6620 against solid tumor panels, including neuroblastoma (Kurmasheva et al., 2018). Consistent with the notion that oncogene-induced replicative stress may confer hypersensitivity to Chk1 inhibitors, a medulloblastoma cell line with high c-MYC was reported to be more sensitive than a Sonic Hedgehog subtype cell line (low c-MYC) to the Chk1 inhibitor AZD-7762 (Krüger et al., 2018). An alternative strategy to disrupt cell-cycle checkpoints is to target Wee1 kinase. DNA damage activates ATR/Chk1, and Chk1 phosphorylates and activates Wee1 that then phosphorylates and inhibits CDK1/Cyclin B function, resulting in G2 arrest potentially allowing for DNA repair (Do et al., 2013). Wee1 kinase is expressed at elevated levels in several pediatric malignancies, including high-grade glioma (Müller et al., 2014), diffuse intrinsic pontine glioma (DIPG) (Caretti et al., 2013), leukemia (Chaudhuri et al., 2014), and osteosarcoma (Kreahling et al., 2013). The Wee1 kinase inhibitor AZD1775 (MK1775) has shown some single agent activity and has enhanced the activity of radiation, some chemotherapeutic agents, and the HDAC inhibitor panobinostat in pediatric cancer cell lines and xenografts (Tibes et al., 2012; Kreahling et al., 2013; Müller et al., 2014; Qi et al., 2015). Introduction of cell-cycle checkpoint inhibitor therapies into pediatric cancer trials is now a major thrust with inhibitors of ATR-Chk1, ATMChk2, Wee1, cyclin-dependent kinases (CDK4/6, CDK4/ 6/9), and mitotic kinases (Aurora A/B, polo-like kinase 1) being evaluated as single agents and in combination (Mills et al., 2017). Thus there are abundant potential combinations that could be tested in clinical trials. Of importance is that there is compelling rationale, based upon genetic deficiencies of particular cancer types or robust preclinical data to support advancing an agent or combination for clinical evaluation. For example, a genetic screen revealed neuroblastoma cells to be highly dependent on the function of Chk1 (Cole et al., 2011), thus establishing a rationale for evaluating Chk1 inhibitors. However, evaluation of the Chk1 inhibitor MK-8776 as a single agent showed almost no single agent activity against neuroblastoma xenograft models, and, even in combination with the Wee1 inhibitor, MK1775 tumors progressed within 2 weeks while on treatment (Russell et al., 2013). Thus, while such preclinical results are of interest, it is worth reiterating the discussion above concerning use of clinically relevant endpoints in preclinical studies for making decisions on advancing drugs or combinations to clinical trial. While cell-cycle checkpoint inhibitors will almost certainly enhance the toxicity of systemic chemotherapy necessitating compromising drug doses, these agents may be valuable in sensitizing tumor tissue to radiation therapy (Qiu et al., 2018).

\section{Targeting the Tumor Microenvironment}

While the focus of many studies is on the cancer cell per se, there is increasing evidence that targeting the tumor microenvironment (TME) may be equally important (Cairns et al., 2006; Kenny et al., 2007). Within tumor tissue, the vasculature is disorganized with structural and functional abnormalities (Vaupel, 2004), a complete lack of lymphatics, and frequently lacking a layer of pericytes or an intact basement membrane making the vessels leaky. Because of pericyte deficiency and lack of basement membrane formation, endothelial pores tend to be larger in tumor tissue allowing extravasation of particles such as nanocarriers, which are not removed efficiently from tumor tissue and are retained (enhanced permeability and retention effect), potentially allowing exploitation of the microenvironment (Danhier et al., 2010). Passive nanocarriers include polymeric micelles, nanoparticles, polymer-drug conjugates, and liposomes. Active vascular targeting strategies include targeting the transferrin receptor, folate receptor, targeting lectins, or 
receptors (VEGF, vascular endothelial growth factor), RGD peptide to target $\alpha_{\mathrm{V}} \beta_{3}$ integrin, VCAM-1, and matrix metalloproteinases expressed on endothelial cells. Strategies directed to the TME include targeting extracellular matrix, intratumoral hypoxia and acidosis, endothelial cells and pericytes, immune infiltrates, chronic inflammation, activating antitumoral activity of the immune system, targeting cancer-associated fibroblasts and targeting TME secreted exosomes (RomaRodrigues et al., 2019).

1. Targeting Angiogenesis. Tumor cells interact with stromal and other cells within the specific microenvironment, which may be different in the context of primary or metastatic disease. Soluble factors secreted by either malignant cells or stroma may impact each other, for example secretion of vascular endothelial growth factor (VEGF) stimulates angiogenesis and can be targeted either by binding ligand (e.g., bevacizumab, VEGF-Trap) or inhibiting VEGF receptors with small molecule kinase inhibitors (e.g., cediranib). Other approaches to preventing angiogenesis include targeting PDGF receptor on pericytes, targeting integrins, and developing vascular targeting agents that occlude the pre-existing blood vessels of tumors, causing cells death from ischemia and hemorrhagic necrosis (Thorpe, 2004). These include microtubule destabilizers, cytokine inducers, and VEGF-toxin conjugates. In preclinical studies from the PPTP, small molecule multikinase inhibitors targeting VEGFR1-3 prolonged time to event, although did not induce tumor regression. Notable was the rapid resumption of tumor growth upon cessation of treatment. The vascular-disrupting agent OXi4503/CA1P also slowed growth of a Ewing sarcoma xenograft model, reducing microvessel density and increasing areas of necrosis in tumor tissue (DuBois et al., 2010).

2. Targeting Tumor-Stroma Interactions. Targeting interactions between stromal cells and malignant cells also appears to be an effective approach to controlling metastatic disease, at least in preclinical models. Although there are multiple examples of stroma-tumor cell interactions, childhood osteosarcoma presents an interesting malignancy, as bone (the primary site) and pulmonary tissue (the metastatic site) are predominantly involved, with only $2 \%$ of patients developing lesions in other organs (Aljubran et al., 2009; Khanna et al., 2014). Thus, this disease is of interest because of the pulmonary tropism for metastatic growth, and a valuable model to identify the tumor-host interactions that may occur within the early metastatic niche (Vanharanta and Massague, 2013). Clinical samples of osteosarcoma, where primary tumor was compared with lung metastasis from the same patient, revealed increased IL-6 and CXCL8 expression in metastatic lesions, and overexpression of these genes induced greater pulmonary seeding and metastatic growth in xenograft models (Gross et al., 2018). It was found that osteosarcoma cells induced a strong interaction with primary bronchial epithelial and smooth muscle cells that increased IL-6 and CXCL8 production. Importantly, while suppression of either IL-6 or CXCL8 had little effect on cell proliferation in vitro or in vivo, combination treatment inhibited metastasis in several osteosarcoma models (Gross, 2018).

3. Targeting Tumor Microenvironment: Clinical Experience. The clinical experience with TMEtargeted therapies is limited to phase I evaluation of bevacizumab in patients with solid tumors (Glade Bender et al., 2008), where several patients demonstrated prolonged disease stabilization, whereas in combination with cytotoxic agents for treatment of Ewing sarcoma the benefit was unclear (Wagner et al., 2013) or combined with irinotecan for treatment of brain tumor patients where the combination showed minimal efficacy (Gururangan et al., 2010). Interestingly, in a phase II trial in patients with rhabdomyosarcoma at relapse (NCT01222715), which compared two antiangiogenic agents, bevacizumab and temsirolimus, a rapamycin analog, combined with the same backbone therapy (cyclophosphamide, vinorelbine), the temsirolimus combination was more effective, suggesting that all antiangiogenic agents are not similar (Mascarenhas et al., 2014); however, temsirolimus also has direct effects on tumor cells. Of note, rapamycin caused therapeutic enhancement with both vincristine and cyclophosphamide in pediatric rhabdomyosarcoma models (Houghton et al., 2010).

4. Genetically Engineered Mouse Models. Genetically engineered mouse (GEM) models of pediatric cancer have been highly valuable for understanding the biology of tumor formation and metastasis (Day et al., 2015) in the context of a normal immune system and, as such, have advantages over PDX models. Advantages and disadvantages of the use of GEMs in cancer research and drug development have been extensively reviewed (Herter-Sprie et al., 2013; Day et al., 2015; Kersten et al., 2017). With respect to pediatric cancers, models of rhabdomyosarcoma (Keller et al., 2004; Abraham et al., 2014), osteosarcoma (Sharpless and Depinho, 2006; Rickel et al., 2017; Jacques et al., 2018), medulloblastoma (Wu et al., 2011), neuroblastoma (Weiss et al., 1997; De Wilde et al., 2017), malignant peripheral nerve sheath tumors (Kim et al., 2017), and leukemia (Hauer et al., 2014) have been developed. The major limitation of use of primary GEM cancer models has been relatively low penetrance of the cancer phenotype, and the period, and variance, to develop cancer. To overcome some of these logistical constraints, primary GEM transplantation to recipient syngeneic mice as orthotopic or heterotopic implants has been used for drug screening, although such approaches negate some of the intrinsic virtues of the GEM concept. However, even using this "pragmatic" approach, relatively few studies using engineered models of pediatric cancer 
have been reported (Sampson et al., 2013; Evageliou et al., 2016; Kim et al., 2017). Inhibition of the polyamine pathway by difluoromethylornithine (DFMO) and other inhibitors has been proposed for treatment of neuroblastoma, and inhibition of this pathway has similar effects in both transgenic and PDX models of neuroblastoma (Evageliou et al., 2016). In contrast, whereas MYCN amplified neuroblastoma GEMs were highly responsive to the curaxin CBL0137 (Carter et al., 2015), neuroblastoma PDX models were completely unresponsive (Lock et al., 2017). Which model system more accurately recapitulates clinical sensitivity will await further examples in which the models yield different results and the subsequent clinical trials.

5. General Limitations to Accurate Model Translation. The experience with preclinical models in drug development has been quite variable, allowing many to question their value. In pediatric cancer, PDX models have identified novel agents that were found to be active in the same disease, although these drugs and combinations have been largely classic cytotoxic agents. The most frequent failure of these models has been overprediction of clinical efficacy due to the host (mouse) being more tolerant to these agents (Peterson and Houghton, 2004) or as a consequence of using "activity" criteria that in a clinical setting would be progressive disease (i.e., tumor growth inhibition rather than tumor volume regression). A further concern arises when targeted therapies are developed specifically using human systems, where murine toxicity (or other species) may not be relevant, for example, with inhibitors of the MDM2-P53 interaction, where target affinity for the human proteins greatly exceeds that for inhibiting the interaction of murine homologs (Canon et al., 2015). These agents demonstrated minimal toxicity until tested in patients (Ray-Coquard et al., 2012). Similarly, two inhibitors of the antiapoptotic protein MCL1, AMG 176 and AZD5991, have greater affinity of human MCL1 compared with mouse, making it difficult to assess therapeutic index in the xenograft model unless the mouse is humanized to express only human MCL1. Thus, with drugs developed specifically against human systems, the toxicity, or lack thereof, in mice may be misleading.

\section{Humanized Mice for Immuno-Oncology}

There are now estimated to be over 240 immunooncology medicines and vaccines in development (https://www.phrma.org/report/list-of-2017-immunooncology-medicines-in-development). One of the obvious limitations of immune-deficient mice to propagate PDXs is the lack of human/murine immunity and human stroma in tumors. The lack of a human immune system obviously impacts the utility of these models to evaluate immune-oncologic agents, such as immune checkpoint inhibitors. To address these deficiencies, concerted efforts have been made to "humanize" mice. Reconstitution of mice with peripheral blood from human donors or tumor infiltrating lymphocytes leads to some immune reconstitution, but leads to graft versus host disease, limiting the window for tumor growth to 2-5 weeks (King et al., 2009; Guichelaar et al., 2013). More contemporary models have focused on using non-obese diabetic (NOD) severe combined immunodeficient (SCID) (IL2-R $\gamma$ )-deficient (NSG) or NOG (NOD/Sci-SCID/IL2R $\gamma$ ) strains to reconstitute the human immune system through transplantation of human hematopoietic stem cells (Drake et al., 2012; Holzapfel et al., 2015) or human mesenchymal stem cells (Ando et al., 2008), in some cases using busulphan as a conditioning regimen with human cord blood-derived CD34+ cells (Kang et al., 2016). A major limitation of the CD34+ reconstituted mouse is that T-cells undergo selection in the context of the mouse histocompatibility complex (Shultz et al., 2012). In part, this can be overcome by implantation of fetal liver and thymus (hu-BLT) under the renal capsule followed by injection of CD34+ hematopoietic cells, providing a more complete human environment for immune cell development (Shimizu et al., 2010; Vatakis et al., 2012). Ideally, CD34+ reconstituted mice would be reconstituted with hematopoietic donor cells from the same patient as tumor (Morton et al., 2016); however, this would not be possible with huBLT mice. NOG mice, reconstituted with human peripheral blood mononuclear cells, have been used to evaluate a novel T-cell bispecific antibody that binds membrane bound carcinoembryonic antigen and increases activation of T-cells and immune infiltrates and causes tumor regression (Bacac et al., 2016; Lehmann et al., 2016), suggesting these models can be valuable in preclinical testing of immuno-oncology approaches.

Of note, PDXs of different origins have been reported to grow in CD34+ reconstituted or hu-BLT mice without prior human leukocyte antigen matching (Kozlowska et al., 2017). These models, although perhaps not optimal, at least offer the potential to explore immune-oncology agents that have been developed specifically for testing in human systems (Byrne et al., 2017).

\section{Immuno-Oncology}

The armamentarium of immune-oncology agents now encompasses immunostimulatory agents, naked antibodies, antibody conjugates and bispecific antibodies, chimeric antigen receptor T-cells (CAR-T), NK cellbased therapeutics, immune checkpoint inhibitors, as well as vaccines including oncolytic viruses. A role for antibody therapy is well established for neuroblastoma, where the anti-GD2 antibody (dinutuximab) has 
significantly improved outcome for patients in first remission in a posttransplant setting (Yu et al., 2010; Hoy, 2016; Ozkaynak et al., 2018), and addition of antiCD20 antibodies (rituximab and ofatumumab) to chemotherapy has improved outcome for several B-cell lineage malignancies (Kochuparambil and Litzow, 2014), including mature B cell (Burkitt) leukemia/ lymphoma, non-Hodgkin lymphoma (Thomas et al., 2006; Meinhardt et al., 2010), and follicular lymphoma (Czuczman et al., 2012). These antibodies trigger antibody-dependent cellular cytotoxicity through engagement of macrophages, NK cells and neutrophils, antibody-dependent phagocytosis, and complementdependent cytotoxicity when bound to the target antigen (Reichert and Valge-Archer, 2007).

\section{A. Antibody Therapy}

Numerous clinical trials have been initiated combining humanized $3 \mathrm{~F} 8$ (Hu3F8) or Ch14;18 antibodies for treatment of neuroblastoma and GD2-positive solid tumors, either as a single agent (NCT01419834, NCT01662804) or combined with allogeneic natural killer (NK) cells, 13-cis-reinoic acid, lenalidomide, granulocyte-macrophage colony stimulating factor, or chemotherapy (Capitini et al., 2014). Infusion of NK cells as a therapeutic intervention is largely restricted to hematologic malignancies, although some trials enroll patients with solid malignancies with or without concomitant recombinant IL-15 (NCT01875601, NCT01337544).

\section{B. Antibody-Drug Conjugates}

Two antibody-drug conjugates directed against CD22 (inotuzumab ozogamicin) and CD33 (gemtuzumab ozogamicin) with calicheamicin "warheads" have been tested in pediatric leukemia patients with 25\%$30 \%$ objective response rates (ORR) in AML (Aplenc et al., 2008) and 52\% complete response rate in ALL (Kantarjian et al., 2012), respectively. Additional antibody-drug conjugates targeting CD19, CD22, and CD33 are in preclinical testing. These have disulfide or protease cleavable linkers and have maytansinoid (DM4) or MMAF or MMAE warheads. SAR3419 (coltuximab ravtansine) has shown good preclinical activity in B-cell leukemia and lymphoma models and signs of clinical activity (Blanc et al., 2011), although with schedule-dependent ocular toxicity. Clinical development of this agent has been terminated. SGNCD33A (vadastuximab talirine), is a humanized antiCD33 antibody with engineered cysteines conjugated to a pyrrolobenzodiazepine dimer, a highly potent, synthetic DNA cross-linking agent, via a proteasecleavable linker (Kung Sutherland et al., 2013). It has shown activity in adult patients with AML (Stein et al., 2018). However, concerns about liver toxicity and toxicity to normal hematopoietic cells have led to termination of a phase III trial. Denintuzumab (SGN-
CD19A) has also shown activity in patients with relapsed/refractory ALL or lymphoma and is also associated with microcystic keratopathy (Wei et al., 2017), although no pediatric trials are proposed. The anti-CD22-MMAE conjugate pinatuzumab vedotin (MMAE, monomethyl auristatin E) has shown encouraging activity in refractory and relapsed non-Hodgkin lymphoma (Advani et al., 2017), but no pediatric trials are ongoing in the United States. Blinatumommab, a bispecific T-cell engager (BiTE) antibody, is a single chain peptide connecting to variable antibody fragments directed against CD3 and CD19 (Bargou et al., 2008) and is the first approved bispecific construct for treatment of relapsed and refractory ALL. Blinatumumab is considered to induce formation of a cytolytic synapsis and activates T-cells without requirement for costimulatory molecules. This leads to continuous recharging of granzymes and continuous killing of leukemic cells without inducing anergy or apoptosis of T-cells (Wong et al., 2013). In patients with ALL with minimal residual disease, stepwise dose escalation [5 $\left(\mu \mathrm{g} / \mathrm{m}^{2}\right) /$ day for 7 days then $15\left(\mu \mathrm{g} / \mathrm{m}^{2}\right) /$ day] appears to have less toxicity compared with starting at the $15(\mu \mathrm{g} /$ $\mathrm{m}^{2}$ )/day dose level (Topp et al., 2014; von Stackelberg et al., 2016). Blinatumumab has activity in pediatric patients with relapsed or refractory BCP-ALL (Hoffman and Gore, 2014; von Stackelberg et al., 2016). A multinational phase I/II study in pediatric ALL patients has been completed (NCT01471782) with preliminary results available (clinicaltrials.gov) and a second trial for pediatric patients with second or later bone-marrow relapse or relapse after alloHSCT is currently accruing (NCT02187354). One advantage of BiTES over T-cells engineered to express a chimeric antigen receptor (CAR-T cells) is that BiTES are biologics that can be produced and stored rather than tailored to each individual patient.

\section{Chimeric Antigen Receptor Engineered T-cells}

CAR-T cells are genetically modified and linked to an antibody directed at a surface antigen expressed on malignant cells, and is a personalized approach using immune cells from a patient that are genetically modified in vitro and reintroduced to the patient (Fig. 6; Davila et al., 2014a). The chimeric receptor cDNA comprises an extracellular domain fused to a single chain variable fragment from a monoclonal antibody, a spacer domain, transmembrane domain, and the intracellular signal transducing domain. Second and third generation CARs incorporate $\mathrm{CD} 3 \zeta$, as in first generation CARs, but with additional intracellular signaling domains from costimulatory molecules (CD28, 4-1BB, or OX40), and have significantly enhanced T-cell cytokine production and ability to expand in vitro and persist in vivo. CARs containing $4-1 \mathrm{BB} / \mathrm{CD} 3 \zeta$ or CD28/ $\mathrm{CD} 3 \zeta$ have been evaluated in clinical trials (Salter et al., 2018). CD19 CAR-T cells are highly effective for 
treating several B-cell malignancies and were recently approved by the US Food and Drug Administration for children and adults with relapsed/refractory ALL or non-Hodgkin lymphoma (Neelapu et al., 2017; Maude et al., 2018). Therapy with CARs is not without toxicity. Cytokine release syndrome onset occurs within the first several days of T-cell infusion and is coincident with activation and proliferation of the CARs. Cytokines associated with an acute inflammatory response are frequently elevated after CAR-T cell infusion (Davila et al., 2014b; Maude et al., 2014b; Lee et al., 2015; Gardner et al., 2017). Symptoms are mild in the majority of cases; however, infrequently patients develop fulminant hemophagocytic lymphohistiocytosis (Maude et al., 2014a). Other toxicities include neurologic symptoms from headache, delirium, and aphasia to more serious conditions including rare incidences of fatal cerebral hemorrhage or edema (Gust et al., 2017; Neelapu et al., 2018). B-cell aplasia is an expected on-target effect of targeting CD19. In most patients, prolonged loss of B-cells is well tolerated, with recovery of B- cells with the decline in CD19 CARs. However, approaches to eliminate CAR-T cells in patients with durable remission, but with persistent B-cell aplasia, are being developed (Paszkiewicz et al., 2016).

\section{Resistance to Chimeric Antigen Receptor Engineered T-cell Therapy}

While immunotherapies targeting CD19 are effective therapeutics for B-ALL, resistance is often associated with loss, mutation, or downregulation of surface CD19 and is increasingly recognized as a cause of treatment failure (Lee et al., 2015; Sotillo et al., 2015; Gardner et al., 2016). CD22-CAR therapy is effective in CD19-resistant disease, but similar to resistance to CD19-CAR therapy, resistance is associated with diminished CD22 site density, although without changes in mRNA levels or detectable mutations (Fry et al., 2018). Based upon this data, and activity of a multispecific CD19/CD22-CARs in a mouse model, it is proposed that targeting multiple antigens may reduce the frequency of antigen loss escape as a mechanism of resistance (Fry et al., 2018). Thus, for immunotherapy, as for chemotherapy or treatment of HIV, simultaneous targeting of several different cellular processes may reduce the probability of resistance emerging.

\section{E. Chimeric Antigen Receptor Engineered T-cell Therapy for Solid Tumors}

Although alternative antigens to CD19 are being developed for B-cell malignancies, extending the CAR$\mathrm{T}$ cell concept to other malignancies presents challenges. For pediatric applications, most of the focus

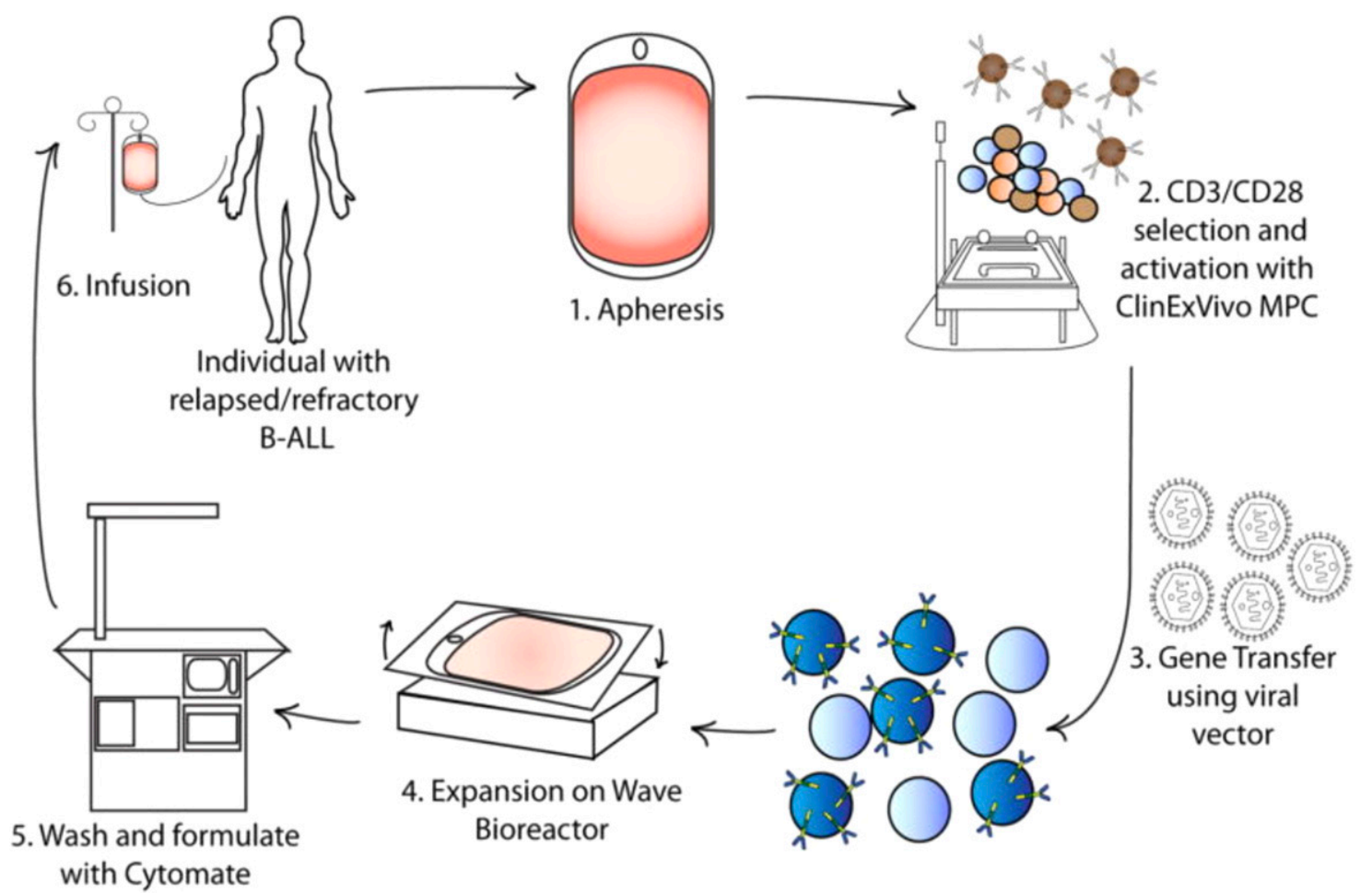

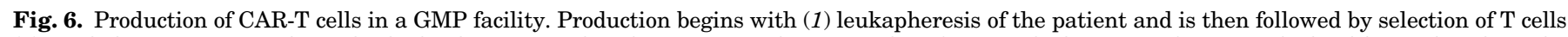

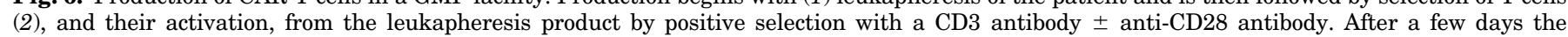

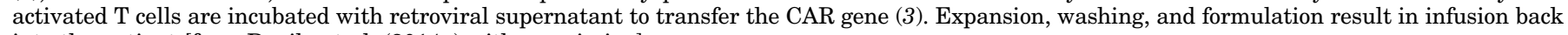
into the patient [from Davila et al. (2014a) with permission]. 
has been to develop CAR-T cell therapy for neuroblastoma. Initial studies used CARs directed to the cell adhesion molecule L1 present on neuroblastoma and other pediatric cancer cells (Park et al., 2007) as well as adrenal medulla. More recent studies have focused on using the ganglioside GD2 as the target for CAR therapy. In a phase I trial in refractory neuroblastoma use of GD2-targeted CARs induced complete remissions, with occasional durable remission of greater than 5 years (Louis et al., 2011). Because cytotoxic T lymphocytes do not survive long term and have limited antitumor activity, Epstein-Barr engineered CTLs expressing a chimeric GD2-specific receptor have been developed. EBV-specific CTLs were shown to survive longer than noninfected T-cells and induced tumor regressions or necrosis in neuroblastoma patients (Pule et al., 2008). Other approaches include using autologous activated T-cells transduced with a third generation GD2-CAR and an inducible caspase 9 as a safety switch within the construct to trigger apoptosis and rapidly eliminate gene modified cells (Di Stasi et al., 2011). A recent phase I/II trial in osteosarcoma using HER2-directed CARs resulted in stable disease for some patients and no dose-limiting toxicities (Ahmed et al., 2015) in contrast to cardiopulmonary toxicity observed in a prior study in adults (Morgan et al., 2010). CAR-T cells engineered to target the testes specific antigen, NY-ESO-1, are in clinical development following initial promising treatment of synovial cell sarcoma patients (Robbins et al., 2011). Application of CAR-T cell therapy for glioblastoma has another added level of complexity, namely distribution and trafficking of cells following intracavity, intraventricular, or intravenous administration (Migliorini et al., 2018). Targeting has been based on expression of IL13R $\alpha 2$ (Brown et al., 2015), HER2 (ERBB2) (Ahmed et al., 2017), or the EGFRvIII variant (O'Rourke et al., 2017; Sahin et al., 2018), which may have relevance also to childhood glioblastoma (Kawakami et al., 2004; Bax et al., 2009). Of importance is the observation that following intravenous administration, EGFRvIII targeting CAR-T cells trafficked to intracerebral tumors, successfully targeting and eradicating this antigen in tumor (Choi et al., 2017). While the role of targeted CARs remains undetermined outside their use in B-cell malignancies, many new ideas in improving their efficacy are in preclinical development for several solid malignancies that have relevance to pediatric cancer (Burgess and Tawbi, 2015; Wedekind et al., 2018).

\section{F. Immune Checkpoint Inhibitors}

The clinical activity of immune checkpoint inhibitors, which boost immunity against cancer cells, has generated considerable excitement with ongoing clinical trials of individual agents and combinations of agents often exceeding the activity of standard of care therapy. Most clinical studies have evaluated the anticancer activity of antibodies directed against PD-1 [programmed death protein-1 (Ishida et al., 1992)] and CTLA-4 (T-lymphocyte-associated protein 4) that have demonstrated significant activity in a range of adult carcinomas (Seidel et al., 2018). The physiologic function of PD-1, its ligands (PDL-1, PDL-2), and CTLA4 is to contain immune responses and avoid immunopathology. Tumor cells abrogate T-cell function through expressing PDL-1 (Fig. 7; Topalian et al., 2016). It is well established that under conditions of chronic inflammation, T-cells become exhausted and upregulate a broad range of nonredundant inhibitory receptors that includes PD-1 and CTLA-4. PD-1 is homologous to the costimulatory molecule CD28 and functions to inhibit immune signaling, being an essential regulator of adaptive immune responses (Nishimura et al., 1999). PD-1-deficient mice develop autoimmune diseases (lupus-like proliferative glomerulonephritis and arthritis) as they age and have exacerbated inflammation during infections (Nishimura et al., 1998, 1999). CTLA-4 knockout mice die within 2 to 3 weeks of birth due to massive lymphoproliferation with infiltration and destruction of major organs (Khattri et al., 1999). CTLA-4 is characteristically expressed on exhausted T-cells and regulatory T-cells and mediates immune suppression by indirectly decreasing signaling through the costimulatory receptor CD28. CTLA- 4 may also remove CD80 and CD86 from the surface of antigen presenting cells, a mechanism by which regulatory T-cells mediate immune suppression of bystander cells (Wing et al., 2008).

Clinical studies show quite variable response rates and durations of response. Hodgkin's lymphoma is highly sensitive to the anti-PD-1 antibody nivolumab, with ORR of $87 \%$ (Ansell et al., 2015), whereas squamous cell carcinoma of head and neck the response rate is far lower (13\%) (Ferris et al., 2016). In treatment of melanoma, anti-PD-1 alone yields response rates around 30\% (Robert et al., 2014; Weber et al., 2015), whereas combination with anti-CTLA-4 increases this to $60 \%$ (Larkin et al., 2015), which correlated with progression-free survival. Because of the variable response rates and the high cost of treatment, there is considerable effort to identify biomarkers that may accurately predict patient response. High level expression of PD-1 and/or PDL-1 may predict poor prognosis in some cancers (melanoma, renal cell, and ovarian carcinomas), whereas it may predict improved survival in others (angiosarcoma, gastric) (Seidel et al., 2018). Intratumoral PD-1 and PD-L1 levels may be of predictive value for anti-PD-1 therapy in NSCLC and melanoma (Buder-Bakhaya and Hassel, 2018). In melanoma, resistance to PD-1 directed therapy may correlate with a transcriptional profile (innate anti-PD-1 resistance) (Hugo et al., 2016). 


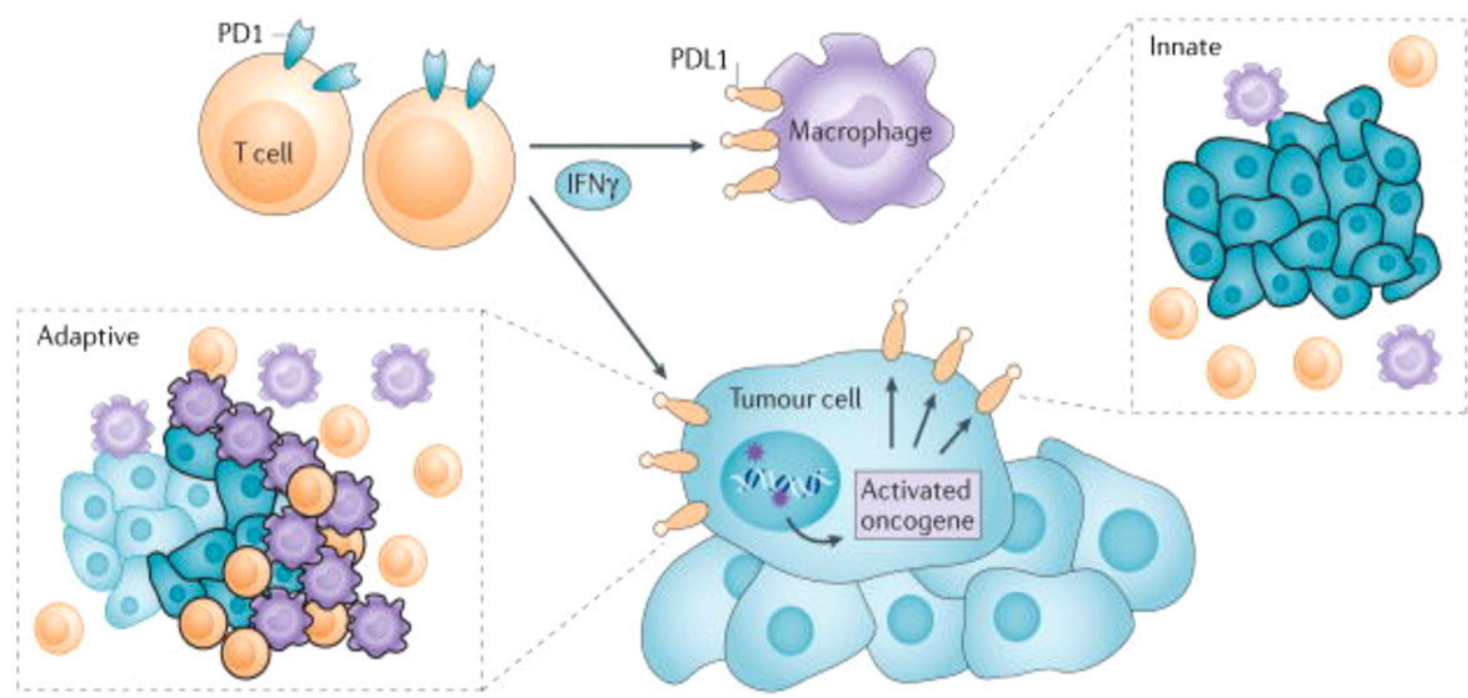

Fig. 7. Constitutive broad (innate) expression of membranous programmed cell death 1 ligand 1 (PDL1) by tumor cells is thought to be driven by dysregulated signaling pathways such as PI3K-AKT, or chromosomal alterations and amplifications such as are found in Hodgkin lymphoma. In contrast, adaptive focal expression of PDL1 by tumor cells and macrophages occurs at the interface of tumor cell nests with immune infiltrates secreting pro-inflammatory factors such as interferon- $\gamma$ (IFN $\gamma$; the "immune front"). The ligation of PDL1 with programmed cell death protein 1 (PD1) molecules will down-modulate T-cell function, essentially creating a negative feedback loop that dampens antitumour immunity. The innate and adaptive mechanisms for PDL1 induction are not mutually exclusive: constitutive oncogene-driven PDL1 expression may be further upregulated by inflammatory cytokines. In boxed insets, tumor cells are shown as blue, macrophages are purple, and T-cells are orange; black outlining of cells indicates PDL1 protein expression, such as would be demonstrated with immunohistochemistry [from Topalian et al. (2016) with permission].

Mutational load may also be a marker for responsiveness, as tumors associated with a high level of mutations have higher response rates to anti-CTLA-4 treatment (ipilimumab) (Lawrence et al., 2014; Rizvi et al., 2015; McGranahan et al., 2016; Balar et al., 2017). Also, in a stratified trial, the response rate for patients with tumors exhibiting mismatch repair deficiency (high microsatellite instability and mismatch repair deficiency) was $40 \%$ whereas there were no responses in the repair proficient stratum (Le et al., 2015). FDA granted biomarker-based approval for pembrolizumab (anti-PD1) for both pediatric and adult patients with unresectable or metastatic solid tumors, and for colorectal cancer with high microsatellite instability or mistmatch repair deficiency (Overman et al., 2017). Of interest is that no pediatric patients were entered into the clinical trial that demonstrated enhanced response to pembrolizumab in microsattelite instability. However, response to immune checkpoint inhibitors is clearly complex, being tumor intrinsic and extrinsic, including the tumor microenvironment, the load of tumor infiltrating lymphocytes, tumor stage or burden, performance status, and the gut microbiome (Buder-Bakhaya and Hassel, 2018; Seidel et al., 2018). As discussed by Seidel et al. (2018), checkpoint inhibitors appear to be most effective in patients that display evidence of an antitumor immune process prior to therapy.

\section{G. Combination Immunotherapies}

The potential combination of immune checkpoint inhibitors with molecularly targeted drugs, vaccines such as talimogene laherparepvec, or cytokine therapies is vast. While the prospect of immune-oncology is exploding in adult cancer trials, there have been relatively few trials of immune checkpoint inhibitors in pediatric cancer. Anti-CTLA-4 targeted treatment is FDA approved for pediatric melanoma, and a recent phase I trial demonstrated increased cytotoxic $\mathrm{T}$ lymphocyte activation, but no antitumor responses were reported (Merchant et al., 2016). CTLA-4 is expressed highly on several other pediatric cancers (Contardi et al., 2005; Wolchok et al., 2010; Hingorani et al., 2015 ), thus offering the prospect of activity in these tumors. Expression of PD-1 in childhood cancer is more controversial, with positivity reported to be $1 \%-33 \%$. In the study by Majzner et al. (2017), which examined over 400 samples, the highest expression was found in Burkitt lymphoma (8 of 10), glioblastoma (5 of 14), and neuroblastoma (17 of 118). Inferior survival was correlated with PD-L1 staining in neuroblastoma. Similarly, a low level of expression was found for PDL1 in Ewing sarcoma samples (0 of 60), with only one and four samples demonstrating infiltration of PD-L1 or PD-1 positive T-cells, respectively (Spurny et al., 2018). In contrast, a higher rate of positivity has been reported (121 of 364) in patients entered in the phase I/II KEYNOTE trial (Georgerer et al., 2017a). Preliminary results from the KEYNOTE-051phase I/II trial indicate occasional responses in several tumor types with an ORR of $6.1 \%$. In sarcoma, the only responses to anti-PD-1 antibody (pembrolizumab) therapy were in pleomorphic sarcoma. In this trial, patients $>12$ years of age with bone tumors were eligible, but 
there were no responses in Ewing sarcoma (0 of 13), with one response in osteosarcoma ( 1 of 22$)$. A phase I/II evaluation of atezolizumab (anti-PD-L1) in children and young adults also showed a relatively low response rate for tumors other than Hodgkin's lymphoma, with no responses in patients with osteosarcoma $(n=12)$, Ewing sarcoma $(n=11)$, neuroblastoma $(n=11)$, rhabdomyosarcoma $(n=10)$, non-RMS $(n=10)$, Wilms tumor $(n=6)$ (Georgerer et al., 2017b).

\section{H. Mutation Frequency}

As discussed above, one of the biomarkers that positively correlates with response to immune checkpoint inhibitors is high mutational load, although the mutational load for most pediatric cancers is low in comparison with adults. Currently, the NCT02992964 trial is accruing patients to a multi-center, pilot study of nivolumab in pediatric patients with recurrent or refractory hypermutant malignancies. This study will assess clinical and radiologic benefits of treatment with nivolumab in children with hypermutated cancers, including those with biallelic mismatch repair deficiency syndrome that is associated with exceptionally high mutation frequencies $(>250 / \mathrm{Mb})$ (Shlien et al., 2015). Nivolumumab alone or in combination with ipilimumab is also being investigated in pediatric patients with high-grade primary central nervous system malignancies (NCT03130959), including DIPG (after completing radiotherapy), and in recurrent or progressive high grade glioma, medulloblastoma, or ependymoma.

\section{Strategies Going Forward}

The cure rate for children with cancer now exceeds $70 \%$, and 5-year event-free survival surpasses $80 \%$. However, patients with advanced or metastatic disease are rarely cured, and for most patients who relapse, prognosis is poor. Current front line and second line chemoradiation therapies for most tumors are highly intensive and toxic, thus more effective and less toxic therapies need to be developed. For those patients that survive cancer, the risk of long-term chronic toxicities and secondary malignancies remain a lifelong consequence of their treatment. For surviving brain tumor patients, the progressive cognitive decline due to high-dose radiation therapy remains a serious consideration. Thus, going forward there are two objectives: first, to improve or maintain cure rates and, second, to reduce the burden of toxicity induced by current multimodality therapy. In the current environment for drug discovery and regulatory reform, there is reason to be optimistic that these goals can be achieved. While "up-front window" trials have fallen out of favor for cytotoxic agents, which have the potential to compromise subsequent "curative" treatments, genetic studies are identifying molecular targets that drive pediatric cancers, and drugs that target these "drivers" may be used in front-line therapies, allowing reduction in the intensity of current cytotoxic agents or radiation therapy. For example, incorporation of CD19/CD22 directed CAR-T cells being used earlier in treatment of B-cell leukemia, use of anti-GD2 antibodies earlier in the treatment of neuroblastoma and other GD2-expressing malignancies, incorporation of PD1 blockade with into frontline therapy for Hodgkins lymphoma (Moy and Younes, 2018), or use of MEK/ BRAF inhibitors in BRAF-mutant low-grade glioma (Banerjee et al., 2017) prior to chemoradiation treatment. As the pediatric MATCH trial matures, we will understand more about the efficacy and limitations of targeting single "drivers" and start to evaluate rational combinations. It is here that development of adequate preclinical models, both in vitro and in vivo, will play an important role in identifying synergistic interactions within the context of the genetic profiles of individual tumors. Again, international cooperation between groups who have developed and genetically annotated PDX models will be essential for enhancing development of combinations. These models will also be important in determining how such targeted therapies will combine with current cytotoxic agents and radiation, with the potential to reduce toxicity. Changes in FDA regulations through the RACE for Children Act will ensure more rapid access to drugs and biologics developed for adult indications where these are relevant to childhood cancer, and the recommendation that children 12 years or older can be included earlier in trials, along with adult patients, will speed the rate at which novel drugs can be evaluated in children. Additionally, initiatives under the Childhood Cancer Survivorship, Treatment, Access, and Research (STAR) Act will expand funding for specimen collection, hence enhance the capabilities for expanding our understanding of genetic and epigenetic caused of childhood cancer.

\section{Summary}

Conventional multimodality treatment of children with cancer has dramatically increased survival over the last five decades, but significant challenges remain. Our current chemo-radiotherapy approaches lead to unacceptable life-long health deficiencies, and cure rates for many cancers, particularly in patients with advanced or metastatic disease or those who relapse, remain quite dismal. In part, the "success" of multimodality therapy presents a challenge to developing new approaches. New drugs and biologics are used in patients that relapse or are refractory to current treatments, and these patients may be a suboptimal signal population to identify drug activity. Strategies that introduce novel therapeutics earlier in treatment regimens, improve outcomes, and reduce long- 
term toxicities need to be developed. The potential for immune therapies either cellular or antibodymediated remains an exciting prospect for the future, with an established role for CD19 CAR-T cells in treatment of B-cell malignancies and clinical trials testing the efficacy of immune check point inhibitors just starting in pediatric cancer. Many innovative approaches to enhance the activity of chemotherapeutic agents or radiation therapy through modulation of DNA damage repair pathways are ongoing. However, the process of clinical trials is slow, in part because there are few patients eligible for these trials, although recent changes in FDA regulations and inclusion of younger patients earlier in trials will alleviate this to some extent. With further subclassification of tumors through genomic profiling, patient numbers eligible for targeted therapies will necessitate globalization of trials, which in itself is not a trivial undertaking. Preclinical models, particularly PDXs have a role in identifying novel therapeutics and, with approaches that allow testing in large numbers of models for each cancer type that simulate the genetic heterogeneity of the clinical disease, offer the potential for biomarker identification (Gao et al., 2015; Murphy et al., 2016). As with international clinical trials, collaborations in the preclinical arena will need coordination and some level of standardization in defining response criteria. Further, some criteria for the level of preclinical activity need to be developed for progressing to clinical testing. While all preclinical models have deficiencies, approaches to humanizing the immune system of mice offer great potential for developing immune therapies that are relevant to treatment of pediatric cancer. Thus, while many challenges to curing childhood cancer with acceptable quality of life remain, this is a time of great excitement as the options for developing effective and less toxic treatments have never been greater.

\section{Authorship Contributions}

Participated in research design: Houghton, Kurmasheva.

Conducted experiments: Houghton, Kurmasheva.

Performed data analysis: Houghton, Kurmasheva.

Wrote or contributed to the writing of the manuscript: Houghton, Kurmasheva.

\section{References}

Abraham J, Nuñez-Álvarez Y, Hettmer S, Carrió E, Chen HI, Nishijo K, Huang ET, Prajapati SI, Walker RL, Davis S, et al. (2014) Lineage of origin in rhabdomyosarcoma informs pharmacological response. Genes Dev 28:1578-1591.

Adamson PC, Houghton PJ, Perilongo G, and Pritchard-Jones K (2014) Drug discovery in paediatric oncology: roadblocks to progress. Nat Rev Clin Oncol 11 732-739.

Adamson PC, Weiner SL, Simone JV, and Gelband H (2005) Making Better Drugs for Children with Cancer, National Academies Press, Washington, DC.

Advani RH, Lebovic D, Chen A, Brunvand M, Goy A, Chang JE, Hochberg E, Yalamanchili S, Kahn R, Lu D, et al. (2017) Phase I study of the anti-CD22 antibody-drug conjugate pinatuzumab vedotin with/without rituximab in patients with relapsed/refractory B-cell non-Hodgkin lymphoma. Clin Cancer Res 23:1167-1176.

Ahmed N, Brawley V, Hegde M, Bielamowicz K, Kalra M, Landi D, Robertson C, Gray TL, Diouf O, Wakefield A, et al. (2017) HER2-specific chimeric antigen receptor-modified virus-specific $\mathrm{T}$ cells for progressive glioblastoma: a phase 1 dose-escalation trial. JAMA Oncol 3:1094-1101.

Ahmed N, Brawley VS, Hegde M, Robertson C, Ghazi A, Gerken C, Liu E, Dakhova O, Ashoori A, Corder A, et al. (2015) Human epidermal growth factor receptor 2 (HER2) -specific chimeric antigen receptor-modified T cells for the immunotherapy of HER2-positive sarcoma. J Clin Oncol 33:1688-1696.

Aljubran AH, Griffin A, Pintilie M, and Blackstein M (2009) Osteosarcoma in adolescents and adults: survival analysis with and without lung metastases. Ann Oncol 20:1136-1141.

Allen CE, Laetsch TW, Mody R, Irwin MS, Lim MS, Adamson PC, Seibel NL, Parsons DW, Cho YJ, and Janeway K; Pediatric MATCH Target and Agent Prioritization Committee (2017) Target and agent prioritization for the Children's Oncology Group-National Cancer Institute Pediatric MATCH trial. J Natl Cancer Inst 109: djw274.

Ando K, Muguruma Y, and Yahata T (2008) Humanizing bone marrow in immunedeficient mice. Curr Top Microbiol Immunol 324:77-86.

Ansell SM, Lesokhin AM, Borrello I, Halwani A, Scott EC, Gutierrez M, Schuster SJ, Millenson MM, Cattry D, Freeman GJ, et al. (2015) PD-1 blockade with nivolumab in relapsed or refractory Hodgkin's lymphoma. $N$ Engl J Med 372: 311-319.

Aplenc R, Alonzo TA, Gerbing RB, Lange BJ, Hurwitz CA, Wells RJ, Bernstein I, Buckley P, Krimmel K, Smith FO, et al.; Children's Oncology Group (2008) Safety and efficacy of gemtuzumab ozogamicin in combination with chemotherapy for pediatric acute myeloid leukemia: a report from the Children's Oncology Group. $J$ Clin Oncol 26:2390-3295.

Babiker HM, McBride A, Cooke LS, and Mahadevan D (2017) Therapeutic potential of investigational CHK-1 inhibitors for the treatment of solid tumors. Expert Opin Investig Drugs 26:1063-1072.

Bacac M, Fauti T, Sam J, Colombetti S, Weinzierl T, Ouaret D, Bodmer W, Lehmann S, Hofer T, Hosse RJ, et al. (2016) A novel carcinoembryonic antigen T-cell bispecific antibody (CEA TCB) for the treatment of solid tumors. Clin Cancer Res 22: 3286-3297.

Balar AV, Galsky MD, Rosenberg JE, Powles T, Petrylak DP, Bellmunt J, Loriot Y, Necchi A, Hoffman-Censits J, Perez-Gracia JL, et al.; IMvigor210 Study Group (2017) Atezolizumab as first-line treatment in cisplatin-ineligible patients with locally advanced and metastatic urothelial carcinoma: a single-arm, multicentre, phase 2 trial. Lancet 389:67-76.

Bandyopadhyay A, Favours E, Phelps DA, Pozo VD, Ghilu S, Kurmashev D, Michalek J, Trevino A, Guttridge D, London C, et al. (2018) Evaluation of patritumab with or without erlotinib in combination with standard cytotoxic agents against pediatric sarcoma xenograft models. Pediatr Blood Cancer 65:65.

Banerjee A, Jakacki RI, Onar-Thomas A, Wu S, Nicolaides T, Young Poussaint T, Fangusaro J, Phillips J, Perry A, Turner D, et al. (2017) A phase I trial of the MEK inhibitor selumetinib (AZD6244) in pediatric patients with recurrent or refractory low-grade glioma: a Pediatric Brain Tumor Consortium (PBTC) study. Neuro-oncol 19:1135-1144.

Bani M, Decio A, Giavazzi R, and Ghilardi C (2017) Contribution of tumor endothelial cells to drug resistance: anti-angiogenic tyrosine kinase inhibitors act as p-glycoprotein antagonists. Angiogenesis 20:233-241.

Bargou R, Leo E, Zugmaier G, Klinger M, Goebeler M, Knop S, Noppeney R, Viardot A, Hess G, Schuler M, et al. (2008) Tumor regression in cancer patients by very low doses of a T cell-engaging antibody. Science 321:974-977.

Bartkova J, Rezaei N, Liontos M, Karakaidos P, Kletsas D, Issaeva N, Vassiliou LV, Kolettas E, Niforou K, Zoumpourlis VC, et al. (2006) Oncogene-induced senescence is part of the tumorigenesis barrier imposed by DNA damage checkpoints. Nature 444:633-637.

Bax DA, Gaspar N, Little SE, Marshall L, Perryman L, Regairaz M, Viana-Pereira M, Vuononvirta R, Sharp SY, Reis-Filho JS, et al. (2009) EGFRvIII deletion mutations in pediatric high-grade glioma and response to targeted therapy in pediatric glioma cell lines. Clin Cancer Res 15:5753-5761.

Bhakta N, Liu Q, Ness KK, Baassiri M, Eissa H, Yeo F, Chemaitilly W, Ehrhardt MJ, Bass J, Bishop MW, et al. (2017) The cumulative burden of surviving childhood cancer: an initial report from the St Jude Lifetime Cohort Study (SJLIFE). Lancet 390:2569-2582.

Bhakta N, Liu Q, Yeo F, Baassiri M, Ehrhardt MJ, Srivastava DK, Metzger ML, Krasin MJ, Ness KK, Hudson MM, et al. (2016) Cumulative burden of cardiovascular morbidity in paediatric, adolescent, and young adult survivors of Hodgkin's lymphoma: an analysis from the St Jude Lifetime Cohort Study. Lancet Oncol 17 1325-1334.

Bicocca VT, Chang BH, Masouleh BK, Muschen M, Loriaux MM, Druker BJ, and Tyner JW (2012) Crosstalk between ROR1 and the Pre-B cell receptor promotes survival of $\mathrm{t}(1 ; 19)$ acute lymphoblastic leukemia. Cancer Cell 22:656-667.

Blanc V, Bousseau A, Caron A, Carrez C, Lutz RJ, and Lambert JM (2011) SAR3419: an anti-CD19-maytansinoid immunoconjugate for the treatment of B-cell malignancies. Clin Cancer Res 17:6448-6458.

Blaney SM, Bernstein M, Neville K, Ginsberg J, Kitchen B, Horton T, Berg SL, Krailo M, and Adamson PC (2004) Phase I study of the proteasome inhibitor bortezomib in pediatric patients with refractory solid tumors: a Children's Oncology Group study (ADVL0015). J Clin Oncol 22:4804-4809.

Borkin D, He S, Miao H, Kempinska K, Pollock J, Chase J, Purohit T, Malik B, Zhao T, Wang J, et al. (2015) Pharmacologic inhibition of the Menin-MLL interaction blocks progression of MLL leukemia in vivo. Cancer Cell 27:589-602.

Brenner JC, Feng FY, Han S, Patel S, Goyal SV, Bou-Maroun LM, Liu M, Lonigro R, Prensner JR, Tomlins SA, et al. (2012) PARP-1 inhibition as a targeted strategy to treat Ewing's sarcoma. Cancer Res 72:1608-1613.

Brohl AS, Solomon DA, Chang W, Wang J, Song Y, Sindiri S, Patidar R, Hurd L, Chen L, Shern JF, et al. (2014) The genomic landscape of the Ewing Sarcoma family of tumors reveals recurrent STAG2 mutation. PLoS Genet 10: e1004475.

Brown CE, Badie B, Barish ME, Weng L, Ostberg JR, Chang WC, Naranjo A, Starr R, Wagner J, Wright C, et al. (2015) Bioactivity and safety of IL13R $\alpha 2$-redirected 
chimeric antigen receptor CD8 $+\mathrm{T}$ cells in patients with recurrent glioblastoma. Clin Cancer Res 21:4062-4072.

Buder-Bakhaya K and Hassel JC (2018) Biomarkers for clinical benefit of immune checkpoint inhibitor treatment-A review from the melanoma perspective and beyond. Front Immunol 9:1474.

Burger JA (2014) Bruton's tyrosine kinase (BTK) inhibitors in clinical trials. Curr Hematol Malig Rep 9:44-49.

Burgess M and Tawbi H (2015) Immunotherapeutic approaches to sarcoma. Curr Treat Options Oncol 16:26.

Byrne AT, Alférez DG, Amant F, Annibali D, Arribas J, Biankin AV, Bruna A, Budinská E, Caldas C, Chang DK, et al. (2017) Interrogating open issues in cancer precision medicine with patient-derived xenografts. Nat Rev Cancer 17:254-268

Cairns R, Papandreou I, and Denko N (2006) Overcoming physiologic barriers to cancer treatment by molecularly targeting the tumor microenvironment. Mol Cancer Res 4:61-70.

Cam H, Easton JB, High A, and Houghton PJ (2010) mTORC1 signaling under hypoxic conditions is controlled by ATM-dependent phosphorylation of HIF-1 $\alpha$. Mol Cell 40:509-520.

Cancer Genome Atlas Research Network (2017) Comprehensive and integrated genomic characterization of adult soft tissue sarcomas. Cell 171:950-965.e28.

Canon J, Osgood T, Olson SH, Saiki AY, Robertson R, Yu D, Eksterowicz J, Ye Q, Jin L, Chen A, et al. (2015) The MDM2 inhibitor AMG 232 demonstrates robust antitumor efficacy and potentiates the activity of p53-inducing cytotoxic agents. $\mathrm{Mol}$ Cancer Ther 14:649-658.

Capitini CM, Otto M, DeSantes KB, and Sondel PM (2014) Immunotherapy in pediatric malignancies: current status and future perspectives. Future Oncol 10:1659-1678.

Caretti V, Hiddingh L, Lagerweij T, Schellen P, Koken PW, Hulleman E, van Vuurden DG, Vandertop WP, Kaspers GJ, Noske DP, et al. (2013) WEE1 kinase inhibition enhances the radiation response of diffuse intrinsic pontine gliomas. $\mathrm{Mol}$ Cancer Ther 12:141-150.

Carol H, Boehm I, Reynolds CP, Kang MH, Maris JM, Morton CL, Gorlick R, Kolb EA, Keir ST, Wu J, et al. (2011) Efficacy and pharmacokinetic/pharmacodynamic evaluation of the Aurora kinase A inhibitor MLN8237 against preclinical models of pediatric cancer. Cancer Chemother Pharmacol 68:1291-1304.

Carrassa L and Damia G (2017) DNA damage response inhibitors: mechanisms and potential applications in cancer therapy. Cancer Treat Rev 60:139-151.

Carter DR, Murray J, Cheung BB, Gamble L, Koach J, Tsang J, Sutton S, Kalla H, Syed S, Gifford AJ, et al. (2015) Therapeutic targeting of the MYC signal by inhibition of histone chaperone FACT in neuroblastoma. Sci Transl Med 7:312ra176.

Chaudhuri L, Vincelette ND, Koh BD, Naylor RM, Flatten KS, Peterson KL, McNally A, Gojo I, Karp JE, Mesa RA, et al. (2014) CHK1 and WEE1 inhibition combine synergistically to enhance therapeutic efficacy in acute myeloid leukemia ex vivo. Haematologica 99:688-696.

Chen X, Bahrami A, Pappo A, Easton J, Dalton J, Hedlund E, Ellison D, Shurtleff S, Wu G, Wei L, et al.; St. Jude Children's Research Hospital-Washington University Pediatric Cancer Genome Project (2014) Recurrent somatic structural variations contribute to tumorigenesis in pediatric osteosarcoma. Cell Reports 7:104-112.

Chmielecki J, Bailey M, He J, Elvin J, Vergilio JA, Ramkissoon S, Suh J, Frampton GM, Sun JX, Morley S, et al. (2017) Genomic profiling of a large set of diverse pediatric cancers identifies known and novel mutations across tumor spectra Cancer Res 77:509-519.

Choi BD, O'Rourke DM, and Maus MV (2017) Engineering chimeric antigen receptor $\mathrm{T}$ cells to treat glioblastoma. J Target Ther Cancer 6:22-25.

Chow EJ, Chen Y, Hudson MM, Feijen EAM, Kremer LC, Border WL, Green DM, Meacham LR, Mulrooney DA, Ness KK, et al. (2018) Prediction of ischemic heart disease and stroke in survivors of childhood cancer. J Clin Oncol 36:44-52.

Choy E, Butrynski JE, Harmon DC, Morgan JA, George S, Wagner AJ, D'Adamo D, Cote GM, Flamand Y, Benes CH, et al. (2014) Phase II study of olaparib in patients with refractory Ewing sarcoma following failure of standard chemotherapy. BMC Cancer 14:813.

Cole KA, Huggins J, Laquaglia M, Hulderman CE, Russell MR, Bosse K, Diskin SJ, Attiyeh EF, Sennett R, Norris G, et al. (2011) RNAi screen of the protein kinome identifies checkpoint kinase 1 (CHK1) as a therapeutic target in neuroblastoma. Proc Natl Acad Sci USA 108:3336-3341.

Contardi E, Palmisano GL, Tazzari PL, Martelli AM, Falà F, Fabbi M, Kato T, Lucarelli E, Donati D, Polito L, et al. (2005) CTLA-4 is constitutively expressed on tumor cells and can trigger apoptosis upon ligand interaction. Int $J$ Cancer 117: $538-550$.

Crompton BD, Stewart C, Taylor-Weiner A, Alexe G, Kurek KC, Calicchio ML, Kiezun A, Carter SL, Shukla SA, Mehta SS, et al. (2014) The genomic landscape of pediatric Ewing sarcoma. Cancer Discov 4:1326-1341.

Czuczman MS, Hess G, Gadeberg OV, Pedersen LM, Goldstein N, Gupta I, Jewell RC, Lin TS, Lisby S, Strange C, et al.; 409 Study Investigators (2012) Chemoimmunotherapy with ofatumumab in combination with CHOP in previously untreated follicular lymphoma. Br J Haematol 157:438-445.

Dahiya S, Haydon DH, Alvarado D, Gurnett CA, Gutmann DH, and Leonard JR (2013) BRAF(V600E) mutation is a negative prognosticator in pediatric ganglioglioma. Acta Neuropathol 125:901-910.

Danhier F, Feron O, and Préat V (2010) To exploit the tumor microenvironment: passive and active tumor targeting of nanocarriers for anti-cancer drug delivery. $J$ Control Release 148:135-146.

Davila ML, Bouhassira DC, Park JH, Curran KJ, Smith EL, Pegram HJ, and Brentjens $\mathrm{R}$ (2014a) Chimeric antigen receptors for the adoptive $\mathrm{T}$ cell therapy of hematologic malignancies. Int $J$ Hematol 99:361-371.

Davila ML, Riviere I, Wang X, Bartido S, Park J, Curran K, Chung SS, Stefanski J, Borquez-Ojeda O, Olszewska M, et al. (2014b) Efficacy and toxicity management of $19-28 \mathrm{z}$ CAR T cell therapy in B cell acute lymphoblastic leukemia. Sci Transl Med 6:224ra25.

Davis RE, Ngo VN, Lenz G, Tolar P, Young RM, Romesser PB, Kohlhammer H, Lamy L, Zhao H, Yang Y, et al. (2010) Chronic active B-cell-receptor signalling in diffuse large B-cell lymphoma. Nature 463:88-92.
Day CP, Merlino G, and Van Dyke T (2015) Preclinical mouse cancer models: a maze of opportunities and challenges. Cell 163:39-53.

De Wilde B, Beckers A, Lindner S, Kristina A, De Preter K, Depuydt P, Mestdagh P, Sante T, Lefever S, Hertwig F, et al. (2017) The mutational landscape of MYCN, Lin28b and $A L K^{F 1174 L}$ driven murine neuroblastoma mimics human disease. Oncotarget 9:8334-8349.

Dias-Santagata D, Lam Q, Vernovsky K, Vena N, Lennerz JK, Borger DR, Batchelor TT, Ligon KL, Iafrate AJ, Ligon AH, et al. (2011) BRAF V600E mutations are common in pleomorphic xanthoastrocytoma: diagnostic and therapeutic implications. PLoS One 6:e17948.

Di Stasi A, Tey SK, Dotti G, Fujita Y, Kennedy-Nasser A, Martinez C, Straathof K, Liu E, Durett AG, Grilley B, et al. (2011) Inducible apoptosis as a safety switch for adoptive cell therapy. N Engl J Med 365:1673-1683.

Do K, Doroshow JH, and Kummar S (2013) Wee1 kinase as a target for cancer therapy. Cell Cycle 12:3159-3164.

Doebele RC, Davis LE, Vaishnavi A, Le AT, Estrada-Bernal A, Keysar S, Jimeno A Varella-Garcia M, Aisner DL, Li Y, et al. (2015) An oncogenic NTRK fusion in a patient with soft-tissue sarcoma with response to the tropomyosin-related kinase inhibitor LOXO-101. Cancer Discov 5:1049-1057.

Dome JS, Graf N, Geller JI, Fernandez CV, Mullen EA, Spreafico F, Van den Heuvel-Eibrink M, and Pritchard-Jones K (2015) Advances in Wilms tumor treatment and biology: progress through international collaboration. J Clin Oncol 33:2999-3007.

Drake AC, Chen Q, and Chen J (2012) Engineering humanized mice for improved hematopoietic reconstitution. Cell Mol Immunol 9·215-224.

Drilon A, Laetsch TW, Kummar S, DuBois SG, Lassen UN, Demetri GD, Nathenson M, Doebele RC, Farago AF, Pappo AS, et al. (2018) Efficacy of larotrectinib in TRK fusion-positive cancers in adults and children. $N$ Engl J Med 378:731-739.

DuBois SG, Marina N, and Glade-Bender J (2010) Angiogenesis and vascular targeting in Ewing sarcoma: a review of preclinical and clinical data. Cancer 116: 749-757.

Eisenhauer EA, Therasse P, Bogaerts J, Schwartz LH, Sargent D, Ford R, Dancey J, Arbuck S, Gwyther S, Mooney M, et al. (2009) New response evaluation criteria in solid tumours: revised RECIST guideline (version 1.1). Eur J Cancer 45 : $228-247$

Eissa HM, Lu L, Baassiri M, Bhakta N, Ehrhardt MJ, Triplett BM, Green DM, Mulrooney DA, Robison LL, Hudson MM, et al. (2017) Chronic disease burden and frailty in survivors of childhood HSCT: a report from the St. Jude Lifetime Cohort Study Blood Adv 1:2243-2246.

Eleveld TF, Oldridge DA, Bernard V, Koster J, Colmet Daage L, Diskin SJ, Schild L, Bentahar NB, Bellini A, Chicard M, et al. (2015) Relapsed neuroblastomas show frequent RAS-MAPK pathway mutations. Nat Genet 47:864-871.

El-Habr EA, Tsiorva P, Theodorou M, Levidou G, Korkolopoulou P, Vretakos G, Petraki L, Michalopoulos NV, Patsouris E, and Saetta AA (2010) Analysis of PIK3CA and B-RAF gene mutations in human astrocytomas: association with activation of ERK and AKT. Clin Neuropathol 29:239-245.

Engert F, Kovac M, Baumhoer D, Nathrath M, and Fulda S (2017) Osteosarcoma cells with genetic signatures of BRCAness are susceptible to the PARP inhibitor talazoparib alone or in combination with chemotherapeutics. Oncotarget 8: 48794-48806.

Erkizan HV, Kong Y, Merchant M, Schlottmann S, Barber-Rotenberg JS, Yuan L, Abaan OD, Chou TH, Dakshanamurthy S, Brown ML, et al. (2009) A small molecule blocking oncogenic protein EWS-FLI1 interaction with RNA helicase A inhibits growth of Ewing's sarcoma. Nat Med 15:750-756

Erlichman C, Boerner SA, Hallgren CG, Spieker R, Wang XY, James CD, Scheffer GL, Maliepaard M, Ross DD, Bible KC, et al. (2001) The HER tyrosine kinase inhibitor CI1033 enhances cytotoxicity of 7-ethyl-10-hydroxycamptothecin and topotecan by inhibiting breast cancer resistance protein-mediated drug efflux. Cancer Res 61:739-748.

Evageliou NF, Haber M, Vu A, Laetsch TW, Murray J, Gamble LD, Cheng NC, Liu K, Reese M, Corrigan KA, et al. (2016) Polyamine antagonist therapies inhibit neuroblastoma initiation and progression. Clin Cancer Res 22:4391-4404.

Fangusaro J, Onar-Thomas A, Young Poussaint T, Wu S, Ligon AH, Lindeman Banerjee A, Packer RJ, Kilburn LB, and Goldman S (2019) Selumetinib in paediatric patients with BRAF-aberrant or neurofibromatosis type 1-associated recurrent, refractory, or progressive low-grade glioma: a multicentre, phase 2 trial. Lancet Oncol 20:1011-1022.

Ferris RL, Blumenschein G Jr, Fayette J, Guigay J, Colevas AD, Licitra L, Harrington K, Kasper S, Vokes EE, Even C, et al. (2016) Nivolumab for recurrent squamous-cell carcinoma of the head and neck. $N$ Engl $J$ Med 375:1856-1867.

Flaherty KT, Robert C, Hersey P, Nathan P, Garbe C, Milhem M, Demidov LV, Hassel JC, Rutkowski P, Mohr P, et al.; METRIC Study Group (2012) Improved survival with MEK inhibition in BRAF-mutated melanoma. $N$ Engl J Med 367 107-114.

Fletcher JI, Ziegler DS, Trahair TN, Marshall GM, Haber M, and Norris MD (2018) Too many targets, not enough patients: rethinking neuroblastoma clinical trials. Nat Rev Cancer 18:389-400.

Forment JV and O'Connor MJ (2018) Targeting the replication stress response in cancer. Pharmacol Ther 188:155-167.

Fry TJ, Shah NN, Orentas RJ, Stetler-Stevenson M, Yuan CM, Ramakrishna S, Wolters P, Martin S, Delbrook C, Yates B, et al. (2018) CD22-targeted CAR T cells induce remission in B-ALL that is naive or resistant to CD19-targeted CAR immunotherapy. Nat Med 24:20-28.

Gandara DR, Lara PN Jr, and Mack PC (2015) Patient-derived xenografts for investigation of acquired resistance in oncogene-driven cancers: building a better mousetrap. J Clin Oncol 33:2839-2840.

Gao H, Korn JM, Ferretti S, Monahan JE, Wang Y, Singh M, Zhang C, Schnell C, Yang G, Zhang Y, et al. (2015) High-throughput screening using patient-derived tumor xenografts to predict clinical trial drug response. Nat Med 21:1318-1325.

Gardner R, Wu D, Cherian S, Fang M, Hanafi LA, Finney O, Smithers H, Jensen MC, Riddell SR, Maloney DG, et al. (2016) Acquisition of a CD19-negative myeloid 
phenotype allows immune escape of MLL-rearranged B-ALL from CD19 CART-cell therapy. Blood 127:2406-2410.

Gardner RA, Finney O, Annesley C, Brakke H, Summers C, Leger K, Bleakley M, Brown C, Mgebroff S, Kelly-Spratt KS, et al. (2017) Intent-to-treat leukemia remission by CD19 CAR T cells of defined formulation and dose in children and young adults. Blood 129:3322-3331.

Garnett MJ, Edelman EJ, Heidorn SJ, Greenman CD, Dastur A, Lau KW, Greninger $\mathrm{P}$, Thompson IR, Luo X, Soares J, et al. (2012) Systematic identification of genomic markers of drug sensitivity in cancer cells. Nature 483:570-575

Geier B, Kurmashev D, Kurmasheva RT, and Houghton PJ (2015) Preclinical childhood sarcoma models: drug efficacy biomarker identification and validation. Front Oncol 5:193.

Geng H, Hurtz C, Lenz KB, Chen Z, Baumjohann D, Thompson S, Goloviznina NA, Chen WY, Huan J, LaTocha D, et al. (2015) Self-enforcing feedback activation between BCL6 and pre-B cell receptor signaling defines a distinct subtype of acute lymphoblastic leukemia. Cancer Cell 27:409-425.

Georgerer B, Kang HJ, Yalon-Oren M, Marshall LV, Vezina C, and Pappo AS (2017a) Phaase 1/2 KEYNOTE-051 study of pembrolizumab (pembro) in pediatric patients (pts) with advanced melanoma or a PD-L1+ advanced, relapsed, or refractory solid tumor or lymphoma (Abstract). J Clin Oncol 35:10525.

Georgerer B, Karski EE, Zwaan M, Casanova M, Marshall LV, DuBois SG, Kowgier M, Tagen M, Kwan A, Das-Thakur M, et al. (2017b) A phase I/II study of atezolizumab in pediatric and young adult patients with refractory/relapsed solid tumors (iMATRIX-Atezolizumab) (Abstract). J Clin Oncol 35:10524.

Glade Bender JL, Adamson PC, Reid JM, Xu L, Baruchel S, Shaked Y, Kerbel RS, Cooney-Qualter EM, Stempak D, Chen HX, et al.; Children's Oncology Group Study (2008) Phase I trial and pharmacokinetic study of bevacizumab in pediatric patients with refractory solid tumors: a Children's Oncology Group Study. J Clin Oncol 26:399-405.

Goel S, Wong AH, and Jain RK (2012) Vascular normalization as a therapeutic strategy for malignant and nonmalignant disease. Cold Spring Harb Perspect Med 2:a006486

Gore L, Ivy SP, Balis FM, Rubin E, Thornton K, Donoghue M, Roberts S, Bruinooge S, Ersek J, Goodman N, et al. (2017) Modernizing clinical trial eligibility: recommendations of the American Society of Clinical Oncology-Friends of Cancer Research Minimum Age Working Group. J Clin Oncol 35:3781-3787.

Gorgoulis VG, Vassiliou LV, Karakaidos P, Zacharatos P, Kotsinas A, Liloglou T, Venere M, Ditullio RA Jr, Kastrinakis NG, Levy B, et al. (2005) Activation of the DNA damage checkpoint and genomic instability in human precancerous lesions. Nature 434:907-913.

Gorthi A, Romero JC, Loranc E, Cao L, Lawrence LA, Goodale E, Iniguez AB, Bernard X, Masamsetti VP, Roston S, et al. (2018) EWS-FLI1 increases transcription to cause R-loops and block BRCA1 repair in Ewing sarcoma. Nature 555:387-391.

Gross AC, Cam H, Phelps DA, Saraf AJ, Bid HK, Cam M, London CA, Winget SA, Arnold MA, Brandolini L, et al. (2018) IL-6 and CXCL8 mediate osteosarcoma-lung interactions critical to metastasis. JCI Insight 3, doi: 10.1172/jci.insight.99791.

Guba M, von Breitenbuch P, Steinbauer M, Koehl G, Flegel S, Hornung M, Bruns CJ, Zuelke C, Farkas S, Anthuber M, et al. (2002) Rapamycin inhibits primary and metastatic tumor growth by antiangiogenesis: involvement of vascular endothelial growth factor. Nat Med 8:128-135.

Guha T and Malkin D (2017) Inherited TP53 mutations and the Li-Fraumeni syndrome. Cold Spring Harb Perspect Med 7:a026187.

Guichelaar T, Emmelot ME, Rozemuller H, Martini B, Groen RW, Storm G, Lokhorst HM, Martens AC, and Mutis T (2013) Human regulatory T cells do not suppress the antitumor immunity in the bone marrow: a role for bone marrow stromal cells in neutralizing regulatory T cells. Clin Cancer Res 19:1467-1475.

Gururangan S, Chi SN, Young Poussaint T, Onar-Thomas A, Gilbertson RJ, Vajapeyam S, Friedman HS, Packer RJ, Rood BN, Boyett JM, et al. (2010) Lack of efficacy of bevacizumab plus irinotecan in children with recurrent malignant glioma and diffuse brainstem glioma: a Pediatric Brain Tumor Consortium study. $J$ Clin Oncol 28:3069-3075.

Gust J, Hay KA, Hanafi LA, Li D, Myerson D, Gonzalez-Cuyar LF, Yeung C, Liles WC, Wurfel M, Lopez JA, et al. (2017) Endothelial activation and blood-brain barrier disruption in neurotoxicity after adoptive immunotherapy with CD19 CART cells. Cancer Discov 7:1404-1419.

Halazonetis TD, Gorgoulis VG, and Bartek J (2008) An oncogene-induced DNA damage model for cancer development. Science 319:1352-1355.

Hartwell LH and Weinert TA (1989) Checkpoints: controls that ensure the order of cell cycle events. Science 246:629-634.

Hauer J, Borkhardt A, Sánchez-García I, and Cobaleda C (2014) Genetically engineered mouse models of human B-cell precursor leukemias. Cell Cycle 13: $2836-2846$.

Hawkins DS, Gupta AA, and Rudzinski ER (2014) What is new in the biology and treatment of pediatric rhabdomyosarcoma? Curr Opin Pediatr 26:50-56.

Henderson TO and Oeffinger KC (2018) Paediatrics: addressing the health burden of childhood cancer survivors - improvements are needed. Nat Rev Clin Oncol 15: 137-138.

Herman SE, Gordon AL, Hertlein E, Ramanunni A, Zhang X, Jaglowski S, Flynn J, Jones J, Blum KA, Buggy JJ, et al. (2011) Bruton tyrosine kinase represents a promising therapeutic target for treatment of chronic lymphocytic leukemia and is effectively targeted by PCI-32765. Blood 117:6287-6296.

Herter-Sprie GS, Kung AL, and Wong KK (2013) New cast for a new era: preclinical cancer drug development revisited. J Clin Invest 123:3639-3645.

Hidalgo M, Amant F, Biankin AV, Budinská E, Byrne AT, Caldas C, Clarke RB, de Jong S, Jonkers J, Mælandsmo GM, et al. (2014) Patient-derived xenograft models: an emerging platform for translational cancer research. Cancer Discov 4:998-1013. Hingorani P, Maas ML, Gustafson MP, Dickman P, Adams RH, Watanabe M, Eshun F, Williams J, Seidel MJ, and Dietz AB (2015) Increased CTLA-4(+) T cells and an increased ratio of monocytes with loss of class II (CD14(+) HLA-DR(lo/neg)) found in aggressive pediatric sarcoma patients. J Immunother Cancer 3:35.
Hoffman LM and Gore L (2014) Blinatumomab, a bi-specific anti-CD19/CD3 BiTE(®) antibody for the treatment of acute lymphoblastic leukemia: perspectives and current pediatric applications. Front Oncol 4:63.

Hollmann TJ and Hornick JL (2011) INI1-deficient tumors: diagnostic features and molecular genetics. Am J Surg Pathol 35:e47-e63.

Holzapfel BM, Wagner F, Thibaudeau L, Levesque JP, and Hutmacher DW (2015) Concise review: humanized models of tumor immunology in the 21st century: convergence of cancer research and tissue engineering. Stem Cells 33:1696-1704. Horowitz ME, Etcubanas E, Christensen ML, Houghton JA, George SL, Green AA and Houghton PJ (1988) Phase II testing of melphalan in children with newly diagnosed rhabdomyosarcoma: a model for anticancer drug development. $J$ Clin Oncol 6:308-314.

Horton TM, Pati D, Plon SE, Thompson PA, Bomgaars LR, Adamson PC, Ingle AM, Wright J, Brockman AH, Paton M, et al. (2007) A phase 1 study of the proteasome inhibitor bortezomib in pediatric patients with refractory leukemia: a Children's Oncology Group study. Clin Cancer Res 13:1516-1522.

Houghton JA, Houghton PJ, and Green AA (1982a) Chemotherapy of childhood rhabdomyosarcomas growing as xenografts in immune-deprived mice. Cancer Res 42:535-539.

Houghton JA, Houghton PJ, and Webber BL (1982b) Growth and characterization of childhood rhabdomyosarcomas as xenografts. J Natl Cancer Inst 68:437-443.

Houghton PJ, Adamson PC, Blaney S, Fine HA, Gorlick R, Haber M, Helman L, Hirschfeld S, Hollingshead MG, Israel MA, et al. (2002) Testing of new agents in childhood cancer preclinical models: meeting summary. Clin Cancer Res 8: 3646-3657.

Houghton PJ, Cheshire PJ, Hallman JC, Bissery MC, Mathieu-Boué A, and Houghton JA (1993) Therapeutic efficacy of the topoisomerase I inhibitor 7ethyl-10-(4-[1-piperidino]-1-piperidino)-carbonyloxy-camptothecin against human tumor xenografts: lack of cross-resistance in vivo in tumors with acquired resistance to the topoisomerase I inhibitor 9-dimethylaminomethyl-10-hydroxycamptothecin. Cancer Res 53:2823-2829.

Houghton PJ, Cheshire PJ, Myers L, Stewart CF, Synold TW, and Houghton JA (1992) Evaluation of 9-dimethylaminomethyl-10-hydroxycamptothecin against xenografts derived from adult and childhood solid tumors. Cancer Chemother Pharmacol 31:229-239.

Houghton PJ, Germain GS, Harwood FC, Schuetz JD, Stewart CF, Buchdunger E, and Traxler P (2004) Imatinib mesylate is a potent inhibitor of the ABCG2 (BCRP) transporter and reverses resistance to topotecan and $\mathrm{SN}-38$ in vitro. Cancer Res 64: 2333-2337.

Houghton PJ and Houghton JA (1989) Xenografts of pediatric solid tumors: predictive intermediate models? Haematol Blood Transfus 32:149-155.

Houghton PJ, Lock R, Carol H, Morton CL, Phelps D, Gorlick R, Kolb EA, Keir ST, Reynolds CP, Kang MH, et al. (2011) Initial testing of the hypoxia-activated prodrug PR-104 by the pediatric preclinical testing program. Pediatr Blood Cancer 57: 443-453.

Houghton PJ, Morton CL, Gorlick R, Lock RB, Carol H, Reynolds CP, Kang MH, Maris JM, Keir ST, Kolb EA, et al. (2010) Stage 2 combination testing of rapamycin with cytotoxic agents by the Pediatric Preclinical Testing Program. Mol Cancer Ther 9:101-112.

Houghton PJ, Morton CL, Kolb EA, Lock R, Carol H, Reynolds CP, Keshelava N, Maris JM, Keir ST, Wu J, et al. (2008) Initial testing (stage 1) of the proteasome inhibitor bortezomib by the pediatric preclinical testing program. Pediatr Blood Cancer 50:37-45.

Houghton PJ, Morton CL, Tucker C, Payne D, Favours E, Cole C, Gorlick R, Kolb EA, Zhang W, Lock R, et al. (2007) The pediatric preclinical testing program: description of models and early testing results. Pediatr Blood Cancer 49:928-940.

Houghton PJ, Shapiro DN, and Houghton JA (1991) Rhabdomyosarcoma. From the laboratory to the clinic. Pediatr Clin North Am 38:349-364.

Howlett NG, Taniguchi T, Olson S, Cox B, Waisfisz Q, De Die-Smulders C, Persky N, Grompe M, Joenje H, Pals G, et al. (2002) Biallelic inactivation of BRCA2 in Fanconi anemia. Science 297:606-609.

Hoy SM (2016) Dinutuximab: a review in high-risk neuroblastoma. Target Oncol 11: $247-253$.

Huether R, Dong L, Chen X, Wu G, Parker M, Wei L, Ma J, Edmonson MN, Hedlund EK, Rusch MC, et al. (2014) The landscape of somatic mutations in epigenetic regulators across 1,000 paediatric cancer genomes. Nat Commun 5:3630.

Hugo W, Zaretsky JM, Sun L, Song C, Moreno BH, Hu-Lieskovan S, Berent-Maoz B, Pang J, Chmielowski B, Cherry G, et al. (2016) Genomic and transcriptomic features of response to anti-PD-1 therapy in metastatic melanoma. Cell 165: $35-44$

Ishida Y, Agata Y, Shibahara K, and Honjo T (1992) Induced expression of PD-1, a novel member of the immunoglobulin gene superfamily, upon programmed cell death. EMBO J 11:3887-3895.

Izumchenko E, Paz K, Ciznadija D, Sloma I, Katz A, Vasquez-Dunddel D, Ben-Zvi I, Stebbing J, McGuire W, Harris W, et al. (2017) Patient-derived xenografts effectively capture responses to oncology therapy in a heterogeneous cohort of patients with solid tumors. Ann Oncol 28:2595-2605.

Jacques C, Renema N, Lezot F, Ory B, Walkley CR, Grigoriadis AE, and Heymann D (2018) Small animal models for the study of bone sarcoma pathogenesis:characteristics, therapeutic interests and limitations. J Bone Oncol 12:7-13.

Jain RK (2014) Antiangiogenesis strategies revisited: from starving tumors to alleviating hypoxia. Cancer Cell 26:605-622.

Jemal A, Ward EM, Johnson CJ, Cronin KA, Ma J, Ryerson B, Mariotto A, Lake AJ, Wilson R, Sherman RL, et al. (2017) Annual report to the Nation on the Status of Cancer, 1975-2014, Featuring Survival. J Natl Cancer Inst 109, doi: 10.1093/jnci/ djx030.

John T, Kohler D, Pintilie M, Yanagawa N, Pham NA, Li M, Panchal D, Hui F, Meng F, Shepherd FA, et al. (2011) The ability to form primary tumor xenografts is predictive of increased risk of disease recurrence in early-stage non-small cell lung cancer. Clin Cancer Res 17:134-141. 
Jones L, Carol H, Evans K, Richmond J, Houghton PJ, Smith MA, and Lock RB (2016) A review of new agents evaluated against pediatric acute lymphoblastic leukemia by the Pediatric Preclinical Testing Program. Leukemia 30:2133-2141.

Kalimuthu SN and Chetty R (2016) Gene of the month: SMARCB1. J Clin Pathol 69: 484-489.

Kang YK, Ko Y, Choi A, Choi HJ, Seo JH, Lee M, and Lee JA (2016) Humanizing NOD/SCID/IL-2R $\gamma$ null (NSG) mice using busulfan and retro-orbital injection of umbilical cord blood-derived CD34(+) cells. Blood Res 51:31-36.

Kantarjian H, Thomas D, Jorgensen J, Jabbour E, Kebriaei P, Rytting M, York S, Ravandi F, Kwari M, Faderl S, et al. (2012) Inotuzumab ozogamicin, an anti-CD22 calecheamicin conjugate, for refractory and relapsed acute lymphocytic leukaemia: a phase 2 study. Lancet Oncol 13:403-411.

Kawakami M, Kawakami K, Takahashi S, Abe M, and Puri RK (2004) Analysis of interleukin-13 receptor alpha2 expression in human pediatric brain tumors. Cancer 101:1036-1042.

Keller C, Arenkiel BR, Coffin CM, El-Bardeesy N, DePinho RA, and Capecchi MR (2004) Alveolar rhabdomyosarcomas in conditional Pax3:Fkhr mice: cooperativity of Ink4a/ARF and Trp53 loss of function. Genes Dev 18:2614-2626.

Kenny PA, Lee GY, and Bissell MJ (2007) Targeting the tumor microenvironment. Front Biosci 12:3468-3474.

Kersten K, de Visser KE, van Miltenburg MH, and Jonkers J (2017) Genetically engineered mouse models in oncology research and cancer medicine. EMBO Mol Med 9:137-153.

Khan OA, Gore M, Lorigan P, Stone J, Greystoke A, Burke W, Carmichael J, Watson AJ, McGown G, Thorncroft M, et al. (2011) A phase I study of the safety and tolerability of olaparib (AZD2281, KU0059436) and dacarbazine in patients with advanced solid tumours. Br J Cancer 104:750-755.

Khan T, Stewart M, Blackman S, Rousseau R, Donoghue M, Cohen K, Seibel N, Fleury M, Benettaib B, Malik R, et al. (2019) Accelerating pediatric cancer drug development: challenges and opportunities for pediatric master protocols. Ther Innov Regul Sci 53:270-278.

Khanna C, Fan TM, Gorlick R, Helman LJ, Kleinerman ES, Adamson PC, Houghton PJ, Tap WD, Welch DR, Steeg PS, et al. (2014) Toward a drug development path that targets metastatic progression in osteosarcoma. Clin Cancer Res 20: $4200-4209$.

Khattri R, Auger JA, Griffin MD, Sharpe AH, and Bluestone JA (1999) Lymphoproliferative disorder in CTLA-4 knockout mice is characterized by CD28-regulated activation of Th2 responses. J Immunol 162:5784-5791.

Kim A, Stewart DR, Reilly KM, Viskochil D, Miettinen MM, and Widemann BC (2017) Malignant peripheral nerve sheath tumors state of the science: leveraging clinical and biological insights into effective therapies. Sarcoma 2017:7429697.

King MA, Covassin L, Brehm MA, Racki W, Pearson T, Leif J, Laning J, Fodor W, Foreman O, Burzenski L, et al. (2009) Human peripheral blood leucocyte non-obese diabetic-severe combined immunodeficiency interleukin-2 receptor gamma chain gene mouse model of xenogeneic graft-versus-host-like disease and the role of host major histocompatibility complex. Clin Exp Immunol 157:104-118.

Knispel S, Zimmer L, Kanaki T, Ugurel S, Schadendorf D, and Livingstone E (2018) The safety and efficacy of dabrafenib and trametinib for the treatment of melanoma. Expert Opin Drug Saf 17:73-87.

Knutson SK, Kawano S, Minoshima Y, Warholic NM, Huang KC, Xiao Y, Kadowaki T, Uesugi M, Kuznetsov G, Kumar N, et al. (2014) Selective inhibition of EZH2 by EPZ-6438 leads to potent antitumor activity in EZH2-mutant non-Hodgkin lymphoma. Mol Cancer Ther 13:842-854

Knutson SK, Warholic NM, Wigle TJ, Klaus CR, Allain CJ, Raimondi A, Porter Scott M, Chesworth R, Moyer MP, Copeland RA, et al. (2013) Durable tumor regression in genetically altered malignant rhabdoid tumors by inhibition of methyltransferase EZH2. Proc Natl Acad Sci USA 110:7922-7927.

Kochuparambil ST and Litzow MR (2014) Novel antibody therapy in acute lymphoblastic leukemia. Curr Hematol Malig Rep 9:165-173.

Köhrer S, Havranek O, Seyfried F, Hurtz C, Coffey GP, Kim E, Ten Hacken E, Jäger U, Vanura K, O'Brien S, et al. (2016) Pre-BCR signaling in precursor B-cell acute lymphoblastic leukemia regulates PI3K/AKT, FOXO1 and MYC, and can be targeted by SYK inhibition. Leukemia 30:1246-1254.

Kolb EA, Gorlick R, Houghton PJ, Morton CL, Neale G, Keir ST, Carol H, Lock R, Phelps D, Kang MH, et al. (2010) Initial testing (stage 1) of AZD6244 (ARRY142886) by the Pediatric Preclinical Testing Program. Pediatr Blood Cancer 55: $668-677$

Konecny GE and Kristeleit RS (2016) PARP inhibitors for BRCA1/2-mutated and sporadic ovarian cancer: current practice and future directions. $\mathrm{Br} J$ Cancer $\mathbf{1 1 5}$ : $1157-1173$

Kovac M, Blattmann C, Ribi S, Smida J, Mueller NS, Engert F, Castro-Giner F, Weischenfeldt J, Kovacova M, Krieg A, et al. (2015) Exome sequencing of osteosarcoma reveals mutation signatures reminiscent of BRCA deficiency. Nat Commun 6:8940.

Kozlowska AK, Kaur K, Topchyan P, and Jewett A (2017) Novel strategies to target cancer stem cells by NK cells; studies in humanized mice. Front Biosci 22:370-384

Kreahling JM, Foroutan P, Reed D, Martinez G, Razabdouski T, Bui MM, Raghavan M, Letson D, Gillies RJ, and Altiok S (2013) Wee1 inhibition by MK-1775 leads to tumor inhibition and enhances efficacy of gemcitabine in human sarcomas. PLoS One 8:e57523.

Krivtsov AV, Hoshii T, and Armstrong SA (2017) Mixed-lineage leukemia fusions and chromatin in leukemia. Cold Spring Harb Perspect Med 7:a026658.

Krüger K, Geist K, Stuhldreier F, Schumacher L, Blümel L, Remke M, Wesselborg S, Stork B, Klöcker N, Bormann S, et al. (2018) Multiple DNA damage-dependent and DNA damage-independent stress responses define the outcome of ATR/Chk1 targeting in medulloblastoma cells. Cancer Lett 430:34-46.

Kummar S, Chen A, Ji J, Zhang Y, Reid JM, Ames M, Jia L, Weil M, Speranza G, Murgo AJ, et al. (2011) Phase I study of PARP inhibitor ABT-888 in combination with topotecan in adults with refractory solid tumors and lymphomas. Cancer Res 71:5626-5634
Kung Sutherland MS, Walter RB, Jeffrey SC, Burke PJ, Yu C, Kostner H, Stone I, Ryan MC, Sussman D, Lyon RP, et al. (2013) SGN-CD33A: a novel CD33-targeting antibody-drug conjugate using a pyrrolobenzodiazepine dimer is active in models of drug-resistant AML. Blood 122:1455-1463.

Kurmasheva RT and Houghton PJ (2016) Identifying novel therapeutic agents using xenograft models of pediatric cancer. Cancer Chemother Pharmacol 78:221-232.

Kurmasheva RT, Kurmashev D, Reynolds CP, Kang M, Wu J, Houghton PJ, and Smith MA (2018) Initial testing (stage 1) of M6620 (formerly VX-970), a novel ATR inhibitor, alone and combined with cisplatin and melphalan, by the Pediatric Preclinical Testing Program. Pediatr Blood Cancer 65, doi: 10.1002/ pbc.26825.

Kurmasheva RT, Sammons M, Favours E, Wu J, Kurmashev D, Cosmopoulos K, Keilhack H, Klaus CR, Houghton PJ, and Smith MA (2017) Initial testing (stage 1) of tazemetostat (EPZ-6438), a novel EZH2 inhibitor, by the Pediatric Preclinical Testing Program. Pediatr Blood Cancer 64, doi: 10.1002/pbc.26218.

Laetsch TW, DuBois SG, Mascarenhas L, Turpin B, Federman N, Albert CM, Nagasubramanian R, Davis JL, Rudzinski E, Feraco AM, et al. (2018) Larotrectinib for paediatric solid tumours harbouring NTRK gene fusions: phase 1 results from a multicentre, open-label, phase 1/2 study. Lancet Oncol 19:705-714

Larkin J, Chiarion-Sileni V, Gonzalez R, Grob JJ, Cowey CL, Lao CD, Schadendorf D, Dummer R, Smylie M, Rutkowski P, et al. (2015) Combined nivolumab and ipilimumab or monotherapy in untreated melanoma. N Engl J Med 373:23-34.

Lawrence MS, Stojanov P, Mermel CH, Robinson JT, Garraway LA, Golub TR, Meyerson M, Gabriel SB, Lander ES, and Getz G (2014) Discovery and saturation analysis of cancer genes across 21 tumour types. Nature 505:495-501.

Le DT, Uram JN, Wang H, Bartlett BR, Kemberling H, Eyring AD, Skora AD, Luber BS, Azad NS, Laheru D, et al. (2015) PD-1 blockade in tumors with mismatchrepair deficiency. $N$ Engl J Med 372:2509-2520.

Lee DW, Kochenderfer JN, Stetler-Stevenson M, Cui YK, Delbrook C, Feldman SA Fry TJ, Orentas R, Sabatino M, Shah NN, et al. (2015) T cells expressing CD19 chimeric antigen receptors for acute lymphoblastic leukaemia in children and young adults: a phase 1 dose-escalation trial. Lancet 385:517-528.

Leggas M, Panetta JC, Zhuang Y, Schuetz JD, Johnston B, Bai F, Sorrentino B, Zhou S, Houghton PJ, and Stewart CF (2006) Gefitinib modulates the function of multiple ATP-binding cassette transporters in vivo. Cancer Res 66:4802-4807.

Leggas M, Stewart CF, Woo MH, Fouladi M, Cheshire PJ, Peterson JK, Friedman HS, Billups C, and Houghton PJ (2002) Relation between Irofulven (MGI-114) systemic exposure and tumor response in human solid tumor xenografts. Clin Cancer Res 8:3000-3007.

Lehmann S, Perera R, Grimm HP, Sam J, Colombetti S, Fauti T, Fahrni L, Schaller $\mathrm{T}$, Freimoser-Grundschober A, Zielonka J, et al. (2016) In vivo fluorescence imaging of the activity of CEA TCB, a novel T-cell bispecific antibody, reveals highly specific tumor targeting and fast induction of T-cell-mediated tumor killing. Clin Cancer Res 22:4417-4427.

Li S, Shen D, Shao J, Crowder R, Liu W, Prat A, He X, Liu S, Hoog J, Lu C, et al. (2013) Endocrine-therapy-resistant ESR1 variants revealed by genomic characterization of breast-cancer-derived xenografts. Cell Reports 4:1116-1130.

Liem NL, Papa RA, Milross CG, Schmid MA, Tajbakhsh M, Choi S, Ramirez CD, Rice AM, Haber M, Norris MD, et al. (2004) Characterization of childhood acute lymphoblastic leukemia xenograft models for the preclinical evaluation of new therapies. Blood 103:3905-3914.

Liu Y, Easton J, Shao Y, Maciaszek J, Wang Z, Wilkinson MR, McCastlain K, Edmonson M, Pounds SB, Shi L, et al. (2017) The genomic landscape of pediatric and young adult T-lineage acute lymphoblastic leukemia. Nat Genet 49:1211-1218. Lock R, Carol H, Maris JM, Kolb EA, Gorlick R, Reynolds CP, Kang MH, Keir ST, Wu J, Purmal A, et al. (2017) Initial testing (stage 1) of the curaxin CBL0137 by the pediatric preclinical testing program. Pediatr Blood Cancer 64, doi: 10.1002/ pbc. 26263

Lock RB, Liem N, Farnsworth ML, Milross CG, Xue C, Tajbakhsh M, Haber M Norris MD, Marshall GM, and Rice AM (2002) The nonobese diabetic/severe combined immunodeficient (NOD/SCID) mouse model of childhood acute lymphoblastic leukemia reveals intrinsic differences in biologic characteristics at diagnosis and relapse. Blood 99:4100-4108

Lord CJ and Ashworth A (2013) Mechanisms of resistance to therapies targeting BRCA-mutant cancers. Nat Med 19:1381-1388.

Louis CU, Savoldo B, Dotti G, Pule M, Yvon E, Myers GD, Rossig C, Russell HV, Diouf O, Liu E, et al. (2011) Antitumor activity and long-term fate of chimeric antigen receptor-positive $\mathrm{T}$ cells in patients with neuroblastoma. Blood 118 $6050-6056$

Lowery CD, VanWye AB, Dowless M, Blosser W, Falcon BL, Stewart J, Stephens J, Beckmann RP, Bence Lin A, and Stancato LF (2017) The checkpoint kinase 1 inhibitor prexasertib induces regression of preclinical models of human neuroblastoma. Clin Cancer Res 23:4354-4363.

Mack SC, Witt H, Piro RM, Gu L, Zuyderduyn S, Stütz AM, Wang X, Gallo M, Garzia L, Zayne K, et al. (2014) Epigenomic alterations define lethal CIMP-positive ependymomas of infancy. Nature 506:445-450.

Majzner RG, Simon JS, Grosso JF, Martinez D, Pawel BR, Santi M, Merchant MS, Geoerger B, Hezam I, Marty V, et al. (2017) Assessment of programmed deathligand 1 expression and tumor-associated immune cells in pediatric cancer tissues. Cancer 123:3807-3815.

Malaney P, Nicosia SV, and Davé V (2014) One mouse, one patient paradigm: new avatars of personalized cancer therapy. Cancer Lett 344:1-12.

Manic G, Obrist F, Sistigu A, and Vitale I (2015) Trial Watch: targeting ATM-CHK2 and ATR-CHK1 pathways for anticancer therapy. Mol Cell Oncol 2:e1012976.

Mardis ER (2015) Xenografts as models of clonal selection and acquired resistance to therapy. Clin Chem 61:769-770.

Mascarenhas L, Lyden ER, Breitfeld PP, Walterhouse DO, Donaldson SS, Paidas CN, Parham DM, Anderson JR, Meyer WH, and Hawkins DS (2010) Randomized phase II window trial of two schedules of irinotecan with vincristine in patients with first relapse or progression of rhabdomyosarcoma: a report from the Children's Oncology Group. J Clin Oncol 28:4658-4663. 
Mascarenhas L, Meyer WH, Lyden E, and Rodeberg DA (2014) Randomized phase II trial of bevacizumab and temsirolimus in combination with vinorelbine (V) and cyclophosphamide (C) for first relapse/disease progression of rhabdomyosarcoma (RMS): a report from the Children's Oncology Group (COG). J Clin Oncol 32:5s

Masliah-Planchon J, Bièche I, Guinebretière JM, Bourdeaut F, and Delattre O (2015) SWI/SNF chromatin remodeling and human malignancies. Annu Rev Pathol 10: 145-171.

Matthay KK, Maris JM, Schleiermacher G, Nakagawara A, Mackall CL, Diller L, and Weiss WA (2016) Neuroblastoma. Nat Rev Dis Primers 2:16078.

Maude SL, Barrett D, Teachey DT, and Grupp SA (2014a) Managing cytokine release syndrome associated with novel T cell-engaging therapies. Cancer $J$ 20:119-122.

Maude SL, Frey N, Shaw PA, Aplenc R, Barrett DM, Bunin NJ, Chew A, Gonzalez VE, Zheng Z, Lacey SF, et al. (2014b) Chimeric antigen receptor T cells for sustained remissions in leukemia. N Engl J Med 371:1507-1517.

Maude SL, Laetsch TW, Buechner J, Rives S, Boyer M, Bittencourt H, Bader P Verneris MR, Stefanski HE, Myers GD, et al. (2018) Tisagenlecleucel in children and young adults with B-cell lymphoblastic leukemia. $N$ Engl J Med 378: $439-448$

Mauz-Körholz C, Metzger ML, Kelly KM, Schwartz CL, Castellanos ME, Dieckmann K, Kluge R, and Körholz D (2015) Pediatric Hodgkin lymphoma. J Clin Oncol 33: $2975-2985$

McBride MJ and Kadoch C (2018) Disruption of mammalian SWI/SNF and polycomb complexes in human sarcomas: mechanisms and therapeutic opportunities $J$ Pathol 244:638-649.

McBride MJ, Pulice JL, Beird HC, Ingram DR, D'Avino AR, Shern JF, Charville GW, Hornick JL, Nakayama RT, Garcia-Rivera EM, et al. (2018) The SS18-SSX fusion oncoprotein hijacks BAF complex targeting and function to drive synovial sarcoma. Cancer Cell 33:1128-1141.

McGranahan N, Furness AJ, Rosenthal R, Ramskov S, Lyngaa R, Saini SK, JamalHanjani M, Wilson GA, Birkbak NJ, Hiley CT, et al. (2016) Clonal neoantigens elicit $\mathrm{T}$ cell immunoreactivity and sensitivity to immune checkpoint blockade. Science 351:1463-1469.

Meinhardt A, Burkhardt B, Zimmermann M, Borkhardt A, Kontny U, Klingebiel T, Berthold F, Janka-Schaub G, Klein C, Kabickova E, et al.; Berlin-FrankfurtMünster group (2010) Phase II window study on rituximab in newly diagnosed pediatric mature B-cell non-Hodgkin's lymphoma and Burkitt leukemia. J Clin Oncol 28:3115-3121.

Merchant MS, Wright M, Baird K, Wexler LH, Rodriguez-Galindo C, Bernstein D, Delbrook C, Lodish M, Bishop R, Wolchok JD, et al. (2016) Phase I clinical trial of ipilimumab in pediatric patients with advanced solid tumors. Clin Cancer Res 22: $1364-1370$

Messinger YH, Gaynon PS, Sposto R, van der Giessen J, Eckroth E, Malvar J, and Bostrom BC; Therapeutic Advances in Childhood Leukemia \& Lymphoma (TACL) Consortium (2012) Bortezomib with chemotherapy is highly active in advanced B-precursor acute lymphoblastic leukemia: Therapeutic Advances in Childhood Leukemia \& Lymphoma (TACL) Study. Blood 120:285-290.

Meyer WH, Houghton JA, Houghton PJ, Webber BL, Douglass EC, and Look AT (1990) Development and characterization of pediatric osteosarcoma xenografts. Cancer Res 50:2781-2785.

Migliorini D, Dietrich PY, Stupp R, Linette GP, Posey AD Jr, and June CH (2018) CAR T-cell therapies in glioblastoma: a first look. Clin Cancer Res 24:535-540.

Mills CC, Kolb EA, and Sampson VB (2017) Recent advances of cell-cycle inhibitor therapies for pediatric cancer. Cancer Res 77:6489-6498.

Mody RJ, Wu YM, Lonigro RJ, Cao X, Roychowdhury S, Vats P, Frank KM, Prensner JR, Asangani I, Palanisamy N, et al. (2015) Integrative clinical sequencing in the management of refractory or relapsed cancer in youth. JAMA 314:913-925.

Moreno L, Caron H, Geoerger B, Eggert A, Schleiermacher G, Brock P, ValteauCouanet D, Chesler L, Schulte JH, De Preter K, et al. (2017) Accelerating drug development for neuroblastoma - New Drug Development Strategy: an Innovative Therapies for Children with Cancer, European Network for Cancer Research in Children and Adolescents and International Society of Paediatric Oncology Europe Neuroblastoma project. Expert Opin Drug Discov 12:801-811.

Morgan RA, Yang JC, Kitano M, Dudley ME, Laurencot CM, and Rosenberg SA (2010) Case report of a serious adverse event following the administration of T cells transduced with a chimeric antigen receptor recognizing ERBB2. Mol Ther 18: 843-851.

Morin RD, Johnson NA, Severson TM, Mungall AJ, An J, Goya R, Paul JE, Boyle M, Woolcock BW, Kuchenbauer F, et al. (2010) Somatic mutations altering EZH2 (Tyr641) in follicular and diffuse large B-cell lymphomas of germinal-center origin. Nat Genet 42:181-185.

Morton CL, Maris JM, Keir ST, Gorlick R, Kolb EA, Billups CA, Wu J, Smith MA and Houghton PJ (2012) Combination testing of cediranib (AZD2171) against childhood cancer models by the pediatric preclinical testing program. Pediatr Blood Cancer 58:566-571.

Morton JJ, Bird G, Keysar SB, Astling DP, Lyons TR, Anderson RT, Glogowska MJ, Estes P, Eagles JR, Le PN, et al. (2016) XactMice: humanizing mouse bone marrow enables microenvironment reconstitution in a patient-derived xenograft model of head and neck cancer. Oncogene 35:290-300.

Mossé YP, Fox E, Teachey DT, Reid JM, Safgren SL, Carol H, Lock RB, Houghton PJ, Smith MA, Hall D, et al. (2019) A phase II study of alisertib in children with recurrent/refractory solid tumors or leukemia: Children's Oncology Group Phase I and Pilot Consortium (ADVL0921). Clin Cancer Res 25:3229-3238.

Moy RH and Younes A (2018) Immune checkpoint inhibition in Hodgkin lymphoma. HemaSphere 2: 20.

Muller IB, De Langen AJ, Honeywell RJ, Giovannetti E, and Peters GJ (2016) Overcoming crizotinib resistance in ALK-rearranged NSCLC with the second-generation ALK-inhibitor ceritinib. Expert Rev Anticancer Ther 16 $147-157$

Müller K, Scheithauer H, Pietschmann S, Hoffmann M, Rössler J, Graf N, Baumert BG, Christiansen H, Kortmann RD, Kramm CM, et al. (2014) Reirradiation as part of a salvage treatment approach for progressive non-pontine pediatric high-grade gliomas: preliminary experiences from the German HIT-HGG study group. Radiat Oncol 9:177.

Mullighan CG (2014) The genomic landscape of acute lymphoblastic leukemia in children and young adults. Hematology (Am Soc Hematol Educ Program) 2014: 174-180.

Murphy B, Yin H, Maris JM, Kolb EA, Gorlick R, Reynolds CP, Kang MH, Keir ST, Kurmasheva RT, Dvorchik I, et al. (2016) Evaluation of alternative in vivo drug screening methodology: a single mouse analysis. Cancer Res 76:5798-5809.

Neale G, Su X, Morton CL, Phelps D, Gorlick R, Lock RB, Reynolds CP, Maris JM, Friedman HS, Dome J, et al. (2008) Molecular characterization of the pediatric preclinical testing panel. Clin Cancer Res 14:4572-4583.

Neelapu SS, Locke FL, Bartlett NL, Lekakis LJ, Miklos DB, Jacobson CA, Braunschweig I, Oluwole OO, Siddiqi T, Lin Y, et al. (2017) Axicabtagene ciloleucel CAR T-cell therapy in refractory large B-cell lymphoma. $N$ Engl J Med 377: 2531-2544

Neelapu SS, Tummala S, Kebriaei P, Wierda W, Gutierrez C, Locke FL, Komanduri $\mathrm{KV}$, Lin Y, Jain N, Daver N, et al. (2018) Chimeric antigen receptor T-cell therapy assessment and management of toxicities. Nat Rev Clin Oncol 15:47-62.

Nicolle D, Fabre M, Simon-Coma M, Gorse A, Kappler R, Nonell L, Mallo M, Haidar H, Déas O, Mussini C, et al. (2016) Patient-derived mouse xenografts from pediatric liver cancer predict tumor recurrence and advise clinical management. Hepatology 64:1121-1135.

Nieto-Soler M, Morgado-Palacin I, Lafarga V, Lecona E, Murga M, Callen E, Azorin D, Alonso J, Lopez-Contreras AJ, Nussenzweig A, et al. (2016) Efficacy of ATR inhibitors as single agents in Ewing sarcoma. Oncotarget 7:58759-58767.

Nishimura H, Minato N, Nakano T, and Honjo T (1998) Immunological studies on PD-1 deficient mice: implication of PD-1 as a negative regulator for $\mathrm{B}$ cell responses. Int Immunol 10:1563-1572.

Nishimura H, Nose M, Hiai H, Minato N, and Honjo T (1999) Development of lupuslike autoimmune diseases by disruption of the PD-1 gene encoding an ITIM motifcarrying immunoreceptor. Immunity 11:141-151.

Northcott PA, Dubuc AM, Pfister S, and Taylor MD (2012) Molecular subgroups of medulloblastoma. Expert Rev Neurother 12:871-884.

Nowell PC and Hungerford DA (1960) A minute chromosome in human chronic granulocytic leukemia. Science 132:1497.

Ognjanovic S, Martel G, Manivel C, Olivier M, Langer E, and Hainaut P (2012) Low prevalence of TP53 mutations and MDM2 amplifications in pediatric rhabdomyosarcoma. Sarcoma 2012:492086.

O'Rourke DM, Nasrallah MP, Desai A, Melenhorst JJ, Mansfield K, Morrissette JJD, Martinez-Lage M, Brem S, Maloney E, Shen A, et al. (2017) A single dose of peripherally infused EGFRvIII-directed CAR $\mathrm{T}$ cells mediates antigen loss and induces adaptive resistance in patients with recurrent glioblastoma. Sci Transl Med 9:eaaa0984.

Overman MJ, McDermott R, Leach JL, Lonardi S, Lenz HJ, Morse MA, Desai J, Hill A, Axelson M, Moss RA, et al. (2017) Nivolumab in patients with metastatic DNA mismatch repair-deficient or microsatellite instability-high colorectal cancer (CheckMate 142): an open-label, multicentre, phase 2 study. Lancet Oncol 18: 1182-1191

Ozkaynak MF, Gilman AL, London WB, Naranjo A, Diccianni MB, Tenney SC, Smith M, Messer KS, Seeger R, Reynolds CP, et al. (2018) A comprehensive safety trial of chimeric antibody 14.18 with GM-CSF, IL-2, and isotretinoin in high-risk neuroblastoma patients following myeloablative therapy: Children's Oncology Group Study ANBL0931. Front Immunol 9:1355.

Park JR, Digiusto DL, Slovak M, Wright C, Naranjo A, Wagner J, Meechoovet HB, Bautista C, Chang WC, Ostberg JR, et al. (2007) Adoptive transfer of chimeric antigen receptor re-directed cytolytic $\mathrm{T}$ lymphocyte clones in patients with neuroblastoma. Mol Ther 15:825-833.

Parsons DW, Jones S, Zhang X, Lin JC, Leary RJ, Angenendt P, Mankoo P, Carter H, Siu IM, Gallia GL, et al. (2008) An integrated genomic analysis of human glioblastoma multiforme. Science 321:1807-1812.

Paszkiewicz PJ, Fräßle SP, Srivastava S, Sommermeyer D, Hudecek M, Drexler I, Sadelain M, Liu L, Jensen MC, Riddell SR, et al. (2016) Targeted antibodymediated depletion of murine CD19 CAR T cells permanently reverses B cell aplasia. J Clin Invest 126:4262-4272.

Peters S and Zimmermann S (2018) Management of resistance to first-line anaplastic lymphoma kinase tyrosine kinase inhibitor therapy. Curr Treat Options Oncol 19 37.

Peterson JK and Houghton PJ (2004) Integrating pharmacology and in vivo cancer models in preclinical and clinical drug development. Eur J Cancer 40 $837-844$

Plummer R, Lorigan P, Steven N, Scott L, Middleton MR, Wilson RH, Mulligan E, Curtin N, Wang D, Dewji R, et al. (2013) A phase II study of the potent PARP inhibitor, Rucaparib (PF-01367338, AG014699), with temozolomide in patients with metastatic melanoma demonstrating evidence of chemopotentiation. Cancer Chemother Pharmacol 71:1191-1199.

Ponader S, Chen SS, Buggy JJ, Balakrishnan K, Gandhi V, Wierda WG, Keating MJ, O'Brien S, Chiorazzi N, and Burger JA (2012) The Bruton tyrosine kinase inhibitor PCI-32765 thwarts chronic lymphocytic leukemia cell survival and tissue homing in vitro and in vivo. Blood 119:1182-1189.

Pondé N, Brandão M, El-Hachem G, Werbrouck E, and Piccart M (2018) Treatment of advanced HER2-positive breast cancer: 2018 and beyond. Cancer Treat Rev 67: $10-20$

Pugh TJ, Morozova O, Attiyeh EF, Asgharzadeh S, Wei JS, Auclair D, Carter SL, Cibulskis K, Hanna M, Kiezun A, et al. (2013) The genetic landscape of high-risk neuroblastoma. Nat Genet 45:279-284.

Puigvert JC, Sanjiv K, and Helleday T (2016) Targeting DNA repair, DNA metabolism and replication stress as anti-cancer strategies. FEBS J 283:232-245.

Pule MA, Savoldo B, Myers GD, Rossig C, Russell HV, Dotti G, Huls MH, Liu E, Gee AP, Mei Z, et al. (2008) Virus-specific T cells engineered to coexpress tumor-specific receptors: persistence and antitumor activity in individuals with neuroblastoma. Nat Med 14:1264-1270. 
Qi W, Zhang W, Edwards H, Chu R, Madlambayan GJ, Taub JW, Wang Z, Wang Y, Li $\mathrm{C}$, Lin $\mathrm{H}$, et al. (2015) Synergistic anti-leukemic interactions between panobinostat and MK-1775 in acute myeloid leukemia ex vivo. Cancer Biol Ther 16:1784-1793.

Qiu Z, Oleinick NL, and Zhang J (2018) ATR/CHK1 inhibitors and cancer therapy. Radiother Oncol 126:450-464.

Ramaswamy V, Remke M, Bouffet E, Bailey S, Clifford SC, Doz F, Kool M, Dufour C, Vassal G, Milde T, et al. (2016) Risk stratification of childhood medulloblastoma in the molecular era: the current consensus. Acta Neuropathol 131:821-831.

Ray-Coquard I, Blay JY, Italiano A, Le Cesne A, Penel N, Zhi J, Heil F, Rueger R, Graves B, Ding M, et al. (2012) Effect of the MDM2 antagonist RG7112 on the P53 pathway in patients with MDM2-amplified, well-differentiated or dedifferentiated liposarcoma: an exploratory proof-of-mechanism study. Lancet Oncol 13: $1133-1140$

Reichert JM and Valge-Archer VE (2007) Development trends for monoclonal antibody cancer therapeutics. Nat Rev Drug Discov 6:349-356.

Rickel K, Fang F, and Tao J (2017) Molecular genetics of osteosarcoma. Bone 102 69-79.

Rizvi NA, Hellmann MD, Snyder A, Kvistborg P, Makarov V, Havel JJ, Lee W, Yuan J, Wong P, Ho TS, et al. (2015) Cancer immunology. Mutational landscape determines sensitivity to PD-1 blockade in non-small cell lung cancer. Science 348: $124-128$

Robbins PF, Morgan RA, Feldman SA, Yang JC, Sherry RM, Dudley ME, Wunderlich JR, Nahvi AV, Helman LJ, Mackall CL, et al. (2011) Tumor regression in patients with metastatic synovial cell sarcoma and melanoma using genetically engineered lymphocytes reactive with NY-ESO-1. J Clin Oncol 29:917-924.

Robert C, Ribas A, Wolchok JD, Hodi FS, Hamid O, Kefford R, Weber JS, Joshua AM, Hwu WJ, Gangadhar TC, et al. (2014) Anti-programmed-death-receptor-1 treatment with pembrolizumab in ipilimumab-refractory advanced melanoma: a randomised dose-comparison cohort of a phase 1 trial. Lancet 384:1109-1117.

Roberts KG, Li Y, Payne-Turner D, Harvey RC, Yang YL, Pei D, McCastlain K, Ding L, Lu C, Song G, et al. (2014) Targetable kinase-activating lesions in Ph-like acute lymphoblastic leukemia. N Engl J Med 371:1005-1015.

Roma-Rodrigues C, Mendes R, Baptista PV, and Fernandes AR (2019) Targeting tumor microenvironment for cancer therapy. Int J Mol Sci 20:E840.

Russell MR, Levin K, Rader J, Belcastro L, Li Y, Martinez D, Pawel B, Shumway SD, Maris JM, and Cole KA (2013) Combination therapy targeting the Chk1 and Wee1 kinases shows therapeutic efficacy in neuroblastoma. Cancer Res 73:776-784.

Sahin A, Sanchez C, Bullain S, Waterman P, Weissleder R, and Carter BS (2018) Development of third generation anti-EGFRvIII chimeric T cells and EGFRvIIIexpressing artificial antigen presenting cells for adoptive cell therapy for glioma. PLoS One 13:e199414.

Salter AI, Pont MJ, and Riddell SR (2018) Chimeric antigen receptor-modified T cells: CD19 and the road beyond. Blood 131:2621-2629.

Sampson VB, Kamara DF, and Kolb EA (2013) Xenograft and genetically engineered mouse model systems of osteosarcoma and Ewing's sarcoma: tumor models for cancer drug discovery. Expert Opin Drug Discov 8:1181-1189.

Samuels AL, Beesley AH, Yadav BD, Papa RA, Sutton R, Anderson D, Marshall GM, Cole CH, Kees UR, and Lock RB (2014) A pre-clinical model of resistance to induction therapy in pediatric acute lymphoblastic leukemia. Blood Cancer J 4:e232.

Sanjiv K, Hagenkort A, Calderón-Montaño JM, Koolmeister T, Reaper PM, Mortusewicz O, Jacques SA, Kuiper RV, Schultz N, Scobie M, et al. (2016) Cancer-specific synthetic lethality between ATR and CHK1 kinase activities. Cell Reports 17: $3407-3416$

Schiffman JD, Hodgson JG, VandenBerg SR, Flaherty P, Polley MY, Yu M, Fisher PG, Rowitch DH, Ford JM, Berger MS, et al. (2010) Oncogenic BRAF mutation with CDKN2A inactivation is characteristic of a subset of pediatric malignant astrocytomas. Cancer Res 70:512-519.

Schindler G, Capper D, Meyer J, Janzarik W, Omran H, Herold-Mende C, Schmieder $\mathrm{K}$, Wesseling P, Mawrin C, Hasselblatt M, et al. (2011) Analysis of BRAF V600E mutation in 1,320 nervous system tumors reveals high mutation frequencies in pleomorphic xanthoastrocytoma, ganglioglioma and extra-cerebellar pilocytic astrocytoma. Acta Neuropathol 121:397-405.

Schramm A, Köster J, Assenov Y, Althoff K, Peifer M, Mahlow E, Odersky A, Beisser D, Ernst C, Henssen AG, et al. (2015) Mutational dynamics between primary and relapse neuroblastomas. Nat Genet 47:872-877.

Schultz KR, Carroll A, Heerema NA, Bowman WP, Aledo A, Slayton WB, Sather H, Devidas M, Zheng HW, Davies SM, et al.; Children's Oncology Group (2014) Longterm follow-up of imatinib in pediatric Philadelphia chromosome-positive acute lymphoblastic leukemia: Children's Oncology Group study AALL0031. Leukemia 28:1467-1471.

Seidel JA, Otsuka A, and Kabashima K (2018) Anti-PD-1 and anti-CTLA-4 therapies in cancer: mechanisms of action, efficacy, and limitations. Front Oncol 8:86.

Sharpless NE and Depinho RA (2006) The mighty mouse: genetically engineered mouse models in cancer drug development. Nat Rev Drug Discov 5:741-754.

Shern JF, Chen L, Chmielecki J, Wei JS, Patidar R, Rosenberg M, Ambrogio L, Auclair D, Wang J, Song YK, et al. (2014) Comprehensive genomic analysis of rhabdomyosarcoma reveals a landscape of alterations affecting a common genetic axis in fusion-positive and fusion-negative tumors. Cancer Discov 4: $216-231$.

Shimizu S, Hong P, Arumugam B, Pokomo L, Boyer J, Koizumi N, Kittipongdaja P Chen A, Bristol G, Galic Z, et al. (2010) A highly efficient short hairpin RNA potently down-regulates CCR5 expression in systemic lymphoid organs in the huBLT mouse model. Blood 115:1534-1544.

Shlien A, Campbell BB, de Borja R, Alexandrov LB, Merico D, Wedge D, Van Loo P, Tarpey PS, Coupland P, Behjati S, et al.; Biallelic Mismatch Repair Deficiency Consortium (2015) Combined hereditary and somatic mutations of replication error repair genes result in rapid onset of ultra-hypermutated cancers. Nat Genet $\mathbf{4 7}$ $257-262$.

Shultz LD, Brehm MA, Garcia-Martinez JV, and Greiner DL (2012) Humanized mice for immune system investigation: progress, promise and challenges. Nat Rev Immunol 12:786-798.
Siegel RL, Miller KD, and Jemal A (2017) Cancer statistics, 2017. CA Cancer J Clin 67:7-30.

Siolas D and Hannon GJ (2013) Patient-derived tumor xenografts: transforming clinical samples into mouse models. Cancer Res 73:5315-5319.

Smith MA, Hampton OA, Reynolds CP, Kang MH, Maris JM, Gorlick R, Kolb EA Lock R, Carol H, Keir ST, et al. (2015a) Initial testing (stage 1) of the PARP inhibitor BMN 673 by the pediatric preclinical testing program: PALB2 mutation predicts exceptional in vivo response to BMN 673. Pediatr Blood Cancer 62:91-98. Smith MA and Houghton P (2013) A proposal regarding reporting of in vitro testing results. Clin Cancer Res 19:2828-2833.

Smith MA, Reynolds CP, Kang MH, Kolb EA, Gorlick R, Carol H, Lock RB, Keir ST, Maris JM, Billups CA, et al. (2015b) Synergistic activity of PARP inhibition by talazoparib (BMN 673) with temozolomide in pediatric cancer models in the pediatric preclinical testing program. Clin Cancer Res 21:819-832.

Sotillo E, Barrett DM, Black KL, Bagashev A, Oldridge D, Wu G, Sussman R, Lanauze C, Ruella M, Gazzara MR, et al. (2015) Convergence of acquired mutations and alternative splicing of CD19 enables resistance to CART-19 immunotherapy. Cancer Discov 5:1282-1295.

Spagnolo F, Ghiorzo P, Orgiano L, Pastorino L, Picasso V, Tornari E, Ottaviano V, and Queirolo P (2015) BRAF-mutant melanoma: treatment approaches, resistance mechanisms, and diagnostic strategies. OncoTargets Ther 8:157-168.

Spurny C, Kailayangiri S, Jamitzky S, Altvater B, Wardelmann E, Dirksen U, Hardes J, Hartmann W, and Rossig C (2018) Programmed cell death ligand 1 (PDL1) expression is not a predominant feature in Ewing sarcomas. Pediatr Blood Cancer 65, doi: 10.1002/pbc.26719.

Stein EM, Walter RB, Erba HP, Fathi AT, Advani AS, Lancet JE, Ravandi F, Kovacsovics T, DeAngelo DJ, Bixby D, et al. (2018) A phase 1 trial of vadastuximab talirine as monotherapy in patients with CD33-positive acute myeloid leukemia. Blood 131:387-396.

Steins A, Ebbing EA, Pistorius MCM, Waasdorp C, Krishnadath KK, Medema JP Wilmink JW, Mathôt RAA, Bijlsma MF, and van Laarhoven HWM (2017) Systemic effects of angiogenesis inhibition alter pharmacokinetics and intratumoral delivery of nab-paclitaxel. Drug Deliv 24:1801-1810.

Stewart CF, Leggas M, Schuetz JD, Panetta JC, Cheshire PJ, Peterson J, Daw N, Jenkins JJ III, Gilbertson R, Germain GS, et al. (2004) Gefitinib enhances the antitumor activity and oral bioavailability of irinotecan in mice. Cancer Res 64: $7491-7499$

Stewart E, Federico S, Karlstrom A, Shelat A, Sablauer A, Pappo A, and Dyer MA (2016) The Childhood Solid Tumor Network: a new resource for the developmental biology and oncology research communities. Dev Biol 411:287-293.

Stewart E, Federico SM, Chen X, Shelat AA, Bradley C, Gordon B, Karlstrom A, Twarog NR, Clay MR, Bahrami A, et al. (2017) Orthotopic patient-derived xenografts of paediatric solid tumours. Nature 549:96-100.

Stewart E, Goshorn R, Bradley C, Griffiths LM, Benavente C, Twarog NR, Miller GM, Caufield W, Freeman BB III, Bahrami A, et al. (2014) Targeting the DNA repair pathway in Ewing sarcoma. Cell Reports 9:829-841.

Stewart EL, Mascaux C, Pham NA, Sakashita S, Sykes J, Kim L, Yanagawa N, Allo G, Ishizawa K, Wang D, et al. (2015) Clinical utility of patient-derived xenografts to determine biomarkers of prognosis and map resistance pathways in EGFR-mutant lung adenocarcinoma. J Clin Oncol 33:2472-2480.

St Pierre R and Kadoch C (2017) Mammalian SWI/SNF complexes in cancer: emerging therapeutic opportunities. Curr Opin Genet Dev 42:56-67.

Taylor AC, Shu L, Danks MK, Poquette CA, Shetty S, Thayer MJ, Houghton PJ, and Harris LC (2000) P53 mutation and MDM2 amplification frequency in pediatric rhabdomyosarcoma tumors and cell lines. Med Pediatr Oncol 35:96-103.

Tew KD, Houghton PJ, and Houghton JA (1993) Modulation of P-glycoproteinmediated multidrug resistance, in Preclinical and Clinical Modulation of Anticancer Drugs (Hollinger MA ed), CRC Press, Boca Raton, FL.

Thomas DA, Faderl S, O’Brien S, Bueso-Ramos C, Cortes J, Garcia-Manero G, Giles FJ, Verstovsek S, Wierda WG, Pierce SA, et al. (2006) Chemoimmunotherapy with hyper-CVAD plus rituximab for the treatment of adult Burkitt and Burkitt-type lymphoma or acute lymphoblastic leukemia. Cancer 106:1569-1580.

Thompson YY, Ramaswamy V, Diamandis P, Daniels C, and Taylor MD (2015) Posterior fossa ependymoma: current insights. Childs Nerv Syst 31:1699-1706.

Thorpe PE (2004) Vascular targeting agents as cancer therapeutics. Clin Cancer Res 10:415-427.

Tibes R, Bogenberger JM, Chaudhuri L, Hagelstrom RT, Chow D, Buechel ME, Gonzales IM, Demuth T, Slack J, Mesa RA, et al. (2012) RNAi screening of the kinome with cytarabine in leukemias. Blood 119:2863-2872.

Tirode F, Surdez D, Ma X, Parker M, Le Deley MC, Bahrami A, Zhang Z, Lapouble E, Grossetête-Lalami S, Rusch M, et al.; St. Jude Children's Research HospitalWashington University Pediatric Cancer Genome Project and the International Cancer Genome Consortium (2014) Genomic landscape of Ewing sarcoma defines an aggressive subtype with co-association of STAG2 and TP53 mutations. Cancer Discov 4:1342-1353.

Topalian SL, Taube JM, Anders RA, and Pardoll DM (2016) Mechanism-driven biomarkers to guide immune checkpoint blockade in cancer therapy. Nat Rev Cancer 16:275-287.

Topp MS, Gökbuget N, Zugmaier G, Klappers P, Stelljes M, Neumann S, Viardot A Marks R, Diedrich H, Faul C, et al. (2014) Phase II trial of the anti-CD19 bispecific $\mathrm{T}$ cell-engager blinatumomab shows hematologic and molecular remissions in patients with relapsed or refractory B-precursor acute lymphoblastic leukemia $J$ Clin Oncol 32:4134-4140.

Turcotte LM, Neglia JP, Reulen RC, Ronckers CM, van Leeuwen FE, Morton LM, Hodgson DC, Yasui Y, Oeffinger KC, and Henderson TO (2018) Risk, risk factors, and surveillance of subsequent malignant neoplasms in survivors of childhood cancer: a review. J Clin Oncol 36:2145-2152.

Vaishnavi A, Le AT, and Doebele RC (2015) TRKing down an old oncogene in a new era of targeted therapy. Cancer Discov 5:25-34.

Vanharanta S and Massague J (2013) Origins of metastatic traits. Cancer Cell 24: 410-421. 
Vatakis DN, Bristol GC, Kim SG, Levin B, Liu W, Radu CG, Kitchen SG, and Zack JA (2012) Using the BLT humanized mouse as a stem cell based gene therapy tumor model. J Vis Exp e4181, doi: 10.3791/4181.

Vaupel P (2004) Tumor microenvironmental physiology and its implications for radiation oncology. Semin Radiat Oncol 14:198-206.

Venneti S, Santi M, Felicella MM, Yarilin D, Phillips JJ, Sullivan LM, Martinez D, Perry A, Lewis PW, Thompson CB, et al. (2014) A sensitive and specific histopathologic prognostic marker for H3F3A K27M mutant pediatric glioblastomas. Acta Neuropathol 128:743-753.

von Stackelberg A, Locatelli F, Zugmaier G, Handgretinger R, Trippett TM, Rizzari C, Bader P, O'Brien MM, Brethon B, Bhojwani D, et al. (2016) Phase I/phase II study of blinatumomab in pediatric patients with relapsed/refractory acute lymphoblastic leukemia. J Clin Oncol 34:4381-4389.

Wagner L, Turpin B, Nagarajan R, Weiss B, Cripe T, and Geller J (2013) Pilot study of vincristine, oral irinotecan, and temozolomide (VOIT regimen) combined with bevacizumab in pediatric patients with recurrent solid tumors or brain tumors. Pediatr Blood Cancer 60:1447-1451.

Wahid M, Jawed A, Mandal RK, Dar SA, Akhter N, Somvanshi P, Khan F, Lohani M, Areeshi MY, and Haque S (2018) Recent developments and obstacles in the treatment of melanoma with BRAF and MEK inhibitors. Crit Rev Oncol Hematol 125:84-88.

Weber JS, D'Angelo SP, Minor D, Hodi FS, Gutzmer R, Neyns B, Hoeller C, Khushalani NI, Miller WH Jr, Lao CD, et al. (2015) Nivolumab versus chemotherapy in patients with advanced melanoma who progressed after anti-CTLA-4 treatment (CheckMate 037): a randomised, controlled, open-label, phase 3 trial. Lancet Oncol 16:375-384.

Wedekind MF, Denton NL, Chen CY, and Cripe TP (2018) Pediatric cancer immunotherapy: opportunities and challenges. Paediatr Drugs 20:395-408.

Wei G, Wang J, Huang H, and Zhao Y (2017) Novel immunotherapies for adult patients with B-lineage acute lymphoblastic leukemia. J Hematol Oncol 10:150.

Weigel BJ, Lyden E, Anderson JR, Meyer WH, Parham DM, Rodeberg DA, Michalski JM, Hawkins DS, and Arndt CA (2016) Intensive multiagent therapy, including dose-compressed cycles of ifosfamide/etoposide and vincristine/doxorubicin/cyclophosphamide, irinotecan, and radiation, in patients with high-risk rhabdomyosarcoma: a report from the Children's Oncology Group. J Clin Oncol 34:117-122.

Weiss WA, Aldape K, Mohapatra G, Feuerstein BG, and Bishop JM (1997) Targeted expression of MYCN causes neuroblastoma in transgenic mice. EMBO $J \mathbf{1 6}$ $2985-2995$.

Whiteford CC, Bilke S, Greer BT, Chen Q, Braunschweig TA, Cenacchi N, Wei JS, Smith MA, Houghton P, Morton C, et al. (2007) Credentialing preclinical pediatric xenograft models using gene expression and tissue microarray analysis. Cancer Res 67:32-40.
Williams JA (2018) Using PDX for preclinical cancer drug discovery: the evolving field. $J$ Clin Med 7:E41.

Wilson BG, Wang X, Shen X, McKenna ES, Lemieux ME, Cho YJ, Koellhoffer EC, Pomeroy SL, Orkin SH, and Roberts CW (2010) Epigenetic antagonism between polycomb and SWI/SNF complexes during oncogenic transformation. Cancer Cell 18:316-328.

Wing K, Onishi Y, Prieto-Martin P, Yamaguchi T, Miyara M, Fehervari Z, Nomura T, and Sakaguchi S (2008) CTLA-4 control over Foxp3+ regulatory T cell function. Science 322:271-275.

Wolchok JD, Weber JS, Hamid O, Lebbé C, Maio M, Schadendorf D, de Pril V, Heller $\mathrm{K}$, Chen TT, Ibrahim R, et al. (2010) Ipilimumab efficacy and safety in patients with advanced melanoma: a retrospective analysis of HLA subtype from four trials. Cancer Immun 10:9.

Wong R, Pepper C, Brennan P, Nagorsen D, Man S, and Fegan C (2013) Blinatumomab induces autologous T-cell killing of chronic lymphocytic leukemia cells. Haematologica 98:1930-1938.

Wu X, Northcott PA, Croul S, and Taylor MD (2011) Mouse models of medulloblastoma. Chin J Cancer 30:442-449.

Xiao X, Garbutt CC, Hornicek F, Guo Z, and Duan Z (2018) Advances in chromosoma translocations and fusion genes in sarcomas and potential therapeutic applications. Cancer Treat Rev 63:61-70.

Yadav BD, Samuels AL, Wells JE, Sutton R, Venn NC, Bendak K, Anderson D, Marshall GM, Cole CH, Beesley AH, et al. (2016) Heterogeneity in mechanisms of emergent resistance in pediatric T-cell acute lymphoblastic leukemia. Oncotarget 7:58728-58742.

Yokoyama A and Cleary ML (2008) Menin critically links MLL proteins with LEDGF on cancer-associated target genes. Cancer Cell 14:36-46.

Yokoyama A, Somervaille TC, Smith KS, Rozenblatt-Rosen O, Meyerson M, and Cleary ML (2005) The menin tumor suppressor protein is an essential oncogenic cofactor for MLL-associated leukemogenesis. Cell 123:207-218.

Young RM and Staudt LM (2013) Targeting pathological B cell receptor signalling in lymphoid malignancies. Nat Rev Drug Discov 12:229-243.

Yu AL, Gilman AL, Ozkaynak MF, London WB, Kreissman SG, Chen HX, Smith M, Anderson B, Villablanca JG, Matthay KK, et al.; Children's Oncology Group (2010) Anti-GD2 antibody with GM-CSF, interleukin-2, and isotretinoin for neuroblastoma. N Engl J Med 363:1324-1334.

Zehir A, Benayed R, Shah RH, Syed A, Middha S, Kim HR, Srinivasan P, Gao J Chakravarty D, Devlin SM, et al. (2017) Mutational landscape of metastatic cancer revealed from prospective clinical sequencing of 10,000 patients. Nat Med 23: 703-713. 